FACULDADE DE ECONOMIA, ADMINISTRAÇÃO E CONTABILIDADE INSTITUTO DE PESQUISAS ECONÔMICAS - DEPARTAMENTO DE ECONOMIA

\title{
Mudanças Climáticas e Secas no Brasil: Uma Análise Espacial Integrada a partir de Modelos IEGC e Monitoramento Climático no Semiárido Brasileiro
}


Prof. Dr Vahan Agopyan

Reitor da Universidade de São Paulo

\section{Prof Dr. Fábio Frezatti}

Diretor da Faculdade de Economia, Administração e Contabilidade

Prof. Dr. José Carlos de Souza Santos

Chefe do Departamento de Economia

Prof Dr. Ariaster Baumgratz Chimeli

Coordenador do Programa de Pós-Graduação em Economia 
Bruno Proença Pacheco Pimenta

\section{Mudanças Climáticas e Secas no Brasil: Uma Análise Espacial Integrada a partir de Modelos IEGC e Monitoramento Climático no Semiárido Brasileiro}

Dissertação apresentada ao Programa de PósGraduação em Economia do Departamento de Economia, Administração e Contabilidade da Universidade de São Paulo, como requisito parcial para a obtenção do título de Mestre em Ciências

Orientador: Eduardo Amaral Haddad

Versão Corrigida

São Paulo

2020 
Catalogação na Publicação (CIP)

Ficha Catalográfica com dados inseridos pelo autor

Pimenta, Bruno.

Mudanças Climáticas e Secas no Brasil: Uma Análise Espacial Integrada a partir de Modelos IEGC e Monitoramento Climático no Semiárido Brasileiro / Bruno Pimenta. - São Paulo, 2020.

$113 \mathrm{p}$.

Dissertação (Mestrado) - Universidade de São Paulo, 2020.

Orientador: Eduardo Haddad.

1. secas. 2. semiárido. 3. produtividade agrícola. 4. economia regional. I. Universidade de São Paulo. Faculdade de Economia, Administração e Contabilidade. II. Título. 



\section{AGRADECIMENTOS}

Gostaria de agradecer ao meu orientador, professor Eduardo Haddad, pelos ensinamentos e oportunidades oferecidos ao longo destes dois anos e meio de mestrado, e, sobretudo, pelo seu carinhoso acolhimento, ao tornar o NEREUS mais do que um núcleo de estudos, mas uma família. Gostaria também de agradecer aos demais professores e participantes do NEREUS, que tornaram o árduo dia a dia destes anos mais leve.

Aos amigos do mestrado, agradeço ao companheirismo e às boas risadas que me proporcionaram, seja na salinha do café, nos bares, ou nos merecidos churrascos de fim de semestre. Aos amigos de $\mathrm{BH}$, obrigado por serem tão palhaços e fazerem este cidadão mais alegre, mesmo que nos encontremos tão pouco.

Agradeço também à toda minha família, por sempre apoiar e acreditar em mim. Ao meu pai, obrigado por entender que, mesmo em cidades diferentes, sempre estaremos juntos. Devo um especial agradecimento à minha família em São Paulo, pelo carinho e amor de todo final de semana, me fizeram sentir em casa durante todo este tempo.

Por fim, gostaria de agradecer à FIPE e ao CNPq, pelo apoio financeiro fornecido durante o primeiro ano de mestrado. Em especial, gostaria de agradecer ao Instituto Escolhas, que acreditou neste estudo e desenvolve um importante trabalho de estímulo à pesquisa de economia e meioambiente no Brasil. 



\section{RESUMO}

As mudanças climáticas resultantes do aquecimento global e seus impactos na natureza e na sociedade são um dos maiores desafios enfrentados pela civilização humana no período atual. No caso brasileiro, a região mais vulnerável socialmente é o Semiárido. Essa região cobre $86 \%$ do interior da parte nordeste do país, que, com sua população de 23 milhões de habitantes em 2017, a garante o título de região seca mais populosa do mundo. Essa região ficará vulnerável a vários impactos climáticos, uma vez que o aumento da temperatura pode fazer com que os locais com déficit hídrico fiquem ainda mais secos e o curto período de chuva pode desaparecer. $\mathrm{O}$ aumento da frequência de secas poderá levar a região a passar por um processo de aridização até o final do século, e essa soma de fatores torna a região uma das mais vulneráveis do mundo às mudanças climáticas. Este trabalho estima o efeito de choques climáticos no Semiárido brasileiro sobre a produtividade agrícola, especificamente na produção de feijão, milho e mandioca, que são as culturas mais representativas da região. Como medida de choques climáticos, usamos o Índice Integrado de Secas e o Índice de Saúde da Vegetação, para projeções futuras. Esses choques de produtividade são então utilizados em um modelo inter-regional equilíbrio geral computável calibrado para as sub-regiões do Semiárido, a fim de calcular o impacto das secas em variáveis como nível de atividade de cada setor, emprego e produto bruto de cada região.

Palavras-chave: seca; semiárido; produtividade agrícola; economia regional 


\begin{abstract}
Climate change resulting from global warming and its impacts on nature and society is one of the greatest challenges faced by human civilization in the current period. In the Brazilian case, the most socially vulnerable region is the Semi-Arid. This region covers $86 \%$ of the interior of the Northeastern portion of the country, which with its population of 23 million people as of 2017 secures it the title of the most populated dry region in the world. This region will be vulnerable to several climatic impacts, since an increase in temperature may cause the locations under water deficit to get even drier, and the short rainy season may disappear. The increase in the frequency of droughts could then lead the region to undergo an aridization process by the end of the century, and this sum of factors could make the region one of the most vulnerable in the world to climate change. This work estimates the effect of climatic shocks in the Brazilian Semi-Arid region on agricultural productivity, specifically in the production of beans, corn, and cassava, which are the most representative crops of the region. As a measure of climate shocks, we use the Integrated Drought Index and the Vegetation Health Index, for future projections. These productivity shocks are then used in an Interregional Computable General Equilibrium model calibrated for the subregions of the Semi-Arid in order to calculate the impact of droughts on variables such as activity level of each sector, employment and gross product of each region.
\end{abstract}

Keywords: drought; semi-arid, agricultural productivity; regional economics 


\section{Lista de Figuras}

Figura 1 - Relações de causalidade capturadas pelos modelos de EGC.

Figura 2- Produção de Milho no Semiárido - Média do Valor Produzido entre 2012 e 2018

Figura 3 - Proporção da Produção do Milho no Total Produzido pelo Setor Agrícola dos Municípios (média 2012-2018)

Figura 4 - Produção de Feijão no Semiárido - Média do Valor Produzido entre 2012 e 2018 .......388

Figura 5 - Proporção da Produção do Feijão no Total Produzido pelo Setor Agrícola dos Municípios (média 2012-2018).

Figura 6 - Produção de Mandioca no Semiárido - Média do Valor Produzido entre 2012 e 20184141

Figura 7 - Proporção da Produção da Mandioca no Total Produzido pelo Setor Agrícola dos Municípios (média 2012-2018). .422

Figura 8 - Média do índice VHI entre 2012 e 2018 .444

Figura 9 - Índice VHI para 2012

Figura 10 - Projeção do Índice VHI para 2040 488

Figura 11 - Projeção do índice VHI para 2070 .499

Figura 12 - Projeção do índice VHI para 2100 .5050

Figura 13 - População estimada em 2015 de cada região. .533

Figura 14 - Participação de cada região na composição do PIB em 2015.....................................54

Figura 15 - Participação de cada região na composição do PIB Agrícola em 2015..........................54

Figura 16 - Participação do Setor Agrícola no PIB regional em 2015 ........................................555

Figura 17 - Participação do Governo no PIB regional em 2015 .................................................566

Figura 18 - Evolução do rendimento médio do feijão no Semiárido ..................................................63

Figura 19 - Evolução do rendimento médio da mandioca no Semiárido...........................................63

Figura 20 - Evolução do rendimento médio do milho no Semiárido ..................................................64

Figura 21 - Migração líquida em relação à população em 2040...................................................76

Figura 22 - Migração líquida em relação à população em 2070...................................................766

Figura 23 - Migração líquida em relação à população em 2100 ..................................................777 


\section{Lista de Tabelas}

Tabela 1-Representatividade de cada cultura em termos de valor produzido no Semiárido 31

Tabela 2-Representatividade de cada cultura em termos de área cultivada no Semiárido...... 32

Tabela 3 - Correlação entre a produção das culturas analisadas e a produção agrícola total (2000/2018)

Tabela 4 - Representatividade dos municípios de cada estado na produção de milho no Semiárido.

Tabela 5 - Representatividade da média municipal do milho no Semiárido em termos de valor agrícola produzido

Tabela 6 - Representatividade do milho em termos de área cultivada nos municípios do Semiárido. 36

Tabela 7 - Representatividade dos municípios de cada estado na produção de feijão no Semiárido

Tabela 8 - Representatividade média municipal do feijão no Semiárido em termos de valor agrícola produzido

Tabela 9 - Representatividade do feijão em termos de área cultivada nos municípios do

Semiárido.

Tabela 10 - Representatividade dos municípios de cada estado na produção de mandioca no Semiárido. 40

Tabela 11 - Representatividade média municipal da mandioca no Semiárido em termos de valor agrícola produzido.

Tabela 12 - Representatividade da mandioca em termos de área cultivada nos municípios do

Semiárido. 41

Tabela 13 - Sumário do índice VHI por estado entre 2012 e 2018. 43

Tabela 14 - Classificação de secas pelos índices VHI e IIS. 45

Tabela 13 - Média mensal do IIS para o Semiárido de cada estado entre 2012 e 2018. .44

Tabela 15 - Sumário do índice VHI por estado entre 2012 e 2018. 45

Tabela 16 - Média do IIS por mês e Semiárido de cada estado em 2012. 46

Tabela 17 - Sumário VHI por estado em 2012. 46

Tabela 18 - Projeção do índice VHI por estado para 2040. 49

Tabela 19 - Projeção do índice VHI por estado para 2070. 50

Tabela 20 - Projeção do índice VHI por estado para 2100. 51

Tabela 21 - Número de municípios contidos nas regiões do modelo. 52

Tabela 22 - Setores do modelo.. 52 
Tabela 23 - Efeitos para trás (em relação ao total).

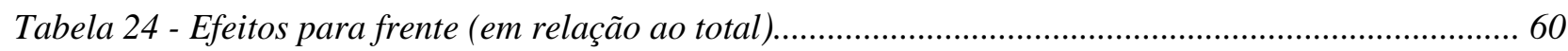

Tabela 25 - Taxa de crescimento anual do rendimento médio por cultura entre 1988 e 2018 no

Semiárido.

Tabela 26 - Choque final de produtividade no Semiárido por região e ano... .68

Tabela 27 - Choque de produtividade por ano para o Semiárido como um todo. .69

Tabela 28 - Impactos nacionais em cada cenário (pontos percentuais). .70

Tabela 29 - Resultados regionais de cada cenário para a produção (pontos percentuais)...... 72

Tabela 30 - Resultados setoriais por região do cenário de 2012 (pontos percentuais)...... 74

Tabela 31 - Resultados setoriais por região do cenário de 2070 (pontos percentuais)............................... 75

Tabela 32 - Decomposição do choque sobre o PRB de 2040 por região ………………………...................78

Tabela 33 - Análise de sensibilidade dos choques de 2100......................................................................... 79

Tabela 34 - Análise de sensibilidade dos choques de 2100 sobre o PRB de cada região............................. 81

Tabela 35 - Proporção entre o valor do autoconsumo e valor da produção agrícola total em 2006 . .84 



\section{SUMÁRIO}

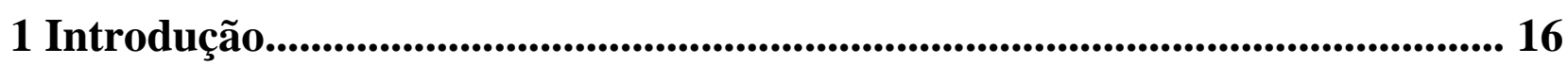

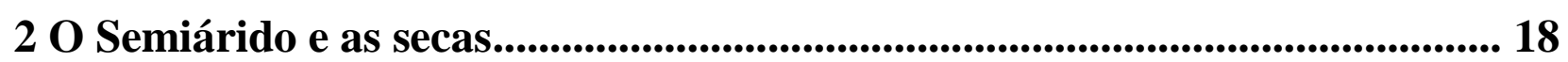

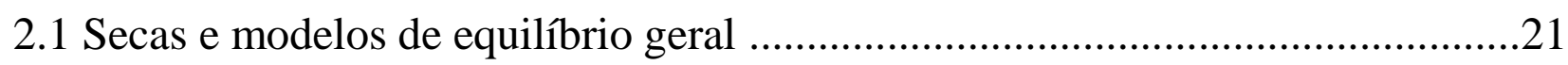

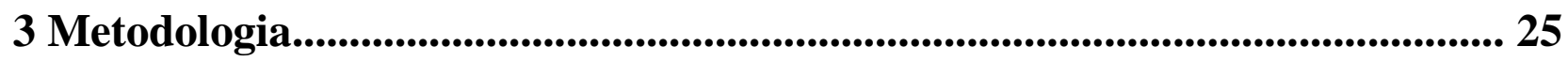

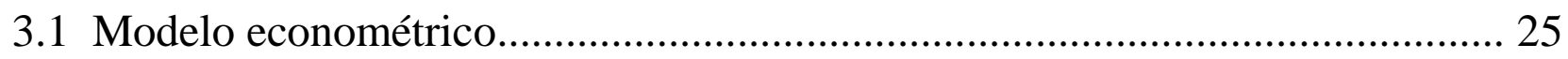

3.2 Modelo de equilíbrio geral computável .........................................................28

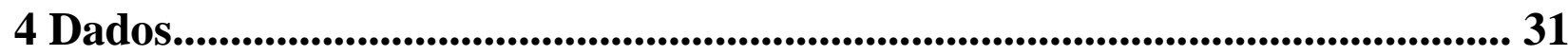

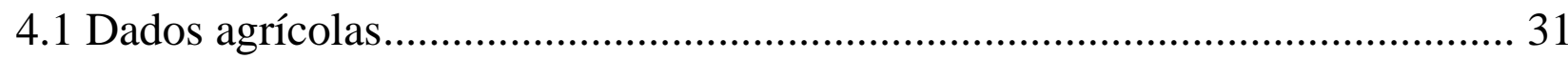

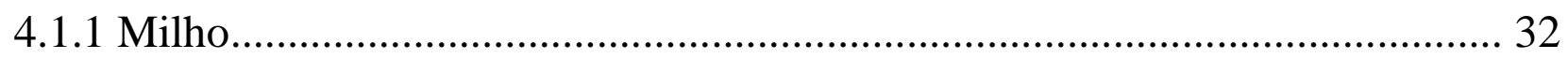

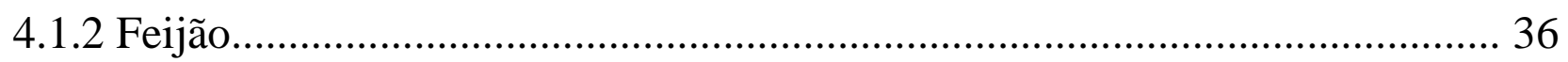

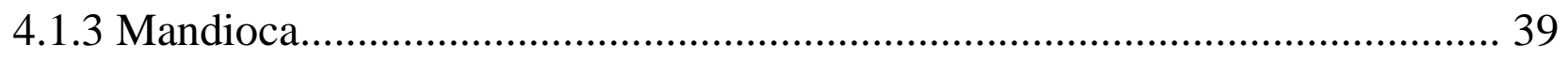

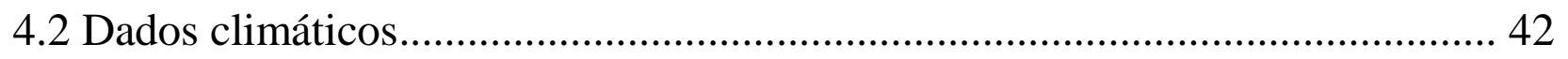

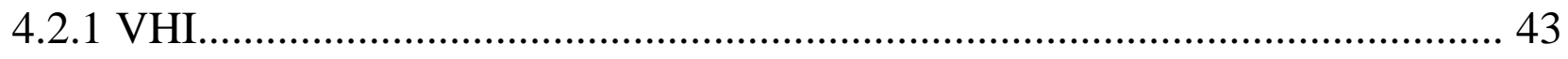

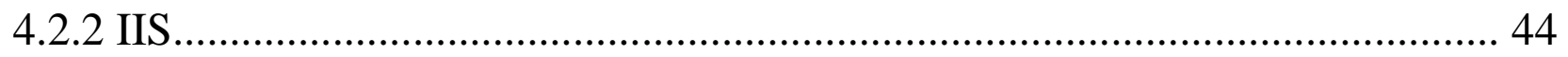

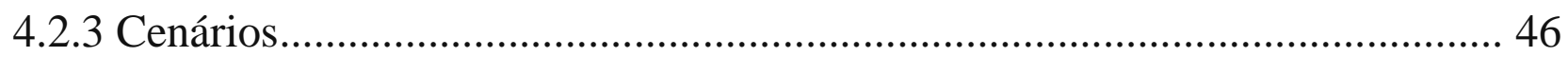

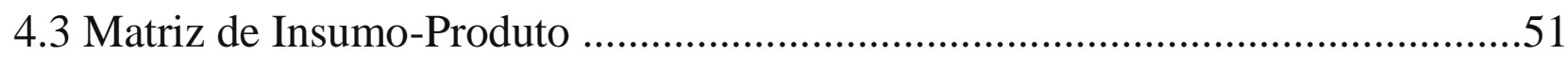

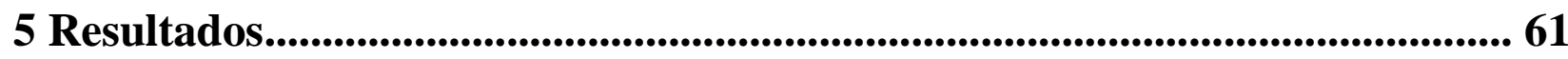

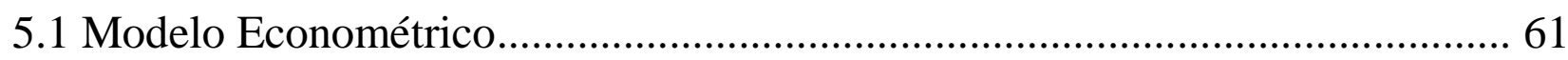

5.2 Resultados da simulação de equilíbrio geral.............................................. 69

5.2.1 Análise de sensibilidade dos choques................................................... 78

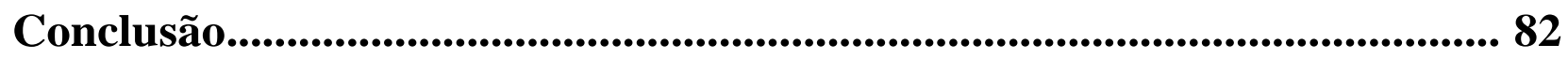

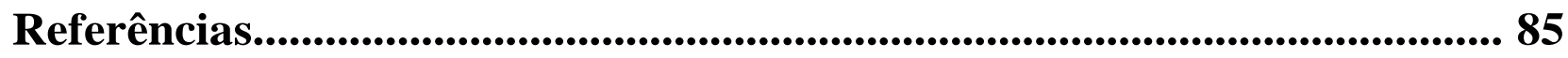

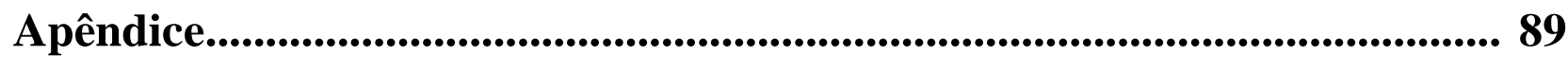





\section{Introdução}

As mudanças climáticas decorrentes do aquecimento global e seus impactos sobre a natureza e a sociedade constituem um dos maiores desafios da civilização humana do século XXI. O aquecimento da atmosfera decorrente da maior concentração de gases de efeito estufa leva a uma aceleração do ciclo da água, o que pode tornar eventos extremos mais frequentes, tais como secas e inundações (Stern, 2007). Segundo a Organização das Nações Unidas para Agricultura e Alimentação (FAO), a seca é o fenômeno climático que afetou o maior número de pessoas nos últimos 40 anos. Secas severas tem o potencial de provocar graves danos à sociedade humana, incluindo perda de vidas. Isto se deve ao fato de que a água é um bem essencial e não substituível, tanto para a nossa sobrevivência quanto para a produção econômica.

O aquecimento da temperatura global pode induzir mudanças bruscas nos padrões climáticos regionais, tendo como consequência mudanças sérias na disponibilidade de água, em especial para as regiões tropicais. Como as mudanças climáticas não ocorrerão de forma homogênea ao redor do globo, se torna necessário compreender como cada região específica será particularmente afetada.

Com o objetivo de melhor compreender e gerar informações científicas de qualidade acerca das diversas dimensões das mudanças climáticas e suas implicações para o Brasil, o Instituto Nacional de Ciência e Tecnologia para Mudanças Climáticas (INCT-MC) foi criado com o apoio do Ministério da Ciência, Tecnologia e Inovação (MCTI). Trata-se de uma ampla rede de 90 grupos de pesquisa de 108 instituições e universidades brasileiras e 18 estrangeiras. Em sua segunda fase, um dos enfoques do programa é estudar os impactos das mudanças climáticas e identificar as principais vulnerabilidades do Brasil relacionadas aos ecossistemas, agricultura, segurança alimentar e economia.

No caso brasileiro, a região mais vulnerável do ponto de vista social à mudança de clima é o Semiárido. (Marengo, 2010). Esta região, que abrange 86\% do interior do território nordestino mais o norte de Minas Gerais, está entre as regiões secas mais populosas do mundo, com sua população de 23 milhões de pessoas em 2017 (Marengo, Torres e Alves, 2017; Marengo, 2010). Configuram municípios do Semiárido aqueles onde a precipitação pluviométrica média anual é 
igual ou inferior a $800 \mathrm{~mm}$, o Índice de Aridez de Thornthwaite é igual ou inferior a 0,50 e o percentual diário de déficit hídrico igual ou superior a $60 \%$, considerando todos os dias do ano. Os municípios desta região apresentaram em 2015 um PIB municipal médio de $\mathrm{R} \$ 237.537,22$ a reais de 2010. Em comparação, a média municipal do PIB brasileiro para o mesmo período foi de R \$1.076.442,91. Segundo Marengo (2010), no futuro o Semiárido estará ainda mais vulnerável às diversas mazelas climáticas, pois um aumento de temperatura poderá deixar as localidades sob déficit hídrico ainda mais secas. O aumento da frequência de secas poderá então levar a região a passar por um processo de aridização até o final do século (Marengo, Torres e Alves, 2017).

Neste contexto, o objetivo deste trabalho é desenvolver e utilizar um sistema de modelagem para fins de avaliação espacial de impactos de secas em municípios do semiárido brasileiro, por meio da integração de modelos de monitoramento de seca com um modelo inter-regional de equilíbrio geral computável (IEGC). Desta forma, no âmbito do Programa INCT Mudanças Climáticas - Fase 2 (INCT-MC2), buscamos realizar a integração dos sub-componentes segurança hídrica, desastres naturais e impactos em setores chave, com enfoque em avaliar a vulnerabilidade socioeconômica e ambiental da população de municípios do Semiárido às secas.

Para tal, a primeira parte do trabalho consiste em relacionar a produtividade agrícola de culturas selecionadas a índices de seca, por meio de uma modelagem econométrica. Com os coeficientes fornecidos por esta etapa em mãos, projetamos choques de produtividade agrícola que serão aplicados no modelo de equilíbrio geral computável inter-regional. Assim, poderemos avaliar o impacto de secas em variáveis como nível de atividade econômica, migração e bem-estar da população.

Este trabalho é composto por 6 seções, incluindo esta introdução. A próxima seção discorre sobre o histórico de secas no Semiárido e seus impactos, além da literatura econômica associada. A terceira seção trata da metodologia que será empregada neste trabalho, destacando as etapas de estimação do modelo econométrico e sua posterior integração ao modelo de equilíbrio geral. A quarta seção descreve o amplo conjunto de dados que foram necessários para a confecção deste trabalho. A quinta seção expõe os resultados do modelo econométrico, enfatizando a construção dos choques que serão aplicados no modelo de equilíbrio geral, e demonstra os resultados obtidos da aplicação destes choques. A sexta seção, por fim, conclui este trabalho. 


\section{O Semiárido e as secas}

Abrangendo todos os estados da região Nordeste do país e mais o norte do estado de Minas Gerais, a região semiárida é caracterizada por uma distribuição de chuvas irregular e frequente estiagem. O regime de chuvas na região é instável e heterogêneo. Na sua porção sul-sudoeste, a estação chuvosa ocorre de outubro a fevereiro, enquanto na sua porção mais ao norte, abrangendo a maior parte do Semiárido, as chuvas ocorrem de fevereiro a maio (Marengo, 2010).

Uma característica marcante da região é o caráter intermitente dos seus rios, que não apresentam fluxo de água durante o período de estiagem, com as importantes exceções do São Francisco e Parnaíba (Gandara, 2015). A presença de solos rasos e ricos em rochas cristalinas e alto índice de evaporação ainda contribuem para uma baixa capacidade de absorção de água, inibindo o desenvolvimento de aquíferos (Alvalá et al., 2019).

A ocorrência de secas na região é relatada desde o início da colonização portuguesa, no século XVI. Eventos marcantes ao longo da história compreendem a seca de 1777-1780, em que metade da população e $85 \%$ dos rebanhos pereceu devido à fome; a seca de 1877-1879, que matou 200.000 pessoas na cidade de Fortaleza, Ceará; e a seca de 1958, que levou 10 milhões de pessoas a abandonar a região (Marengo, Torres e Alves, 2017).

A colonização efetiva da região teve início no século XVII, motivada, principalmente, pelas invasões holandesas e disputa de terras entre lavouras e pastos. Segundo Roberto Simonsen, foi a criação de gado o instrumento mais importante de ocupação dos sertões e sua primeira atividade econômica de maior relevância, tendo como objetivo abastecer as regiões açucareiras (Linhares et al., 1990). Estas áreas de pecuária eram caracterizadas por maior pobreza, rusticidade e menor densidade de escravos que outras partes da colônia, além de uma hierarquia social mais frouxa (Linhares et al, 1990).

A segunda atividade econômica a representar importância histórica na região foi a cultura do algodão, tendo seu pico no século XIX, quando a Guerra Civil Americana e a boa produtividade do solo, ainda não degradado, trouxe ao Semiárido a demanda por este produto pelos mercados europeus (Marengo, 2010). Já na fase final da escravidão, a crise da cultura canavieira nas 
tradicionais regiões produtoras levou parte da elite fundiária nordestina à pecuária, expulsando as populações camponesas para as regiões mais áridas (Linhares et al, 1990). Este processo acabou por fomentar a acentuação da fome e pobreza no Semiárido, que até hoje persistem.

As graves secas ao longo da história impeliram os governantes a investir na prevenção e mitigação de seus efeitos. A seca de 1877 levou o governo imperial a ordenar a construção do primeiro reservatório de água da região, o açude do Cedro em Quixadá, Ceará (Marengo, 2010). Desde então, mais reservatórios foram criados e o elevado número de mortes registrado nos eventos do passado passou a ser evitado, porém, as secas continuam a afligir os moradores do sertão, provocando choques econômicos e sociais.

No campo da saúde, Rocha e Soares (2015) analisam o impacto de flutuações das chuvas em variáveis como mortalidade infantil e peso da criança ao nascer, tendo como base a região do Semiárido. O estudo constata que choques adversos de chuva estão fortemente correlacionados com maior mortalidade infantil e menor peso ao nascer. Já na área da educação, Branco e Féres (2018) investigam o impacto de secas no desempenho escolar nas regiões rurais do Nordeste. Evidências apontam que, caso a escola não disponha de cisternas, secas estão relacionadas a um pior desempenho escolar.

O Semiárido tem sido historicamente uma região de expulsão populacional. Delazeri, Cunha e Couto-Santos (2018) estimam que choques de temperatura no Semiárido levarão os trabalhadores a migrar para regiões urbanizadas ao final do século, sendo o impacto maior em regiões rurais. Tal resultado é corroborado por Corbi e Ferraz (2018), que encontram uma relação negativa entre pluviosidade e emigração.

Considerando os impactos econômicos das secas, o setor tradicionalmente mais vulnerável é o da agropecuária, que pode absorver até $80 \%$ de todos os impactos diretos, provocando efeitos na segurança alimentar e bem-estar das comunidades rurais (FAO, 2019). Além da escassez hídrica, o aumento da temperatura decorrente das mudanças climáticas também poderá trazer choques de produtividade ao setor. Contudo, cada cultura em cada região poderá responder de forma heterogênea. Um dos trabalhos pioneiros a relacionar produtividade agrícola e condições climáticas foi o de Oury (1965), que encontra uma correlação positiva para precipitação e negativa para temperatura. 
Mais recentemente, Deschênes e Greenstone (2007) apontam para evidências de que aumentos na precipitação nos EUA estão associados a maior produtividade de soja e milho, enquanto choques positivos de temperatura causam impactos negativos e não lineares para a produção de soja. Na mesma linha, Kucharik e Serbin (2008) também encontram uma relação positiva entre precipitação e produtividade de milho e soja.

Todavia, a literatura está longe do consenso em relação aos choques climáticos e produtividade agrícola. McCarl, Villavencio e Wu (2008) encontram efeitos positivos de choques de temperatura na produtividade de soja nos EUA, mas não encontram efeitos significantes para outras culturas. Além disso, os autores sugerem uma relação negativa entre pluviosidade e produtividade do trigo e positiva para produtividade do algodão, enquanto não encontra relação significativa para as demais culturas.

Kuwayama et al. (2019) investigam o impacto de cada semana adicional de seca na produtividade de milho e soja nos Estados Unidos, além de seu impacto na renda rural. Os autores encontram evidências de que cada semana adicional de seca está associada a menores rendimentos de milho e soja, tanto em municípios irrigados quanto não irrigados. Contudo, não encontram impactos significantes para a renda rural.

Para o caso brasileiro, Sanghi e Mendelsohn (2008) estimam a relação entre choques climáticos e valor das propriedades rurais, utilizando dados de censos agrícolas de 1960 a 1990 . Baseado em projeções climáticas, os autores concluem que, até 2100, o país deverá perder de $1 \%$ a 39\% do valor de sua produção agrícola, em comparação ao período estudado.

Gori Maia et al. (2016) estimam que elevações na temperatura e diminuições na precipitação estão associadas a impactos adversos na produção de milho, leite, gado bovino, caprino e ovino no sertão da Bahia. Tais impactos seriam mais significantes na produção de milho e leite, e para este último, seriam mais graves com eventos extremos.

Araújo et al. (2014) estudam o impacto de variações de chuvas e temperatura na produtividade agrícola média de mandioca, milho e cana para o Nordeste como um todo. Os autores usam dados de censos agrícolas para a estimação de um modelo Tobit de efeitos aleatórios, concluindo que as mudanças climáticas deverão causar grande impacto no rendimento 
das três culturas, principalmente nos estados do Rio Grande do Norte, Paraíba e Pernambuco, além do centro-sul e sul da Bahia.

De acordo com projeções climáticas para o Nordeste Brasileiro, a temperatura média deverá aumentar entre $1,3{ }^{\circ} \mathrm{C}$ e $4,4{ }^{\circ} \mathrm{C}$ na região até o final do século, a depender do cenário de emissões tomado como base (Marengo, Torres e Alves, 2017). As projeções pluviométricas sobre a região são incertas e heterogêneas, podendo apresentar impactos positivos ou negativos (Marengo, Torres e Alves, 2017). De toda forma, utilizando as projeções climáticas e modelos físicos de produtividade agrícola, o Quinto Relatório do Painel Intergovernamental sobre Mudanças Climáticas (IPCC) estima já para 2030 uma perda de produção de até 10\% para o cultivo de milho e arroz e até $14 \%$ para o cultivo de trigo no Nordeste, com base nos valores de 2008 (Pachauri et al., 2014).

Se as projeções de aumento da frequência de longas secas para o Semiárido se confirmarem, será impossível a prática agrícola na região sem o uso de irrigação. Contudo, mesmo a agricultura irrigada poderá estar vulnerável, uma vez que a falta de reposição de água pelas chuvas e a sobreexploração dos recursos subterrâneos poderá levar ao esgotamento das reservas de água do subsolo. O Quarto Relatório do IPCC apontou que até 2050 o volume dos aquíferos do Nordeste pode cair em até 70\% em relação ao volume de 2007 (Pachauri e Reisinger, 2008).

\subsection{Secas e modelos de equilíbrio geral}

Mesmo considerando as possibilidades de se usar irrigação, a falta de recursos financeiros por parte dos agricultores de subsistência, mais pobres e maioria no Semiárido, dificulta a implantação deste investimento e diminui sua capacidade de adaptação (Marengo, 2010). Assim, os agricultores mais pobres estão entre os mais expostos aos efeitos extremos de uma seca, devido à perda de suas safras e ao encarecimento de gêneros alimentícios (Alvalá et al., 2017). A seca de 1991-92 no Zimbábue, por exemplo, causou um impacto de 72\% nos preços de alimentos (IMF, 2003). Como estes produtos são bens necessários e que compõem proporcionalmente uma fração maior da cesta de consumo dos mais pobres, o impacto pode ser ainda mais grave em termos proporcionais para estas populações. 
No entanto, o choque de oferta de alimentos provocado por uma seca traz consigo efeitos simultâneos e contrários ao pequeno agricultor: o aumento de preços pode trazer consigo maior renda às famílias, mas tais famílias também pagarão mais caro para obter alimentos os quais não produzem, que, como mencionado, podem consistir grande parte de seu orçamento. Se o produtor ganhará ou perderá neste processo, dependerá se é um vendedor ou comprador líquido de alimentos. Este último grupo constitui a maior parte das famílias rurais pobres (Pachauri et al., 2014).

Estes efeitos múltiplos e simultâneos que as mudanças climáticas provocam sobre cada indivíduo e a economia como um todo tornam os modelos de equilíbrio geral computável (EGC) o ferramental ideal para tratar este tipo de problema. Neste tipo de modelo, a economia é descrita como um sistema de equações, em que consumidores buscam maximizar seu bem-estar, produtores seu lucro, investidores seu retorno, etc., cada um sujeito às suas restrições, sendo que cada setor da economia é interligado a outros por meio de compras e vendas.

Segundo Griffith (2012), dada a alta complexidade que os efeitos indiretos de um impacto proveniente de uma mudança climática sobre a economia pode apresentar, sua previsão de forma analítica ou por meio de equilíbrio parcial torna-se difícil, sendo mais efetivo o uso de modelos de equilíbrio geral computável. Boyd e Ibarrarán (2009) salientam que as vantagens oferecidas por este tipo de modelagem são de crucial importância no estudo de impactos climáticos como secas extremas, que afetam alguns setores diretamente e outros indiretamente. A título de exemplo, estudando os efeitos de uma seca no Canadá, Wittrock, Kulshreshtha e Wheaton (2011) relatam diversos efeitos sistêmicos observados sobre as comunidades (Wittrock, Kulshreshtha e Wheaton., 2011, p. 279):

Reduced sales of fertilizer and other farm inputs; local newspapers were impacted because fewer people placed advertisements; financial institutions made higher profits because borrowing deme rose significantly; many agricultural producers, particularly grain producers, decided to take off-farm jobs; oil and gas companies had to pay more for accessing water during the drought years; many trees died during or because of the droughts; water utilities benefitted with increased revenue during the drought years as people used more water; and machinery dealers were negatively impacted because producers were not spending any money on equipment. 
Utilizando este tipo de ferramental, Boyd e Ibarrarán (2009) estimam o impacto de uma seca extendida no México, testando ainda a eficácia de estratégias de adaptação para o setor agrícola e madeireiro. Os autores estimam perdas para os setores de grãos, pecuária, madeireiro e demais setores agrícolas na ordem de 11,56\%,13,78\%, 18,52\% e 12,23\%, respectivamente, tendo como base o ano de 2005. Analisando os impactos de uma seca em 2000 na China, Zhong et al (2016) estimam que as famílias rurais teriam uma perda de $15 \%$ em seu bem-estar.

Wittwer e Griffith (2011) estudam os efeitos dinâmicos de secas na bacia Murray-Darling, na Austrália, usando o arcabouço dinâmico de EGC. Secas ocorridas nos anos de 2006 a 2009 acarretariam em impactos como perdas de emprego que persistiriam até 2018. Como impacto imediato, a região perderia 5,7\% de seu produto nos anos de 2007 e 2008.

Levando em consideração a modelagem da incerteza dos choques climáticos, Thurlow, Dorosh e Yu (2012) criam uma série histórica hipotética aleatória a partir de uma série histórica real como base para um modelo de equilíbrio geral para avaliar os impactos das mudanças climáticas sobre a economia de Bangladesh. O estudo aponta para perdas na produção de arroz de 8,8\% em 2050, em comparação a 2005, além de perdas na economia de Bangladesh na ordem de 4,7\% na década de 2040, em comparação com o cenário sem variabilidade climática.

Haddad et al. (2014) estudam os impactos das mudanças climáticas no Líbano, medidos por meio de variações projetadas de precipitação e temperatura, e seus choques no setor agrícola. Tendo como base o ano de 2010, o estudo estima que as mudanças climáticas poderiam causar um impacto na economia libanesa na ordem de 5,5\% a 7,75\% em 2030, em que os consumidores perderiam $4 \%$ de seu consumo anual.

Para o caso brasileiro, Haddad, Porsse e Pereda (2012) estimam os impactos da variabilidade climática sobre a economia do país, por meio dos efeitos da variação do regime de chuvas em relação à média histórica sobre a produção agrícola dos municípios. Um modelo baseado em uma função lucro foi estimado para capturar a relação entre a variação das chuvas e a produtividade agrícola. Tais resultados foram usados em um modelo EGC como choques de produtividade sobre o setor agrícola. Os autores concluem que uma perda de $\mathrm{R} \$ 1,00$ no setor agrícola causa uma perda adicional de $\mathrm{R} \$ 3,25$ na economia como um todo. 
Faria e Haddad (2017) utilizam um modelo EGC em que tanto a oferta quanto a demanda por terra é modelada explicitamente para calcular os efeitos das mudanças climáticas, tendo como janela o período de 2010 a 2099, sobre a economia Brasileira. O estudo indica que, até o final do século, atividades agrícolas perderão espaço para pecuária e silvicultura.

Souza (2018) investiga os impactos de longo prazo de mudanças de temperatura e precipitação nos estados Brasileiros, concluindo que a perda de produtividade agrícola teria o potencial de gerar perdas equivalentes de 11,1\% até 81,6\% do PIB Brasileiro em 2011, dependendo do cenário de referência. Ainda, a região Centro-Oeste seria aquela mais vulnerável, devido ao peso do setor agrícola em sua economia.

Tendo como foco de estudo o Nordeste, Domingues, Magalhães e Ruiz (2011), utilizando-se de um modelo de equilíbrio geral multi-regional, concluem que os efeitos das mudanças climáticas sobre a agricultura fariam com que o PIB da região fosse $13 \%$ menor em 2050 em relação a 2005. Já Barbieri et al. (2010) utilizam o ferramental de EGC para estudar como as mudanças climáticas, via agricultura, impactariam a migração. Os estudos apontam para perda de população na maior parte do território nordestino entre 2025 e 2050.

Este trabalho tem como objetivo contribuir para a literatura ao integrar modelos de monitoramento de seca a um modelo de equilíbrio geral computável calibrado para o Semiárido. Esta integração se dará por meio do impacto de variáveis climáticas na produtividade agrícola, estimado por um modelo econométrico. A abordagem econométrica segue o estudo desenvolvido por Mérel e Gammans (2018), que propõe um modelo de modo a levar em consideração a possibilidade de adaptação dos produtores às mudanças climáticas, separando assim choques de curto e longo prazo. 


\section{Metodologia}

O núcleo central deste trabalho será um modelo de equilíbrio geral computável (EGC). Este tipo de modelagem busca representar as interações de uma economia por meio de um sistema de equações, em que consumidores maximizam sua utilidade e os produtores, seu lucro. Ainda, é possível desagregar esta economia em seus diversos setores e regiões.

Neste estudo, investigaremos os impactos diretos e indiretos de choques provenientes de secas na economia do Semiárido, utilizando um modelo inter-regional calibrado para a região, tendo como base o ano de 2015. Para se computar tais impactos no âmbito da modelagem de equilíbrio geral, devemos aplicar um choque de produtividade no setor agrícola do modelo. Tal choque será calculado a partir de coeficientes obtidos de estimações econométricas que relacionam variáveis climáticas com a produtividade agrícola. Dispondo de tais estimativas, poderemos calcular choques de produtividade advindos de diversos cenários climáticos.

\subsection{Modelo econométrico}

A estratégia empírica para se estimar a relação entre choques climáticos e produtividade agrícola segue o modelo proposto por Mérel e Gammans (2018):

$$
y_{i t}=\alpha_{i}+\beta_{1} x_{i t}+\beta_{2} x_{i t}^{2}+\beta_{3}\left(x_{i t}-\mu_{i}\right)^{2}+\epsilon_{i t}
$$

Em que y é a variável de produtividade agrícola observada no município $i$ no ano $t, \alpha$ agrega os efeitos fixos para o município $i, x$ é a variável climática observada e $\mu$ é a média da variável climática da região. Ou seja, $x$ se refere ao conceito de tempo, que observamos no curto prazo, enquanto $\mu$ se refere ao clima, a média de variações do tempo em um longo período. Ainda, supomos que o tempo é uma variável aleatória centrada em um clima estacionário, isto é:

$$
\mathbb{E}\left[x_{i t} \mid \mu_{i}\right]=\mu_{i}
$$


Apesar de ser uma hipótese restritiva, o clima ser estacionário no período observado não implica que o clima futuro será o mesmo atual.

A forma funcional quadrática com efeitos fixos, ou seja, excluindo-se o termo de $\beta_{3}$ da equação (1), ganhou bastante popularidade na estimação do impacto de variáveis climáticas sobre variáveis econômicas de interesse após o estudo de Deschênes e Greenstone (2007). As vantagens desta forma quadrática incluem permitir relações não monotônicas entre as variáveis de interesse, que é comum em processos climáticos, e permitir que diferentes locais apresentem diferentes respostas marginais ao clima (Mérel e Gammans, 2018). Além disto, a abordagem de dados em painel permite o pesquisador controlar por variáveis omitidas não variantes no tempo que podem perturbar a estimação do efeito climático em estudos de cross-section (Mérel e Gammans, 2018).

Contudo, tal especificação não leva em consideração a possível adaptação dos produtores às mudanças climáticas, e assim, não distingue impactos climáticos de curto e longo prazo. No modelo proposto, o termo adicionado por $\beta_{3}$ tem como objetivo diferenciar a possibilidade de adaptação dos produtores a choques de curto e longo prazo. Assim, pressupõe-se que a possibilidade de adaptação dos produtores no longo prazo é maior que no curto, uma vez que investimentos demoram certo tempo para serem concluídos. Além disto, mesmo que os produtores soubessem de antemão qual seria a realização climática daquele ano em específico, certos investimentos poderiam não compensar. Auffhammer e Schlenker (2014) exemplificam que talvez não fosse vantajosa a construção de canais de irrigação devido a uma seca pontual, mas que provavelmente tal construção seria benéfica em um clima árido.

Desta forma, a melhor resposta dos produtores é considerar que a realização climática daquele ano será igual a sua média, ou seja, $x_{i t}=\mu_{i}$, e assim planejar seus investimentos para dado período de acordo. O termo $\beta_{3}\left(x_{i t}-\mu_{i}\right)^{2}$ constitui assim uma penalidade na produção do agricultor pela realização climática daquele ano ter diferido de sua média histórica.

Assim, a equação (1) nos permite definir os impactos de curto e longo prazo de variáveis climáticas sobre as variáveis de interesse. No curto prazo, os produtores têm de se adaptar àquele clima específico e não podem realizar todo o conjunto de investimentos, de forma que:

$$
\mathbb{E}\left[y^{C P} \mid \alpha_{i}, \mu_{i}, x_{i}\right]=\alpha_{i}+\beta_{1} x_{i t}+\beta_{2} x_{i t}^{2}+\beta_{3}\left(x_{i t}-\mu_{i}\right)^{2}
$$


No longo prazo, os choques serão interpretados pelos produtores como alterações no clima e os produtores então se adaptarão àquele clima, ou seja:

$$
\mathbb{E}\left[y^{L P} \mid \alpha_{i}, \mu_{i}, x_{i}\right]=\alpha_{i}+\beta_{1} x_{i t}+\beta_{2} x_{i t}^{2}
$$

Para aplicações práticas, Merél e Gammans (2018) demonstram que é possível obter estimativas consistentes de $\mu_{i}$ utilizando sua contraparte amostral, ou seja, $\bar{x}=\frac{\Sigma_{t} x_{i t}}{T}$, onde T é o número de períodos observados.

Para este estudo, foi construído um painel municipal, tendo como recorte espacial o Semiárido, com dados do rendimento médio de milho, mandioca e feijão. A estratégia de identificação do modelo segue a proposta por Deschênes e Greenstone (2007), em que a especificação de preferência inclui efeitos fixos municipais e também efeitos fixos de estado-ano. Desta forma, os parâmetros de interesse serão obtidos a partir de choques climáticos específicos do município sobre sua média histórica depois de se controlar por choques comuns para todos os municípios dentro de um estado em determinado ano (Deschênes e Greenstone, 2007). Estas variações são presumidamente ortogonais às variáveis omitidas que determinam a produtividade agrícola. Logo, a equação a ser estimada é dada por:

$$
y_{i t}^{c}=\alpha_{i}+\gamma_{s t}+\boldsymbol{X}_{i t}^{\prime} \boldsymbol{\beta}_{1}+\boldsymbol{X}_{i t}^{2 \prime} \boldsymbol{\beta}_{2}+\left(\boldsymbol{X}_{i t}-\overline{\boldsymbol{X}}_{i}\right)^{2 \prime} \boldsymbol{\beta}_{3}+\epsilon_{i t}(4)
$$

Em que $y_{i t}^{c}$ representa o rendimento médio da cultura $c$ no município $i$ no ano $t, \alpha_{i}$ é o efeito fixo muncipal, $\gamma_{s t}$ é o efeito fixo do estado $s$ no ano $t$ e $\boldsymbol{X}_{i t}$ é um vetor de variáveis climáticas. Para este estudo, as culturas serão dadas por mandioca, milho e feijão, enquanto as variáveis climáticas serão índices de seca.

Ainda, cada regressão é ponderada pela raiz quadrada da área cultivada total no município, assim como em Deschênes e Greenstone (2007). Isto é feito pois as variáveis estimadas em municípios com maiores operações agrícolas tendem a ser mais precisas que em municípios menores, de modo que esta ponderação corrige a heterocedasticidade associada a estas diferenças na precisão. Finalmente, todas as estimações utilizaram cluster em nível estadual. 


\subsection{Modelo de equilíbrio geral computável}

Neste trabalho, utilizaremos o modelo de equilíbrio geral computável B-MARIA, desenvolvido por Haddad (2018) e adaptado para a região do Semiárido. A estrutura teórica do modelo segue a tradição australiana de modelos de equilíbrio geral computável, em que a economia é descrita como um sistema de equações, que representam o comportamento dos agentes representados. Tais equações determinam o equilíbrio da economia, e o sistema de equações é linearizado, de modo a permitir calcular os efeitos de uma mudança percentual de uma variável exógena sobre as endógenas, em pontos percentuais.

Cada região representada pelo modelo terá um consumidor representativo, um investidor representativo, governos regionais, além dos produtores de cada setor. Cada agente de cada setor e região pode comprar ou vender produtos para os demais, dentro e fora de sua própria região.

No modelo, são utilizados os pressupostos de mercados competitivos, em que as firmas e consumidores são tomadores de preços. Os consumidores maximizam sua utilidade dados os preços e sua restrição orçamentária, formada pelos retornos recebidos pelo uso por parte das firmas dos fatores primários. Já as firmas maximizam seus lucros, aplicada a hipótese de competição perfeita, sujeitas aos preços e à tecnologia disponível.

A produção do modelo é caracterizada por cada bem ser produzido em uma estrutura aninhada de insumos e também fatores primários, sendo estes capital e trabalho. De um lado, capital e trabalho se combinam por meio de uma função de elasticidade de substituição constante, formando um composto de fatores intermediários. Do outro lado, um composto de insumo específico é combinado utilizando como origem este mesmo insumo produzido nas demais regiões, também por meio de uma função de elasticidade de substituição constante. Por exemplo, o insumo milho utilizado na produção do setor de maizena no semiárido de Pernambuco é um composto de milho em que uma proporção é produzida na própria região, outras nas demais regiões do país, e uma proporção é importada. Ou seja, é utilizada a hipótese de Armington, em que cada bem produzido em dada região é substituto imperfeito do mesmo bem produzido nas outras regiões. Este composto de insumo é combinado com outros insumos utilizados na produção também por meio de uma função elasticidade de substituição constante, formando um composto 
de agregado de bens intermediários, que é então combinado com o composto de fatores primários por meio de uma função de Leontief, ou seja, em proporções fixas.

Este é um modelo de estática comparativa, ou seja, não há dinâmica. A distinção entre curto e longo prazo é dada pela diferença na mobilidade de capital e trabalho. Neste tipo de modelagem, é comum haver mais parâmetros desconhecidos que equações, de modo que necessitamos determinar variáveis exógenas e endógenas, de forma a tornar o sistema identificado. No chamado fechamento de curto prazo, consideramos salários reais e estoque de capital exógenos, e emprego e retorno do capital são endógenos. Já no fechamento de longo prazo, isto se inverte. Além disto, a migração entre regiões é realizada apenas no longo prazo. No fechamento de curto prazo a mobilidade do trabalho é feita apenas entre setores da mesma região, já no longo prazo a taxa de desemprego é dada, de forma que os trabalhadores se deslocam entre regiões de modo a equilibrar esta taxa.

Para avaliar os efeitos de uma seca, será dado um choque de produtividade sobre o setor agrícola, com base nos resultados do modelo econométrico. Dessa forma, uma perda de produtividade de $10 \%$ relacionada à produção agrícola em dada região significa que serão necessários $10 \%$ a mais de todos os fatores primários e todos os insumos para se produzir a mesma quantidade de bens agrícolas naquela região.

Este tipo de modelagem nos permite capturar os efeitos diretos e indiretos de uma diminuição na produtividade de um setor provocada pela seca, em cada setor e cada região. Quando a produtividade agrícola no semiárido da Bahia cai, por exemplo, o produto agrícola se torna mais caro de produzir, e então há um aumento no preço deste bem. Assim, a renda real das famílias cai, o setor agrícola do semiárido da Bahia se torna menos competitivo e o retorno esperado dos investidores cai. Isto diminui a demanda, tanto doméstica quanto externa, por bens agrícolas desta região; logo há uma menor produção e então menor demanda por insumos e fatores, o que leva a uma pressão por diminuição de preços.

Ao mesmo tempo, como é necessário mais de todos os insumos e fatores para se produzir a mesma quantidade de bens agrícolas no semiárido da Bahia, há um aumento na demanda por insumos e fatores, levando, em última instância, a uma pressão sobre o aumento de preços dos 
fatores e, consequentemente, maior renda das famílias, que então, por meio do consumo, pressionariam por um aumento de preços.

Por fim, o setor agrícola das demais regiões se torna relativamente mais produtivo, logo seus produtos ficarão relativamente mais baratos e então a demanda sobe, o que leva este setor das demais regiões a demandar mais insumos e fatores, inclusive dos setores do semiárido da Bahia, levando a uma pressão de aumento de preços. O modelo interage todos estes efeitos até convergir no efeito líquido sobre cada variável endógena, que, a priori, é indefinido. A Figura 1 ilustra esta cadeia simultânea de efeitos.

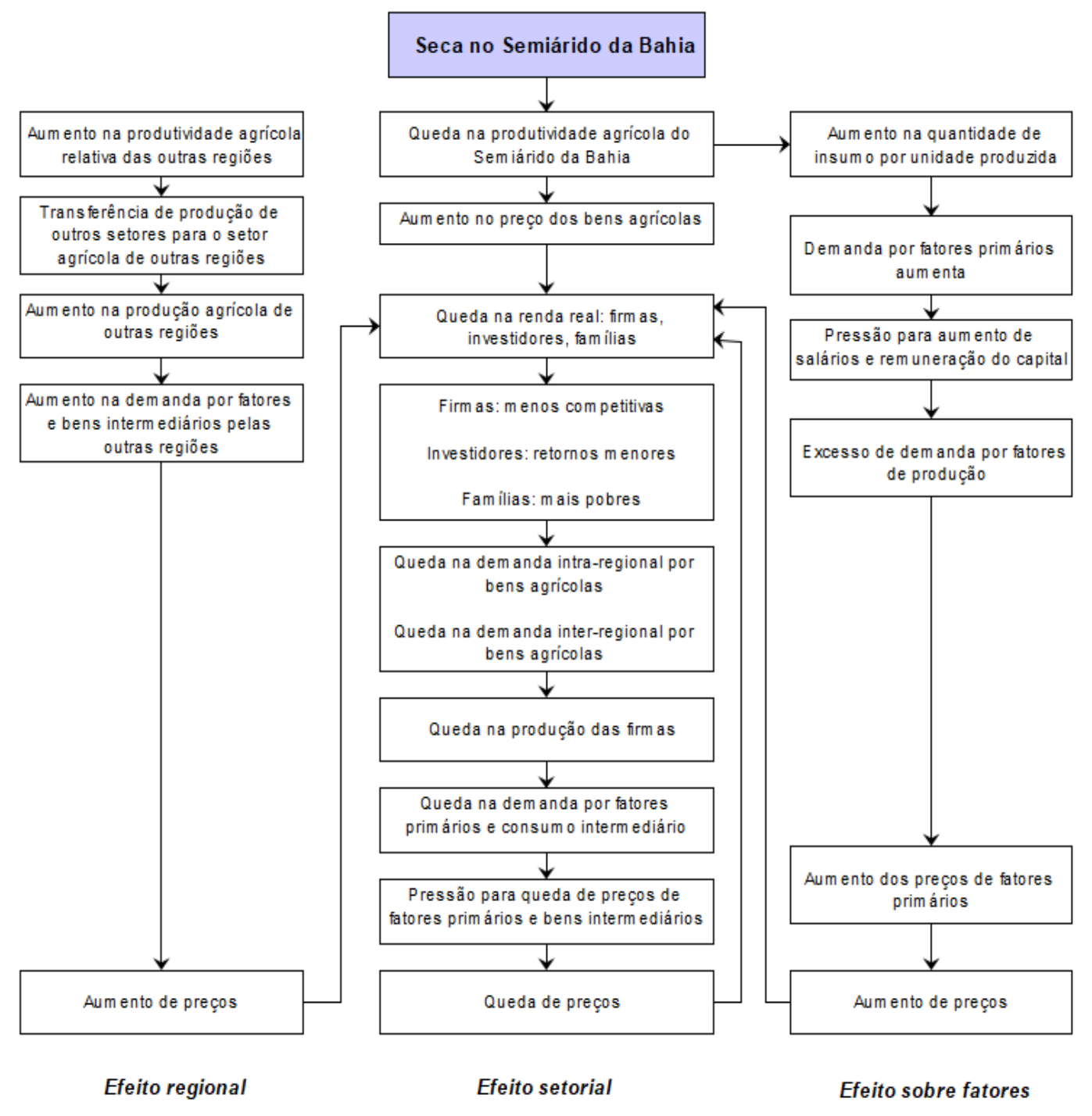

Figura 1 - Relações de causalidade capturadas pelos modelos de EGC. Elaboração própria, com base em Santos (2018) 


\section{Dados}

\subsection{Dados agrícolas}

Tendo como recorte espacial e temporal os municípios do Semiárido entre 2001 e 2018, foram coletados dados agrícolas provenientes da Pesquisa Agrícola Municipal (PAM), conduzida pelo IBGE. A variável de interesse para as estimações é o rendimento médio, medido em toneladas por hectare, para feijão, mandioca e milho. Tais culturas foram escolhidas por sua importância histórica como alimento básico da região.

A Tabela 1 expõe a representatividade de cada cultura no valor total produzido pela agricultura dos municípios do Semiárido nos anos de 2012 a 2018. No total produzido pelo Semiárido, milho, feijão e mandioca apresentam importância semelhante, em que o peso médio de cada cultura no período está situada em torno de $6 \%$ e 7\%. A importância conjunta das três culturas varia em torno de $20 \%$ em todo o período.

Tabela 1- Representatividade de cada cultura em termos de valor produzido no Semiárido

\begin{tabular}{lrrrrrrrr}
\hline Cultura/Ano & 2012 & 2013 & 2014 & 2015 & 2016 & 2017 & 2018 & Média \\
\hline Milho & $5,12 \%$ & $6,98 \%$ & $8,27 \%$ & $7,99 \%$ & $5,09 \%$ & $10,18 \%$ & $7,28 \%$ & $7,27 \%$ \\
Feijão & $4,78 \%$ & $6,88 \%$ & $6,14 \%$ & $6,72 \%$ & $7,01 \%$ & $6,82 \%$ & $5,89 \%$ & $6,32 \%$ \\
Mandioca & $11,01 \%$ & $6,84 \%$ & $7,21 \%$ & $6,82 \%$ & $5,99 \%$ & $5,42 \%$ & $5,05 \%$ & $6,91 \%$ \\
\hline Total & $20,91 \%$ & $20,70 \%$ & $21,62 \%$ & $21,53 \%$ & $18,09 \%$ & $22,42 \%$ & $18,22 \%$ & $20,50 \%$ \\
\hline
\end{tabular}

Já a Tabela 2 indica a importância de cada cultura em termos de área cultivada nos municípios do Semiárido. A média da área cultivada de milho para o período é ligeiramente superior a um terço da área cultivada da região, enquanto a de feijão é pouco superior a um quarto. Já a área cultivada de mandioca é significativamente menor, girando em torno de 5\% da área total. Conjuntamente, as três culturas representam em torno de dois terços da área cultivada do Semiárido. A comparação com sua representatividade conjunta em relação ao valor produzido, em torno de um quinto, demonstra a importância de tais culturas na agricultura de subsistência, caracterizada pelo seu baixo valor produzido e ampla presença nos municípios da região. 
Tabela 2-Representatividade de cada cultura em termos de área cultivada no Semiárido

\begin{tabular}{|c|c|c|c|c|c|c|c|c|}
\hline Cultura/Ano & 2012 & 2013 & 2014 & 2015 & 2016 & 2017 & 2018 & Média \\
\hline Milho & $31,02 \%$ & $29,65 \%$ & $33,78 \%$ & $35,13 \%$ & $36,34 \%$ & $37,88 \%$ & $39,41 \%$ & $34,75 \%$ \\
\hline Feijão & $24,05 \%$ & $24,42 \%$ & $27,78 \%$ & $26,61 \%$ & $26,92 \%$ & $29,92 \%$ & $29,35 \%$ & $27,01 \%$ \\
\hline Mandioca & $6,72 \%$ & $4,97 \%$ & $4,84 \%$ & $5,08 \%$ & $4,94 \%$ & $3,53 \%$ & $4,15 \%$ & $4,89 \%$ \\
\hline Total & $61,79 \%$ & $59,04 \%$ & $66,40 \%$ & $66,82 \%$ & $68,20 \%$ & $71,34 \%$ & $72,91 \%$ & $66,64 \%$ \\
\hline
\end{tabular}

A Tabela 3 expõe a correlação entre a produção de cada cultura e a produção agrícola total do semiárido em cada estado, para o período de 2000 a 2018. Com exceção da Bahia, todos estados têm uma correlação superior a 0,6 em pelo menos uma das culturas, de forma que a produção das culturas em questão representa um termômetro razoável da produção agrícola total da região.

\section{Tabela 3 - Correlação entre a produção das culturas analisadas e a produção agrícola total (2000/2018)}

\begin{tabular}{cccc}
\hline Estado & Milho & Feijão & Mandioca \\
\hline PI & 0.7635 & 0.8046 & 0.8819 \\
CE & 0.4917 & 0.6152 & 0.4712 \\
RN & 0.5032 & 0.5306 & 0.6688 \\
PB & 0.8800 & 0.9311 & 0.6858 \\
PE & 0.5546 & 0.7204 & 0.5649 \\
AL & 0.6796 & 0.9224 & 0.8697 \\
SE & 0.8185 & 0.9029 & 0.8504 \\
BA & 0.4972 & 0.5153 & 0.5658 \\
MG & 0.7828 & 0.7883 & 0.7268 \\
\hline
\end{tabular}

\subsubsection{Milho}

Sendo o cereal mais cultivado no Brasil e importante alimento básico da população, o milho apresenta grande heterogeneidade em sua produtividade nas diferentes regiões do país, a depender das condições climáticas e práticas de cultivo (Souza et al., 2011). É um cultivo de grande importância para a agricultura familiar, responsável pela metade de sua produção no país (Souza et al., 2011), mas sua produtividade em nível nacional é considerada baixa (Ferreira et al., 2010). Sua importância econômica se estende para além da alimentação humana, podendo ser usado como alimento para animais e matéria prima na produção de amido, óleo, álcool, flocos alimentícios e bebidas (Ferreira et al., 2010). Apesar de ser considerada uma cultura de alta 
demanda hídrica, também apresenta grande eficiência no uso da água, com alta relação de produção de matéria seca por unidade de água absorvida (Silva et al., 2012).

Seu período de plantio e colheita pode variar bastante conforme a região, segundo dados da Companhia Nacional de Abastecimento (Conab, 2019). É uma cultura que pode apresentar mais de uma safra por estado, sendo que o período do plantio compreende as estações da primavera, verão ou outono no Nordeste, conforme cada região.

A região do Semiárido foi responsável por 3\% da produção nacional de milho em 2015, de acordo com a PAM. A Tabela 4 apresenta a importância de cada estado na produção de milho no Semiárido. Os estados com maior produção média no período de 2012 a 2018 são Bahia, Sergipe e Piauí, respectivamente.

Tabela 4 - Representatividade dos municípios de cada estado na produção de milho no Semiárido

\begin{tabular}{crrrrrrrr}
\hline Estado/Ano & \multicolumn{1}{c}{2012} & \multicolumn{1}{c}{2013} & \multicolumn{1}{c}{2014} & \multicolumn{1}{c}{2015} & \multicolumn{1}{l}{2016} & \multicolumn{2}{l}{2017} & \multicolumn{2}{l}{2018} & Média \\
\hline PI & $24,45 \%$ & $5,72 \%$ & $10,57 \%$ & $15,34 \%$ & $21,25 \%$ & $17,01 \%$ & $33,07 \%$ & $18,20 \%$ \\
CE & $14,41 \%$ & $10,46 \%$ & $22,79 \%$ & $8,41 \%$ & $15,74 \%$ & $17,45 \%$ & $29,66 \%$ & $16,99 \%$ \\
RN & $0,34 \%$ & $1,05 \%$ & $0,98 \%$ & $0,26 \%$ & $0,33 \%$ & $0,24 \%$ & $1,97 \%$ & $0,74 \%$ \\
PB & $0,50 \%$ & $1,29 \%$ & $1,41 \%$ & $0,49 \%$ & $1,51 \%$ & $1,17 \%$ & $3,91 \%$ & $1,47 \%$ \\
PE & $2,85 \%$ & $2,00 \%$ & $3,44 \%$ & $2,19 \%$ & $1,97 \%$ & $2,27 \%$ & $5,58 \%$ & $2,90 \%$ \\
AL & $0,07 \%$ & $0,45 \%$ & $0,46 \%$ & $1,02 \%$ & $0,55 \%$ & $0,81 \%$ & $0,16 \%$ & $0,50 \%$ \\
SE & $35,46 \%$ & $38,32 \%$ & $34,31 \%$ & $28,02 \%$ & $13,88 \%$ & $34,42 \%$ & $4,72 \%$ & $27,02 \%$ \\
BA & $17,33 \%$ & $37,98 \%$ & $22,44 \%$ & $40,59 \%$ & $36,57 \%$ & $23,66 \%$ & $17,56 \%$ & $28,02 \%$ \\
MG & $4,59 \%$ & $2,72 \%$ & $3,58 \%$ & $3,67 \%$ & $8,19 \%$ & $2,97 \%$ & $3,36 \%$ & $4,16 \%$ \\
\hline
\end{tabular}

Tabela 5 - Representatividade da média municipal do milho no Semiárido em termos de valor agrícola produzido

\begin{tabular}{ccccccccc}
\hline Estado/Ano & 2012 & 2013 & 2014 & 2015 & 2016 & 2017 & 2018 & Média \\
\hline PI & $24,09 \%$ & $12,78 \%$ & $16,66 \%$ & $20,12 \%$ & $26,32 \%$ & $22,04 \%$ & $24,43 \%$ & $20,92 \%$ \\
CE & $4,69 \%$ & $4,36 \%$ & $11,42 \%$ & $5,93 \%$ & $6,13 \%$ & $9,89 \%$ & $12,28 \%$ & $7,82 \%$ \\
RN & $0,20 \%$ & $0,94 \%$ & $1,23 \%$ & $0,34 \%$ & $0,22 \%$ & $0,32 \%$ & $1,57 \%$ & $0,69 \%$ \\
PB & $1,57 \%$ & $4,37 \%$ & $6,94 \%$ & $2,76 \%$ & $4,71 \%$ & $6,78 \%$ & $14,39 \%$ & $5,93 \%$ \\
PE & $0,74 \%$ & $0,73 \%$ & $1,99 \%$ & $1,18 \%$ & $0,62 \%$ & $1,39 \%$ & $2,32 \%$ & $1,28 \%$ \\
AL & $0,21 \%$ & $2,96 \%$ & $4,93 \%$ & $10,22 \%$ & $4,95 \%$ & $8,02 \%$ & $1,21 \%$ & $4,64 \%$ \\
SE & $63,20 \%$ & $69,49 \%$ & $80,32 \%$ & $79,89 \%$ & $53,78 \%$ & $83,55 \%$ & $50,15 \%$ & $68,63 \%$ \\
BA & $2,57 \%$ & $7,51 \%$ & $4,45 \%$ & $6,93 \%$ & $4,28 \%$ & $6,93 \%$ & $3,68 \%$ & $5,19 \%$ \\
MG & $2,29 \%$ & $1,76 \%$ & $3,06 \%$ & $2,95 \%$ & $3,45 \%$ & $3,80 \%$ & $3,22 \%$ & $2,93 \%$ \\
\hline
\end{tabular}




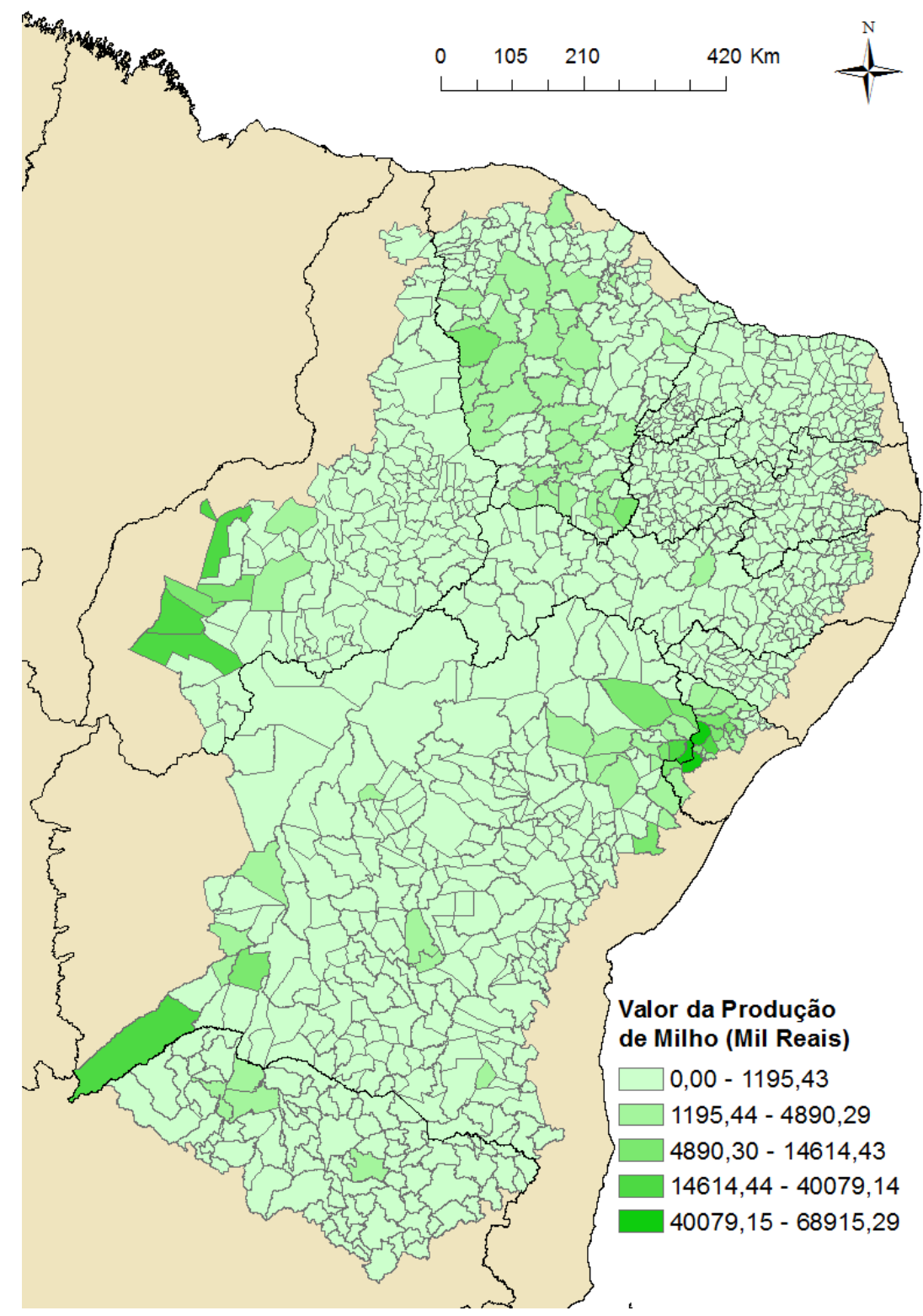

Figura 2- Produção de Milho no Semiárido - Média do Valor Produzido entre 2012 e 2018

A importância dos municípios do Sergipe, um estado pequeno, é refletida na participação do milho dentro do total produzido pela agricultura dos municípios do Semiárido deste estado, mostrado pela Tabela 5. Para a maioria dos estados, sua importância média não excede $8 \%$ do valor produzido pela agricultura, sendo o estado com menor importância relativa o Rio Grande do Norte. Contudo, a importância média para os municípios do Piauí gira em torno de um quinto, e para o Sergipe, quase $70 \%$. Para este último estado, há anos em que a produção de milho atinge quase $85 \%$ do valor produzido pela agricultura local. 
Já a Tabela 6 informa a importância do milho para os municípios do Semiárido de cada estado em termos de área cultivada. Para a maioria dos estados, este valor gira em torno de um terço, o que demonstra sua importância como cultura de subsistência. O estado do Sergipe apresenta valores de área cultivada proporcionalmente mais próximos ao de valor produzido, sendo o estado com maior importância relativa em ambas variáveis.

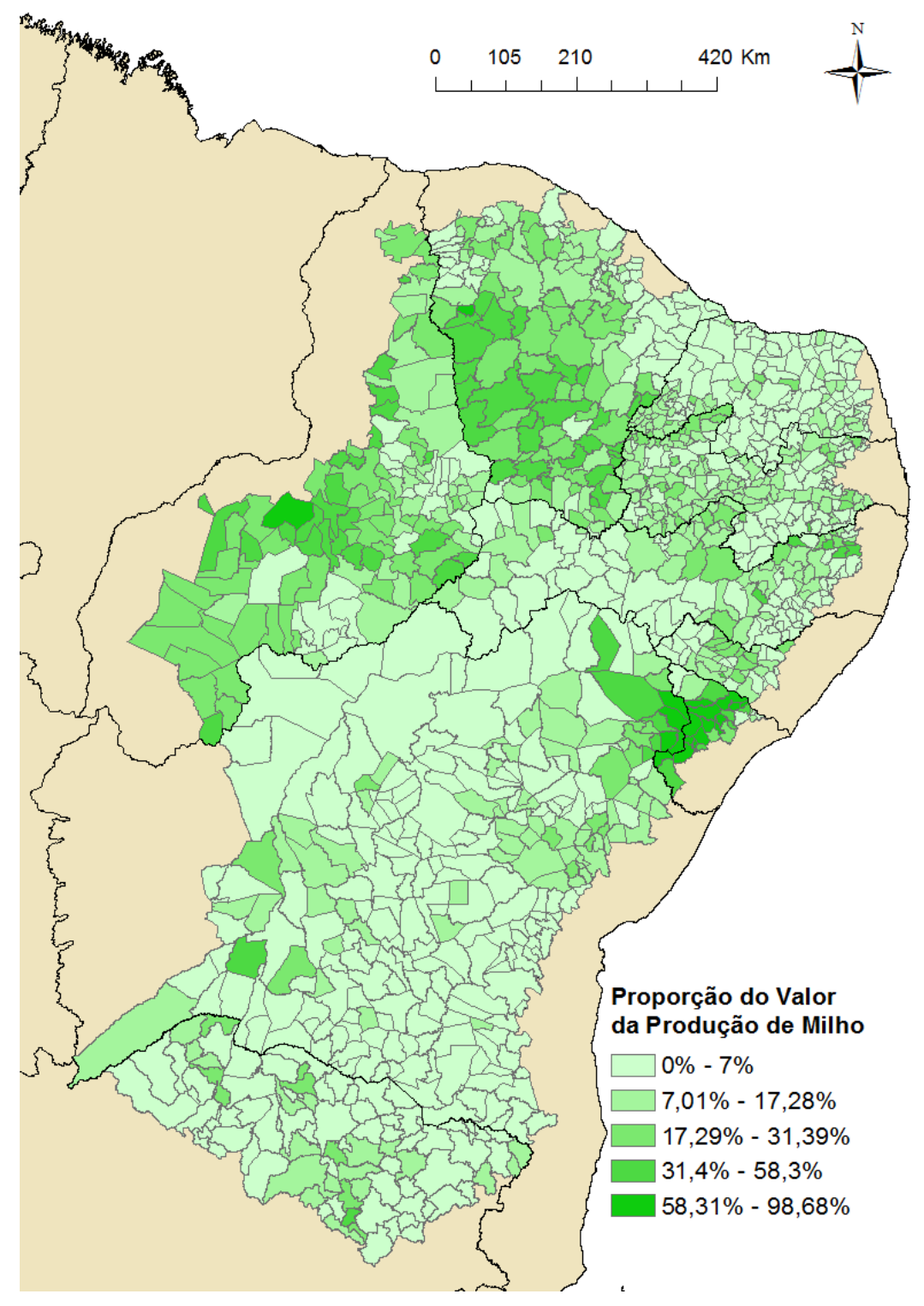

Figura 3 - Proporção da Produção do Milho no Total Produzido pelo Setor Agrícola dos Municípios (média 2012-2018) 
Tabela 6 - Representatividade do milho em termos de área cultivada nos municípios do Semiárido

\begin{tabular}{ccccccccc}
\hline Estado/Ano & 2012 & 2013 & 2014 & 2015 & 2016 & 2017 & 2018 & Média \\
\hline PI & $29,03 \%$ & $31,71 \%$ & $32,53 \%$ & $34,61 \%$ & $38,85 \%$ & $35,80 \%$ & $37,83 \%$ & $34,34 \%$ \\
CE & $36,57 \%$ & $31,82 \%$ & $37,52 \%$ & $39,45 \%$ & $40,05 \%$ & $43,95 \%$ & $46,10 \%$ & $39,35 \%$ \\
RN & $8,70 \%$ & $16,26 \%$ & $17,31 \%$ & $17,66 \%$ & $17,13 \%$ & $15,48 \%$ & $18,68 \%$ & $15,89 \%$ \\
PB & $41,74 \%$ & $32,78 \%$ & $41,46 \%$ & $38,81 \%$ & $42,34 \%$ & $42,93 \%$ & $43,89 \%$ & $40,56 \%$ \\
PE & $37,81 \%$ & $20,24 \%$ & $38,37 \%$ & $38,21 \%$ & $38,24 \%$ & $37,91 \%$ & $38,30 \%$ & $35,58 \%$ \\
AL & $24,80 \%$ & $28,89 \%$ & $31,54 \%$ & $31,61 \%$ & $32,59 \%$ & $36,48 \%$ & $35,94 \%$ & $31,69 \%$ \\
SE & $83,54 \%$ & $81,54 \%$ & $88,90 \%$ & $89,81 \%$ & $89,30 \%$ & $89,40 \%$ & $93,04 \%$ & $87,93 \%$ \\
BA & $21,22 \%$ & $24,95 \%$ & $26,72 \%$ & $28,75 \%$ & $28,10 \%$ & $29,50 \%$ & $32,52 \%$ & $27,39 \%$ \\
MG & $32,01 \%$ & $32,52 \%$ & $33,28 \%$ & $33,13 \%$ & $33,74 \%$ & $33,76 \%$ & $29,26 \%$ & $32,53 \%$ \\
\hline
\end{tabular}

\subsubsection{Feijão}

No Semiárido, a variedade de feijão mais importante é o feijão-caupi (Vigna unguiculata), também conhecido por feijão macassar ou feijão de corda (Souza et al., 2011). Esta cultura desempenha importante função ao ser fonte de proteínas e aminoácidos para as populações rurais mais carentes, além de poder ser usada como diversificação de renda (Souza et al., 2011; Pereira et al., 2013). Apesar de a agricultura familiar ser responsável por dois terços de sua produção no país (Souza et al. 2011), a elevada quantidade de mão de obra demandada no seu cultivo cria diversos empregos diretos e indiretos (Pereira et al., 2013).

Segundo dados do Conab (2019), é uma cultura com três safras anuais. No Nordeste, seu período de plantio compreende de dois a três meses, que pode ocorrer na primavera, verão ou outono, conforme a safra e a região.

Segundo dados da PAM, a região do Semiárido foi responsável por 12,4\% do valor total produzido de feijão no país em 2015. Os municípios da Bahia concentram a maior produção de feijão, seguido pelo Ceará, como exposto na Tabela 7. A Tabela 8 mostra a importância relativa desta cultura em relação ao valor produzido por cada município do Semiárido. Sua importância média abrange de $1,95 \%$ a 13,18\% no período analisado, sendo o estado com menor importância relativa o Rio Grande do Norte e o maior, a Paraíba. 
Tabela 7 - Representatividade dos municípios de cada estado na produção de feijão no Semiárido

\begin{tabular}{crrrrrrrr}
\hline Estado/Ano & \multicolumn{1}{c}{2012} & \multicolumn{1}{c}{2013} & \multicolumn{1}{c}{2014} & \multicolumn{1}{c}{2015} & \multicolumn{1}{c}{2016} & \multicolumn{2}{l}{2017} & \multicolumn{2}{l}{2018} & Média \\
\hline PI & $9,04 \%$ & $7,97 \%$ & $8,75 \%$ & $9,59 \%$ & $5,87 \%$ & $17,44 \%$ & $20,41 \%$ & $11,30 \%$ \\
CE & $40,03 \%$ & $16,05 \%$ & $27,88 \%$ & $16,78 \%$ & $25,21 \%$ & $33,18 \%$ & $31,29 \%$ & $27,20 \%$ \\
RN & $1,21 \%$ & $2,40 \%$ & $2,48 \%$ & $0,93 \%$ & $1,20 \%$ & $2,88 \%$ & $6,06 \%$ & $2,45 \%$ \\
PB & $1,32 \%$ & $5,19 \%$ & $3,85 \%$ & $1,34 \%$ & $2,99 \%$ & $4,64 \%$ & $6,64 \%$ & $3,71 \%$ \\
PE & $11,09 \%$ & $9,92 \%$ & $14,86 \%$ & $12,48 \%$ & $15,88 \%$ & $14,47 \%$ & $14,22 \%$ & $13,28 \%$ \\
AL & $0,63 \%$ & $2,85 \%$ & $1,71 \%$ & $1,74 \%$ & $0,41 \%$ & $1,88 \%$ & $0,33 \%$ & $1,36 \%$ \\
SE & $1,89 \%$ & $3,45 \%$ & $1,50 \%$ & $0,96 \%$ & $0,62 \%$ & $2,27 \%$ & $0,36 \%$ & $1,58 \%$ \\
BA & $21,16 \%$ & $46,23 \%$ & $35,01 \%$ & $51,77 \%$ & $40,10 \%$ & $19,78 \%$ & $16,48 \%$ & $32,93 \%$ \\
MG & $13,63 \%$ & $5,95 \%$ & $3,96 \%$ & $4,40 \%$ & $7,73 \%$ & $3,46 \%$ & $4,19 \%$ & $6,19 \%$ \\
\hline
\end{tabular}

Tabela 8 - Representatividade média municipal do feijão no Semiárido em termos de valor agrícola produzido

\begin{tabular}{ccccccccc}
\hline Estado/Ano & 2012 & 2013 & 2014 & 2015 & 2016 & \multicolumn{1}{c}{2017} & 2018 & Média \\
\hline PI & $8,33 \%$ & $17,55 \%$ & $10,23 \%$ & $10,58 \%$ & $10,01 \%$ & $15,13 \%$ & $12,21 \%$ & $12,00 \%$ \\
CE & $12,19 \%$ & $6,60 \%$ & $10,37 \%$ & $9,95 \%$ & $13,51 \%$ & $12,59 \%$ & $10,49 \%$ & $10,81 \%$ \\
RN & $0,68 \%$ & $2,12 \%$ & $2,31 \%$ & $1,02 \%$ & $1,11 \%$ & $2,52 \%$ & $3,90 \%$ & $1,95 \%$ \\
PB & $3,90 \%$ & $17,26 \%$ & $14,04 \%$ & $6,41 \%$ & $12,79 \%$ & $18,09 \%$ & $19,80 \%$ & $13,18 \%$ \\
PE & $2,69 \%$ & $3,55 \%$ & $6,38 \%$ & $5,68 \%$ & $6,92 \%$ & $5,92 \%$ & $4,79 \%$ & $5,13 \%$ \\
AL & $1,91 \%$ & $18,52 \%$ & $13,56 \%$ & $14,61 \%$ & $5,05 \%$ & $12,50 \%$ & $2,03 \%$ & $9,74 \%$ \\
SE & $3,15 \%$ & $6,17 \%$ & $2,61 \%$ & $2,29 \%$ & $3,28 \%$ & $3,68 \%$ & $3,13 \%$ & $3,47 \%$ \\
BA & $2,93 \%$ & $9,01 \%$ & $5,16 \%$ & $7,44 \%$ & $6,46 \%$ & $3,88 \%$ & $2,80 \%$ & $5,38 \%$ \\
MG & $6,36 \%$ & $3,79 \%$ & $2,51 \%$ & $2,97 \%$ & $4,48 \%$ & $2,96 \%$ & $3,25 \%$ & $3,76 \%$ \\
\hline \hline
\end{tabular}

Tabela 9 - Representatividade do feijão em termos de área cultivada nos municípios do Semiárido

\begin{tabular}{ccccccccc}
\hline Estado/Ano & 2012 & 2013 & 2014 & 2015 & 2016 & 2017 & 2018 & Média \\
\hline PI & $25,05 \%$ & $26,24 \%$ & $27,50 \%$ & $26,00 \%$ & $28,21 \%$ & $27,68 \%$ & $27,87 \%$ & $26,94 \%$ \\
CE & $29,87 \%$ & $27,04 \%$ & $30,85 \%$ & $31,00 \%$ & $31,17 \%$ & $33,56 \%$ & $33,17 \%$ & $30,95 \%$ \\
RN & $8,45 \%$ & $13,91 \%$ & $15,87 \%$ & $18,02 \%$ & $17,07 \%$ & $19,50 \%$ & $23,26 \%$ & $16,58 \%$ \\
PB & $31,80 \%$ & $38,63 \%$ & $40,14 \%$ & $38,79 \%$ & $41,21 \%$ & $40,94 \%$ & $41,59 \%$ & $39,01 \%$ \\
PE & $39,39 \%$ & $32,99 \%$ & $40,96 \%$ & $37,32 \%$ & $41,34 \%$ & $42,90 \%$ & $39,31 \%$ & $39,17 \%$ \\
AL & $27,34 \%$ & $46,11 \%$ & $44,33 \%$ & $44,38 \%$ & $39,98 \%$ & $40,93 \%$ & $30,07 \%$ & $39,02 \%$ \\
SE & $9,04 \%$ & $11,10 \%$ & $5,28 \%$ & $5,88 \%$ & $6,14 \%$ & $6,95 \%$ & $3,67 \%$ & $6,87 \%$ \\
BA & $16,56 \%$ & $22,83 \%$ & $25,23 \%$ & $23,72 \%$ & $20,73 \%$ & $25,78 \%$ & $25,42 \%$ & $22,90 \%$ \\
MG & $16,96 \%$ & $15,76 \%$ & $15,47 \%$ & $14,65 \%$ & $16,15 \%$ & $21,80 \%$ & $20,93 \%$ & $17,39 \%$ \\
\hline
\end{tabular}


Em relação à área cultivada, a Tabela 9 mostra a importância do feijão como cultura de subsistência, assim como o milho. Para quatro estados, sua área cultivada média é maior do que $30 \%$ da área total no período analisado, sendo os estados com maior importância relativa Paraíba, Pernambuco e Alagoas, e o menor, Sergipe.

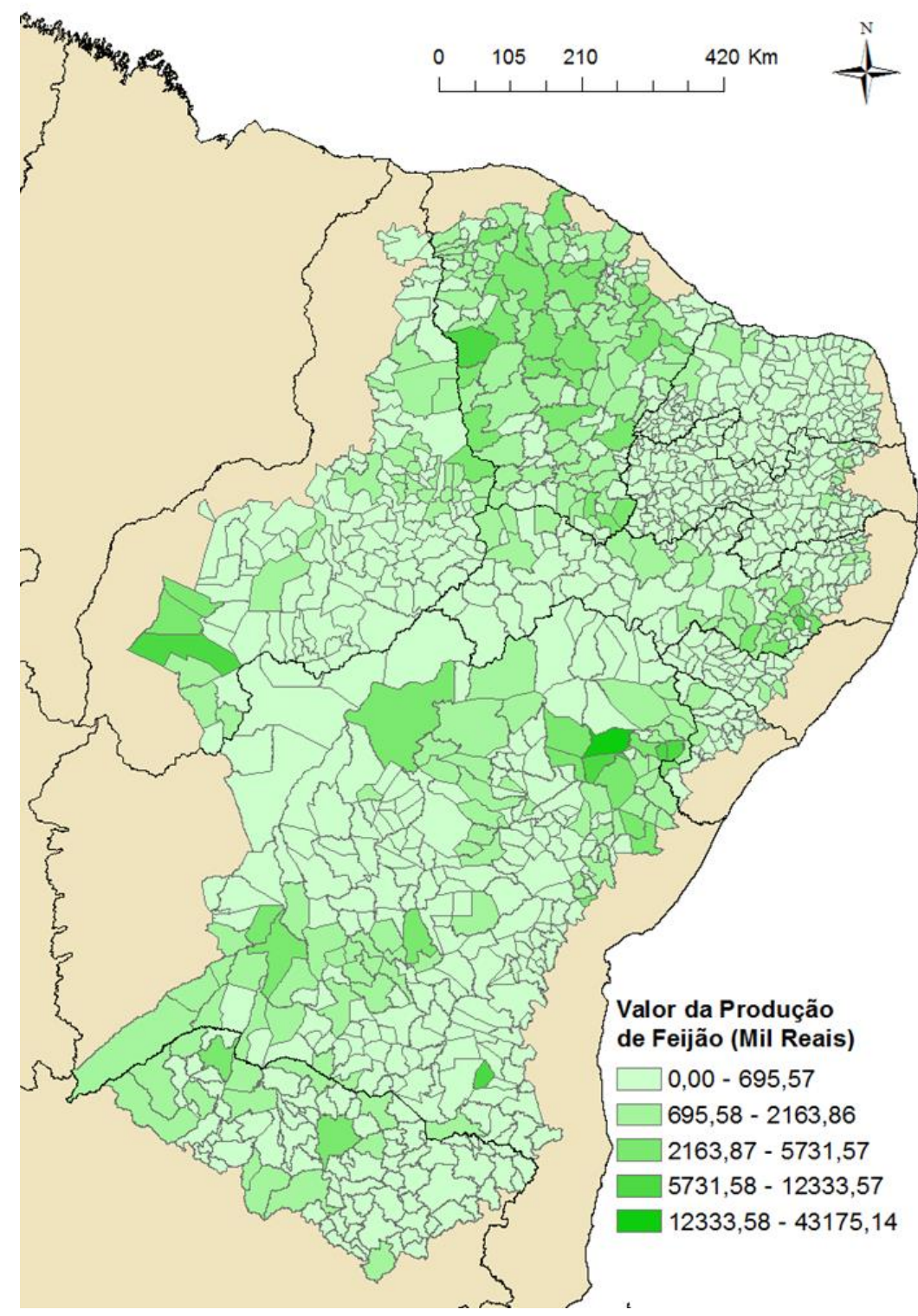

Figura 4 - Produção de Feijão no Semiárido - Média do Valor Produzido entre 2012 e 2018 


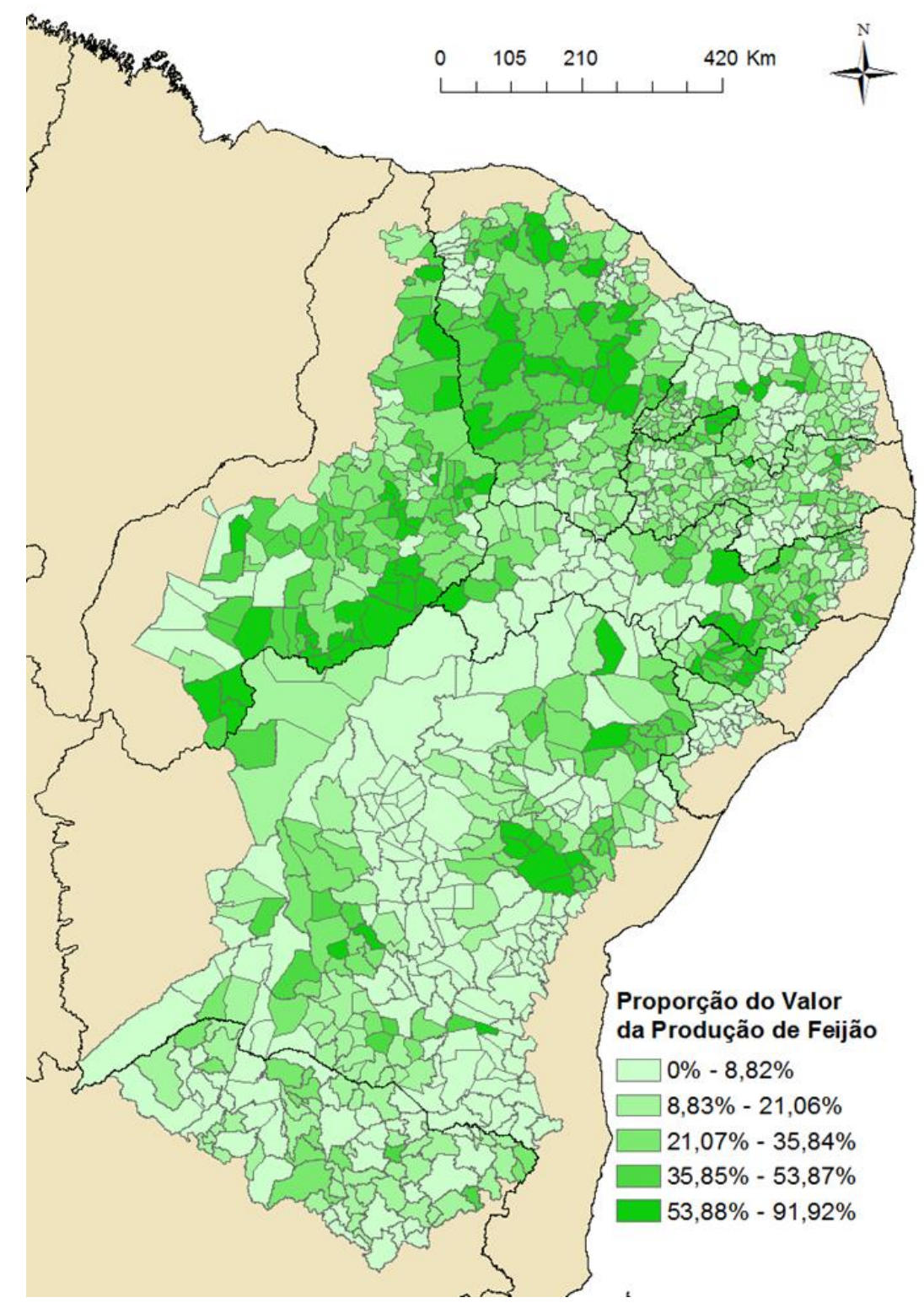

Figura 5 - Proporção da Produção do Feijão no Total Produzido pelo Setor Agrícola dos Municípios (média 2012-2018)

\subsubsection{Mandioca}

A mandioca é uma cultura altamente tolerante às secas, graças a sua capacidade de usar a água eficientemente (Castricini et al., 2014), de forma que esta cultura desempenha importante papel em regiões áridas e semiáridas (Silva et al., 2009). Outra vantagem da mandioca é sua baixa exigência nutricional e de manejo, que a permite ser cultivada inclusive pelos agricultores com menos recursos disponíveis (Silva et al., 2009). De fato, sua forma de cultivo atual é mesma praticada pela população indígena antes da era dos descobrimentos (Silva et al., 2009). 
A região do Semiárido foi responsável por 9,2\% da produção nacional de mandioca em 2015, de acordo com a PAM. A Bahia concentra os municípios que mais produzem mandioca no Semiárido no período analisado, seguida por Pernambuco, conforme a Tabela 10. As tabelas 11 e 12 demonstram a importância relativa da mandioca nos municípios de cada estado em termos de valor produzido e área cultivada, respectivamente. Diferentemente do milho e feijão, a mandioca apresenta valores médios mais próximos para as duas variáveis, com exceção do estado do Alagoas, que se destaca com 45,26\% de média para valor produzido e 13,71\% para área cultivada. Contudo, é possível observar uma tendência de queda em ambas variáveis ao longo dos anos.

Tabela 10 - Representatividade dos municípios de cada estado na produção de mandioca no Semiárido

\begin{tabular}{|c|c|c|c|c|c|c|c|c|}
\hline Estado/Ano & 2012 & 2013 & 2014 & 2015 & 2016 & 2017 & 2018 & Média \\
\hline $\mathrm{PI}$ & $2,66 \%$ & $2,01 \%$ & $1,63 \%$ & $3,92 \%$ & $4,15 \%$ & $3,57 \%$ & $5,10 \%$ & $3,29 \%$ \\
\hline CE & $5,82 \%$ & $10,49 \%$ & $12,55 \%$ & $6,98 \%$ & $11,09 \%$ & $16,47 \%$ & $16,56 \%$ & $11,42 \%$ \\
\hline RN & $7,76 \%$ & $4,97 \%$ & $4,37 \%$ & $4,45 \%$ & $5,58 \%$ & $9,65 \%$ & $11,25 \%$ & $6,86 \%$ \\
\hline PB & $1,65 \%$ & $2,74 \%$ & $2,01 \%$ & $2,32 \%$ & $2,58 \%$ & $3,43 \%$ & $3,33 \%$ & $2,58 \%$ \\
\hline PE & $30,99 \%$ & $22,19 \%$ & $15,47 \%$ & $14,83 \%$ & $10,30 \%$ & $14,42 \%$ & $17,91 \%$ & $18,02 \%$ \\
\hline$A L$ & $10,70 \%$ & $8,05 \%$ & $4,69 \%$ & $4,24 \%$ & $4,26 \%$ & $7,50 \%$ & $4,87 \%$ & $6,33 \%$ \\
\hline SE & $3,13 \%$ & $5,57 \%$ & $2,62 \%$ & $2,35 \%$ & $3,61 \%$ & $3,18 \%$ & $1,52 \%$ & $3,14 \%$ \\
\hline BA & $29,31 \%$ & $34,22 \%$ & $46,98 \%$ & $52,26 \%$ & $47,81 \%$ & $32,85 \%$ & $29,52 \%$ & $38,99 \%$ \\
\hline MG & $7,98 \%$ & $9,78 \%$ & $9,69 \%$ & $8,64 \%$ & $10,62 \%$ & $8,93 \%$ & $9,94 \%$ & $9,37 \%$ \\
\hline
\end{tabular}

Tabela 11 - Representatividade média municipal da mandioca no Semiárido em termos de valor agrícola produzido

\begin{tabular}{ccccccccc}
\hline Estado/Ano & 2012 & 2013 & 2014 & 2015 & 2016 & 2017 & 2018 & Média \\
\hline PI & $5,64 \%$ & $4,40 \%$ & $2,24 \%$ & $4,39 \%$ & $6,05 \%$ & $2,46 \%$ & $2,61 \%$ & $3,97 \%$ \\
CE & $4,08 \%$ & $4,29 \%$ & $5,48 \%$ & $4,21 \%$ & $5,08 \%$ & $4,97 \%$ & $4,76 \%$ & $4,69 \%$ \\
RN & $10,05 \%$ & $4,36 \%$ & $4,78 \%$ & $5,00 \%$ & $4,41 \%$ & $6,71 \%$ & $6,21 \%$ & $5,93 \%$ \\
PB & $11,22 \%$ & $9,04 \%$ & $8,60 \%$ & $11,27 \%$ & $9,46 \%$ & $10,62 \%$ & $8,50 \%$ & $9,82 \%$ \\
PE & $17,33 \%$ & $7,88 \%$ & $7,81 \%$ & $6,85 \%$ & $3,84 \%$ & $4,69 \%$ & $5,17 \%$ & $7,65 \%$ \\
AL & $74,60 \%$ & $52,05 \%$ & $43,64 \%$ & $36,24 \%$ & $44,94 \%$ & $39,68 \%$ & $25,68 \%$ & $45,26 \%$ \\
SE & $12,01 \%$ & $9,89 \%$ & $5,34 \%$ & $5,72 \%$ & $16,43 \%$ & $4,11 \%$ & $11,22 \%$ & $9,25 \%$ \\
BA & $9,33 \%$ & $6,63 \%$ & $8,13 \%$ & $7,63 \%$ & $6,58 \%$ & $5,12 \%$ & $4,29 \%$ & $6,81 \%$ \\
MG & $8,57 \%$ & $6,19 \%$ & $7,20 \%$ & $5,92 \%$ & $5,26 \%$ & $6,08 \%$ & $6,62 \%$ & $6,55 \%$ \\
\hline \hline
\end{tabular}




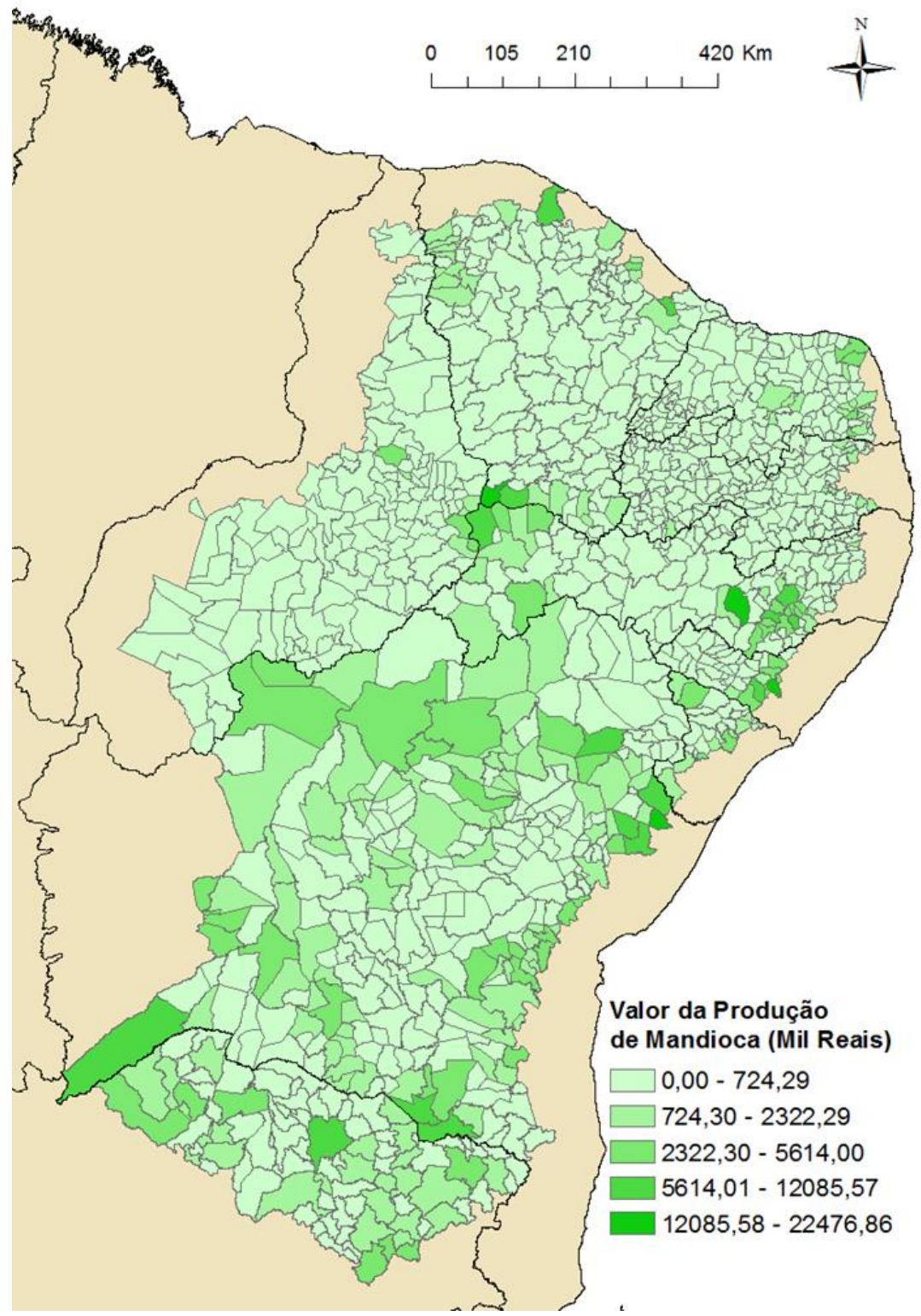

Figura 6 - Produção de Mandioca no Semiárido - Média do Valor Produzido entre 2012 e 2018

Tabela 12 - Representatividade da mandioca em termos de área cultivada

\begin{tabular}{ccccccccc}
\hline Estado/Ano & 2012 & 2013 & 2014 & 2015 & 2016 & 2017 & 2018 & Média \\
\hline PI & $4,75 \%$ & $1,96 \%$ & $1,40 \%$ & $2,79 \%$ & $2,64 \%$ & $2,53 \%$ & $1,99 \%$ & $2,58 \%$ \\
CE & $3,37 \%$ & $3,76 \%$ & $2,54 \%$ & $2,05 \%$ & $2,29 \%$ & $1,85 \%$ & $2,37 \%$ & $2,60 \%$ \\
RN & $10,64 \%$ & $2,39 \%$ & $5,39 \%$ & $5,86 \%$ & $4,50 \%$ & $5,90 \%$ & $9,17 \%$ & $6,26 \%$ \\
PB & $4,49 \%$ & $3,43 \%$ & $2,10 \%$ & $3,17 \%$ & $2,24 \%$ & $2,32 \%$ & $1,98 \%$ & $2,82 \%$ \\
PE & $7,42 \%$ & $14,27 \%$ & $6,03 \%$ & $8,79 \%$ & $7,02 \%$ & $4,26 \%$ & $8,90 \%$ & $8,10 \%$ \\
AL & $24,07 \%$ & $12,50 \%$ & $12,39 \%$ & $12,28 \%$ & $11,27 \%$ & $8,52 \%$ & $14,96 \%$ & $13,71 \%$ \\
SE & $3,03 \%$ & $2,64 \%$ & $2,22 \%$ & $1,71 \%$ & $1,43 \%$ & $1,20 \%$ & $0,91 \%$ & $1,88 \%$ \\
BA & $8,88 \%$ & $5,16 \%$ & $6,64 \%$ & $6,19 \%$ & $6,85 \%$ & $4,76 \%$ & $3,98 \%$ & $6,06 \%$ \\
MG & $10,34 \%$ & $10,45 \%$ & $9,66 \%$ & $9,89 \%$ & $9,74 \%$ & $6,38 \%$ & $7,33 \%$ & $9,11 \%$ \\
\hline \hline
\end{tabular}




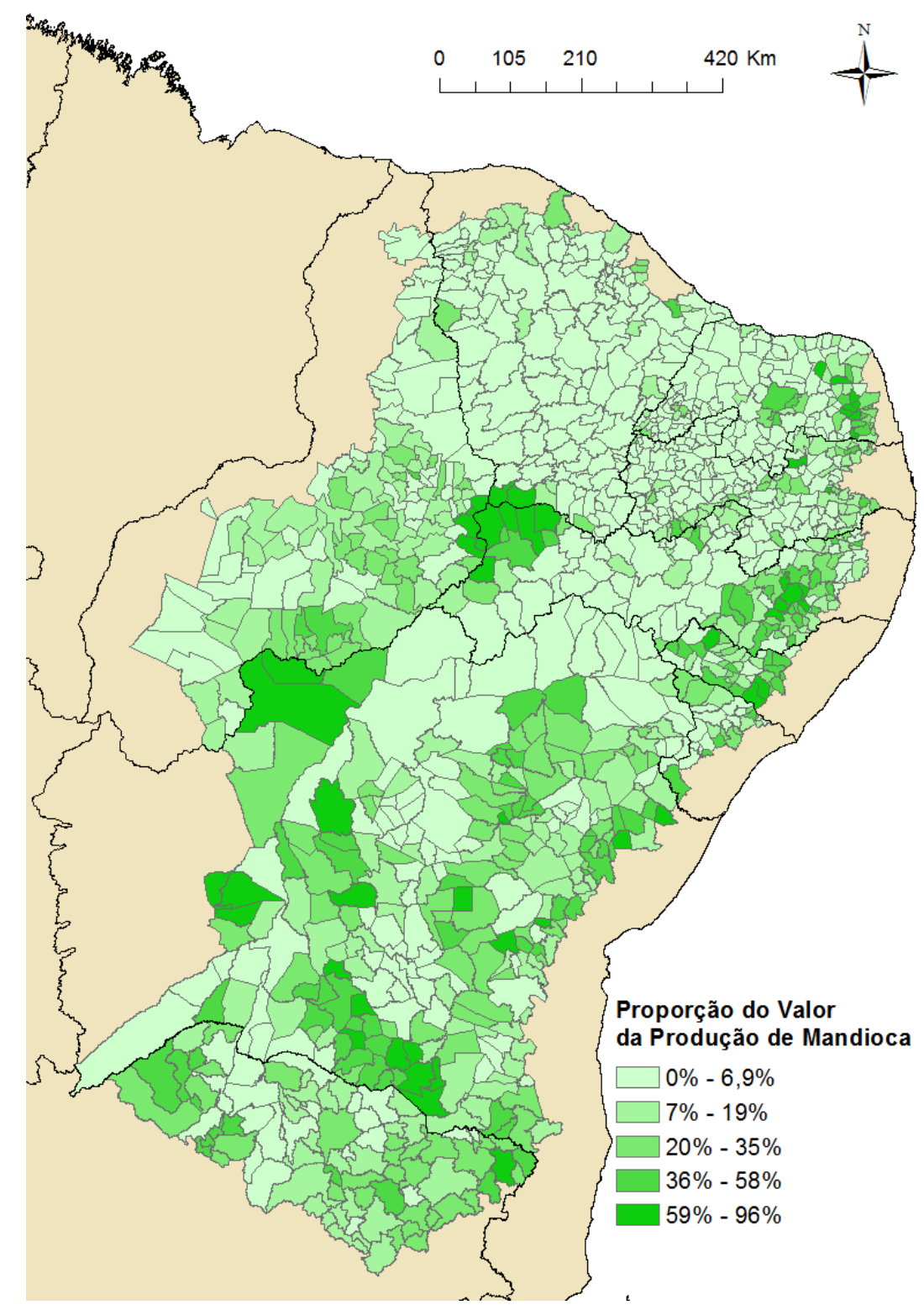

Figura 7 - Proporção da Produção da Mandioca no Total Produzido pelo Setor Agrícola dos Municípios (média 2012-2018)

\subsection{Dados climáticos}

Os dados climáticos foram disponibilizados pelo Centro Nacional de Monitoramento e Alertas de Desastres Naturais (CEMADEN). Alvalá et al. (2017) argumenta que apesar do método de monitoramento tradicional de secas ser por dados de precipitação, a baixa densidade por área de estações meteorológicas no Semiárido inviabiliza o uso deste método. Desta forma, o 
CEMADEN elabora mensalmente para todos os municípios da SUDENE, tendo início em 2012, o Índice Integrado de Seca (IIS), como descrito em Alvalá et al. (2017).

\subsubsection{VHI}

Disponibilizado pelo CEMADEN, o Vegetation Health Index (VHI) é definido da seguinte maneira (Karnieli et al, 2006, p. 1):

The Vegetation Health index (VHI) is based on a combination of products extracted from vegetation signals, namely the Normalized Difference Vegetation Index (NDVI) and from the brightness temperatures, both derived from the NOAA Advanced Very High Resolution Radiometer (AVHRR) sensor. VH users rely on a strong inverse correlation between NDVI and land surface temperature, since increasing land temperatures are assumed to act negatively on vegetation vigour and consequently to cause stress.

O índice compreende valores de 0 a 100, e valores mais altos estão associados a melhor saúde da vegetação. Um evento de seca é verificado quando o índice registra valores inferiores a 40 por dois meses consecutivos, sendo que o término deste evento é indicado quando o índice retorna a valores superiores a 45 (CEMADEN, 2020). Um índice maior que 30 e abaixo de 40 indica uma seca fraca, maior do que 20 e abaixo de 30 uma seca moderada, maior que 12 e abaixo de 20 uma seca severa e abaixo ou igual a 6, uma seca excepcional.

Estes dados foram coletados para os mesmos municípios, para os anos de 2001 a 2018. Diferentemente do IIS, a temporalidade do índice VHI disponível é anual. A Tabela 13 apresenta a média do índice VHI para cada estado no período de 2012 a 2018. De acordo com o critério de seca acima definido, todos os estados, na média, enfrentam secas, com exceção do Alagoas, que também apresenta média bem próxima a 40.

Tabela 13 - Sumário do índice VHI por estado entre 2012 e 2018

\begin{tabular}{cccc}
\hline Estado & Média & Min & Max \\
\hline PI & 28,21 & 10,38 & 53,23 \\
CE & 38,97 & 9,43 & 67,04 \\
RN & 39,85 & 14,74 & 70,66 \\
PB & 39,65 & 10,55 & 66,39 \\
PE & 38,59 & 8,50 & 67,40 \\
AL & 40,46 & 16,87 & 64,19 \\
SE & 37,89 & 22,56 & 57,42 \\
BA & 32,60 & 6,39 & 65,25 \\
MG & 35,07 & 10,82 & 58,94 \\
\hline
\end{tabular}




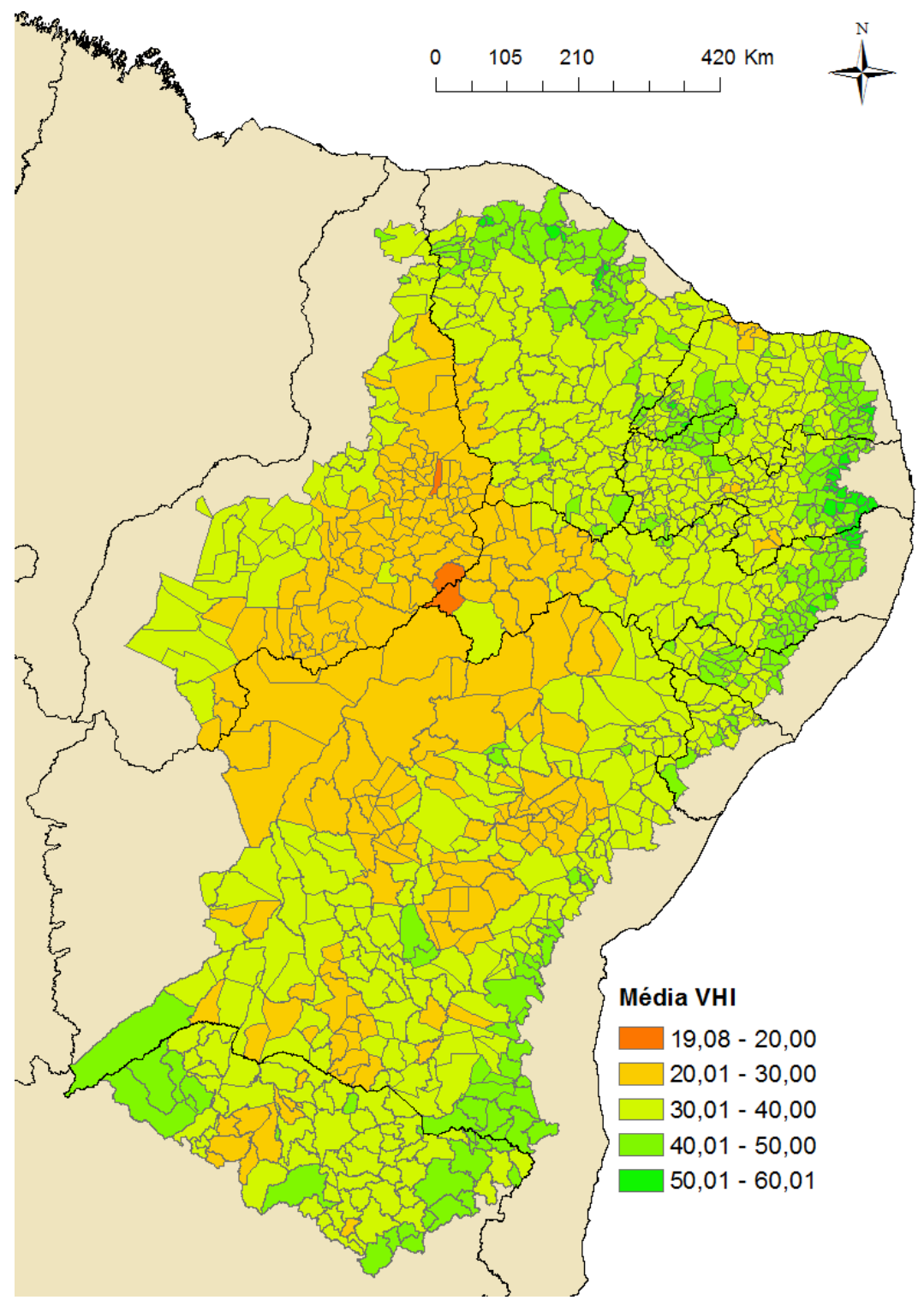

Figura 8 - Média do índice VHI entre 2012 e 2018

\subsubsection{IIS}

De acordo com CEMADEN (2020):

O Índice Integrado de Seca (IIS) consiste na combinação do Índice de Precipitação Padronizada (SPI) com o Índice de Suprimento de Água para a Vegetação (VSWI) ou com o Índice de Saúde da Vegetação (VHI), ambos estimados por sensoriamento remoto. Para integrar o IIS, o SPI é calculado a partir de dados observacionais de precipitação disponíveis no CEMADEN, no Instituto Nacional de Meteorologia (INMET), no Instituto Nacional de 
Pesquisas Espaciais (INPE) e Centros Estaduais de Meteorologia. O cálculo do SPI é baseado na formulação proposta por Mckee et al. (1993), considerando as escalas de 3, 6 e 12 meses, obtendo-se o produto final na resolução espacial de $5 \mathrm{~km}$.

O IIS pode assumir as seguintes categorias: condição normal (6), seca fraca (5), seca moderada (4), seca severa (3), seca extrema (2) e seca excepcional (1). Ou seja, valores mais baixos correspondem a secas mais intensas. Os dados mensais foram coletados para o período de 2012 a 2018 em nível municipal. A área de estudo é composta por 1134 municípios, de acordo com a delimitação do Semiárido antes de setembro de 2017. A Tabela 14 expõe a correspondência entre os índices VHI e IIS.

Tabela 14- Classificação de secas pelos índices VHI e IIS

\begin{tabular}{ccc}
\hline VHI & IIS & Classificação da Seca \\
\hline$>40$ & 6 & Normal \\
30 a 40 & 5 & Seca fraca \\
20 a 30 & 4 & Seca moderada \\
12 a 20 & 3 & Seca severa \\
6 a 12 & 2 & Seca extrema \\
$<6$ & 1 & Seca excepcional \\
\hline
\end{tabular}

A Tabela 15 apresenta a média estadual do índice para cada mês para os municípios do Semiárido, entre os anos de 2012 a $2018^{1}$. Pode-se observar que há considerável uniformidade da média do índice por estado e mês, com valores próximos a 4 e 5, ou seja, na média, a região é acometida por secas fracas a moderadas a cada mês.

Tabela 15 - Média mensal do IIS para o Semiárido de cada estado entre 2012 e 2018

\begin{tabular}{ccccccccccccc}
\hline Estado/Mês & Jan & Fev & Mar & Abr & Mai & Jun & Jul & Ago & Set & Out & Nov & Dez \\
\hline PI & 4,80 & 4,88 & 4,92 & 4,79 & 4,61 & 4,55 & 4,63 & 5,13 & 5,02 & 5,04 & 5,03 & 4,75 \\
CE & 5,22 & 5,00 & 5,19 & 5,02 & 4,81 & 4,57 & 4,57 & 4,82 & 5,14 & 5,24 & 5,32 & 5,16 \\
RN & 5,20 & 4,85 & 4,92 & 4,67 & 4,57 & 4,45 & 4,69 & 4,97 & 5,18 & 5,19 & 5,29 & 5,28 \\
PB & 5,05 & 4,64 & 4,54 & 4,51 & 4,46 & 4,34 & 4,45 & 4,75 & 5,07 & 4,99 & 5,07 & 5,06 \\
PE & 5,10 & 4,51 & 4,28 & 4,33 & 4,54 & 4,84 & 4,77 & 4,82 & 5,08 & 4,95 & 4,96 & 4,99 \\
AL & 5,40 & 4,80 & 4,37 & 4,50 & 4,60 & 4,94 & 4,91 & 4,78 & 4,81 & 4,73 & 4,79 & 5,06 \\
SE & 5,41 & 4,96 & 4,50 & 4,16 & 4,00 & 4,40 & 4,59 & 4,37 & 4,57 & 4,78 & 4,83 & 5,07 \\
BA & 5,06 & 4,96 & 4,45 & 4,43 & 4,60 & 4,99 & 5,33 & 5,50 & 5,45 & 5,23 & 5,16 & 4,93 \\
MG & 5,17 & 5,33 & 4,83 & 4,53 & 4,66 & 5,08 & 5,52 & 5,72 & 5,10 & 4,86 & 4,91 & 5,15 \\
\hline
\end{tabular}

\footnotetext{
${ }^{1}$ No Apêndice A, há mapas municipais para a média mensal do índice.
} 


\subsubsection{Cenários}

Os choques que aplicaremos no modelo de equilíbrio geral neste trabalho são baseados nos índices de seca derivados de cenários base. O primeiro cenário que tomaremos como referência será o ano de 2012, que na série histórica do índice IIS (2012 a 2018) foi aquele que apresentou as piores secas. As tabelas 16 e 17 apresentam a média por estado e mês dos índices IIS e VHI para 2012, respectivamente. Pode-se observar a forte incidência da seca nos meses de abril, maio e junho daquele ano, com médias de seca extrema a excepcional. Neste ano, todos estados registraram média anual do índice VHI inferiores a 40, valor referência para o desenvolvimento saudável da vegetação.

Tabela 16 - Média do IIS por mês e Semiárido de cada estado em 2012

\begin{tabular}{ccccccccccccc}
\hline Estado/Mês & Jan & Fev & Mar & Abr & Mai & Jun & Jul & Ago & Set & Out & Nov & Dez \\
\hline PI & 4,41 & 3,98 & 3,71 & 2,78 & 2,35 & 2,35 & 4,02 & 5,25 & 5,05 & 4,44 & 5,02 & 4,75 \\
CE & 5,54 & 5,25 & 5,39 & 3,97 & 2,36 & 2,03 & 2,74 & 4,03 & 4,63 & 4,83 & 5,18 & 4,40 \\
RN & 5,56 & 5,54 & 5,05 & 2,42 & 1,21 & 1,61 & 3,14 & 4,20 & 4,78 & 4,71 & 5,01 & 4,55 \\
PB & 5,45 & 4,86 & 4,18 & 2,28 & 1,37 & 2,11 & 3,46 & 4,57 & 4,76 & 4,61 & 4,66 & 3,92 \\
PE & 5,42 & 4,48 & 3,78 & 2,27 & 1,92 & 2,59 & 3,85 & 4,84 & 4,76 & 4,80 & 4,70 & 4,10 \\
AL & 5,97 & 4,82 & 4,87 & 3,53 & 2,16 & 2,29 & 3,82 & 5,66 & 4,82 & 5,58 & 4,76 & 4,21 \\
SE & 6,00 & 4,69 & 4,69 & 2,52 & 1,14 & 1,28 & 2,62 & 4,31 & 4,24 & 5,69 & 5,31 & 4,34 \\
BA & 5,40 & 4,36 & 2,48 & 1,82 & 1,82 & 2,80 & 4,18 & 5,15 & 5,04 & 4,58 & 5,44 & 4,71 \\
MG & 5,89 & 5,40 & 3,48 & 2,53 & 3,40 & 4,68 & 5,52 & 5,69 & 5,27 & 4,32 & 5,61 & 5,54 \\
\hline
\end{tabular}

Tabela 17 - Sumário VHI por estado em 2012

\begin{tabular}{cccc}
\hline Estado & Média & Min & Max \\
\hline PI & 25,73 & 12,38 & 46,93 \\
CE & 37,67 & 23,31 & 64,37 \\
RN & 33,30 & 17,00 & 52,21 \\
PB & 35,30 & 16,03 & 54,99 \\
PE & 31,33 & 17,05 & 47,01 \\
AL & 37,22 & 26,07 & 45,34 \\
SE & 35,01 & 26,52 & 44,90 \\
BA & 25,74 & 9,66 & 47,59 \\
MG & 35,68 & 23,37 & 50,40 \\
\hline
\end{tabular}




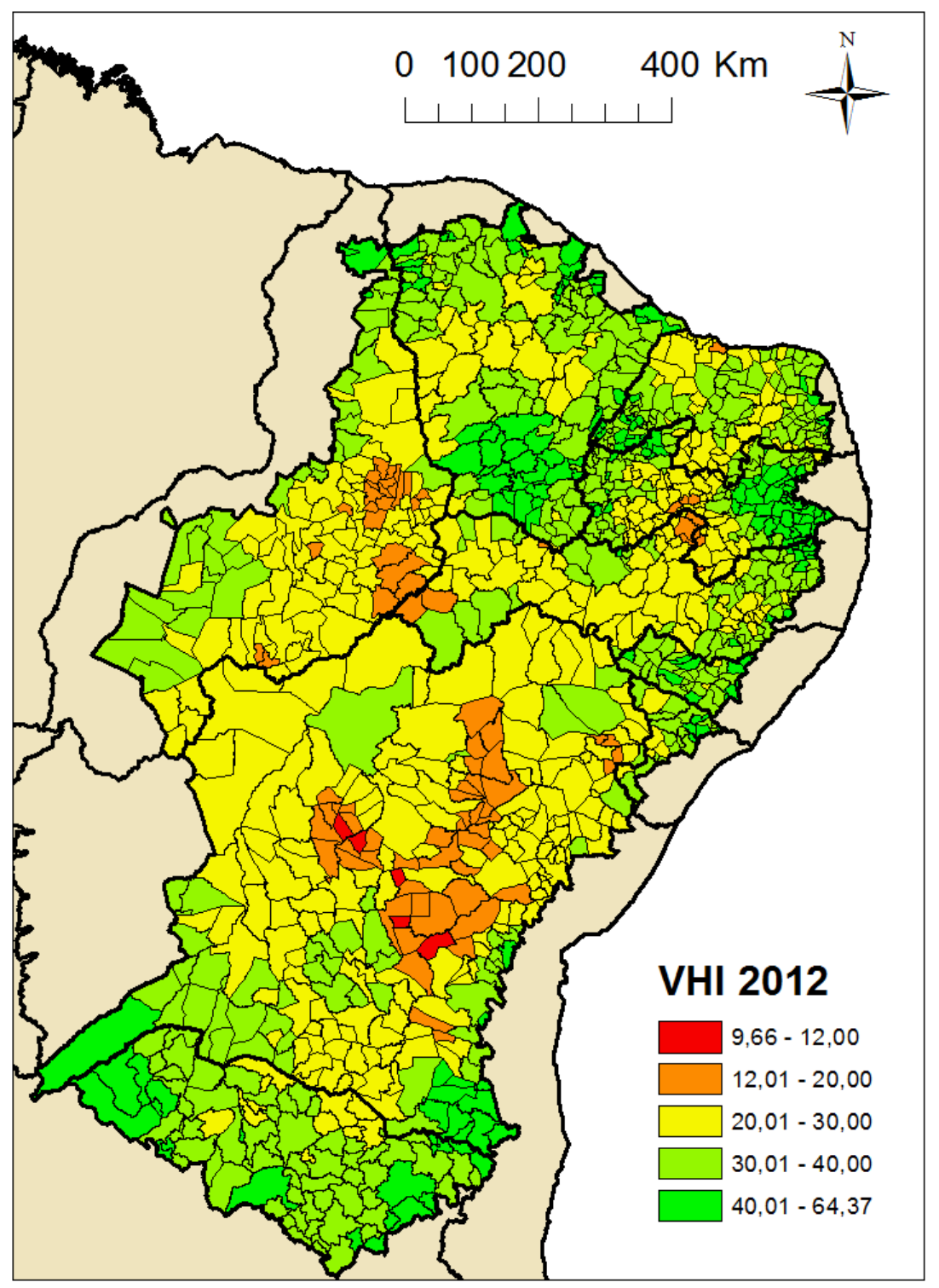

Figura 9 - Índice VHI para 2012

Para cenários futuros, utilizaremos projeções do índice VHI elaboradas pelo CEMADEN para os anos de 2040, 2070 e 2100, de acordo com Marengo et al. (2019). Estes cenários foram elaborados seguindo o RCP 8.5 (Representative Concentration Pathways, Moss et al., 2010), a projeção que considera a maior emissão de gases estufa ao longo do século. Considerando tal nível de emissões, modelos físicos são utilizados para prever o aumento da temperatura em cada regiãol. Há projeções elaboradas para o VHI para todos os estados, com exceção de Minas Gerais. Infelizmente, não há projeções futuras para o IIS. As tabelas 18, 19 e 20 apresentam dados de média, mínimo e máximo do índice VHI para os anos de 2040, 2070 e 2100, respectivamente. 
Nota-se uma deterioração das condições climáticas no decorrer do século. Já em 2040, é esperado que todos os estados tenham média inferior a 40, e, a exceção do Piauí, devem apresentar municípios com eventos de secas extremas, representado pelo valor mínimo inferior a 12. Em 2070, é esperado que ocorra secas excepcionais (valor mínimo inferior a 6) em todas as regiões. Ainda, observa-se uma melhor projeção para os municípios nos limites do Semiárido, observado pelas Figuras 11 e 12. Estes municípios contribuirão para compensar a perda de produção esperada dos demais.

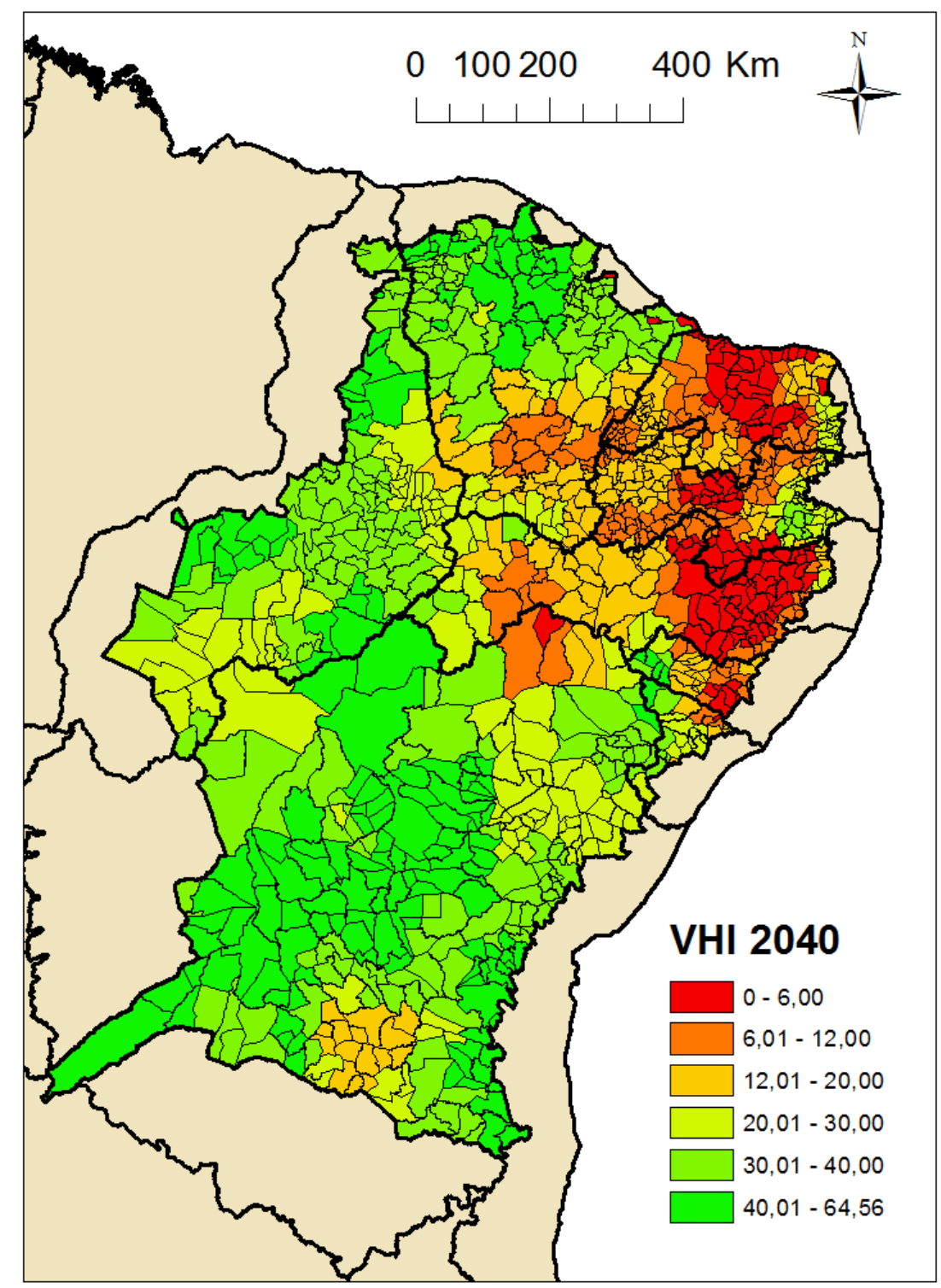

Figura 10 - Projeção do Índice VHI para 2040 
Tabela 18 - Projeção do índice VHI por estado para 2040

\begin{tabular}{cccc}
\hline Estado & Média & Min & Max \\
\hline PI & 33,92 & 19,53 & 55,79 \\
CE & 28,64 & 7,34 & 49,75 \\
RN & 11,76 & 1,10 & 30,30 \\
PB & 13,87 & 0,00 & 37,46 \\
PE & 10,11 & 0,00 & 33,65 \\
AL & 16,04 & 0,56 & 43,44 \\
SE & 22,36 & 0,63 & 42,91 \\
BA & 35,82 & 4,21 & 56,64 \\
\hline
\end{tabular}

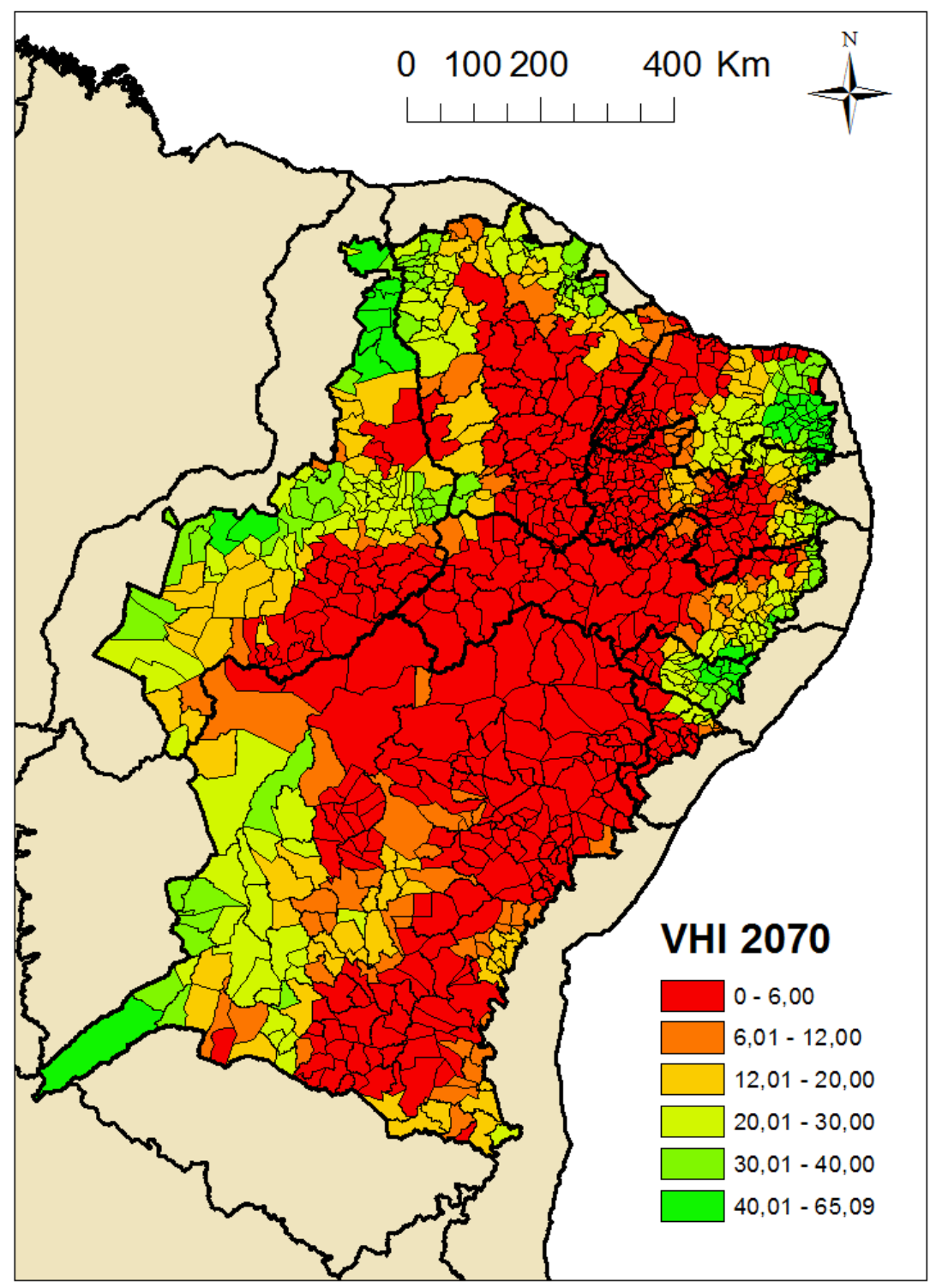

Figura 11 - Projeção do índice VHI para 2070 
Tabela 19 - Projeção do índice VHI por estado para 2070

\begin{tabular}{cccc}
\hline Estado & Média & Min & Max \\
\hline PI & 20,26 & 0 & 64,18 \\
CE & 13,43 & 0 & 38,11 \\
RN & 19,62 & 0 & 51,03 \\
PB & 8,70 & 0 & 47,14 \\
PE & 10,53 & 0 & 39,47 \\
AL & 27,30 & 0 & 57,56 \\
SE & 4,77 & 0 & 29,50 \\
BA & 6,61 & 0 & 55,20 \\
\hline
\end{tabular}

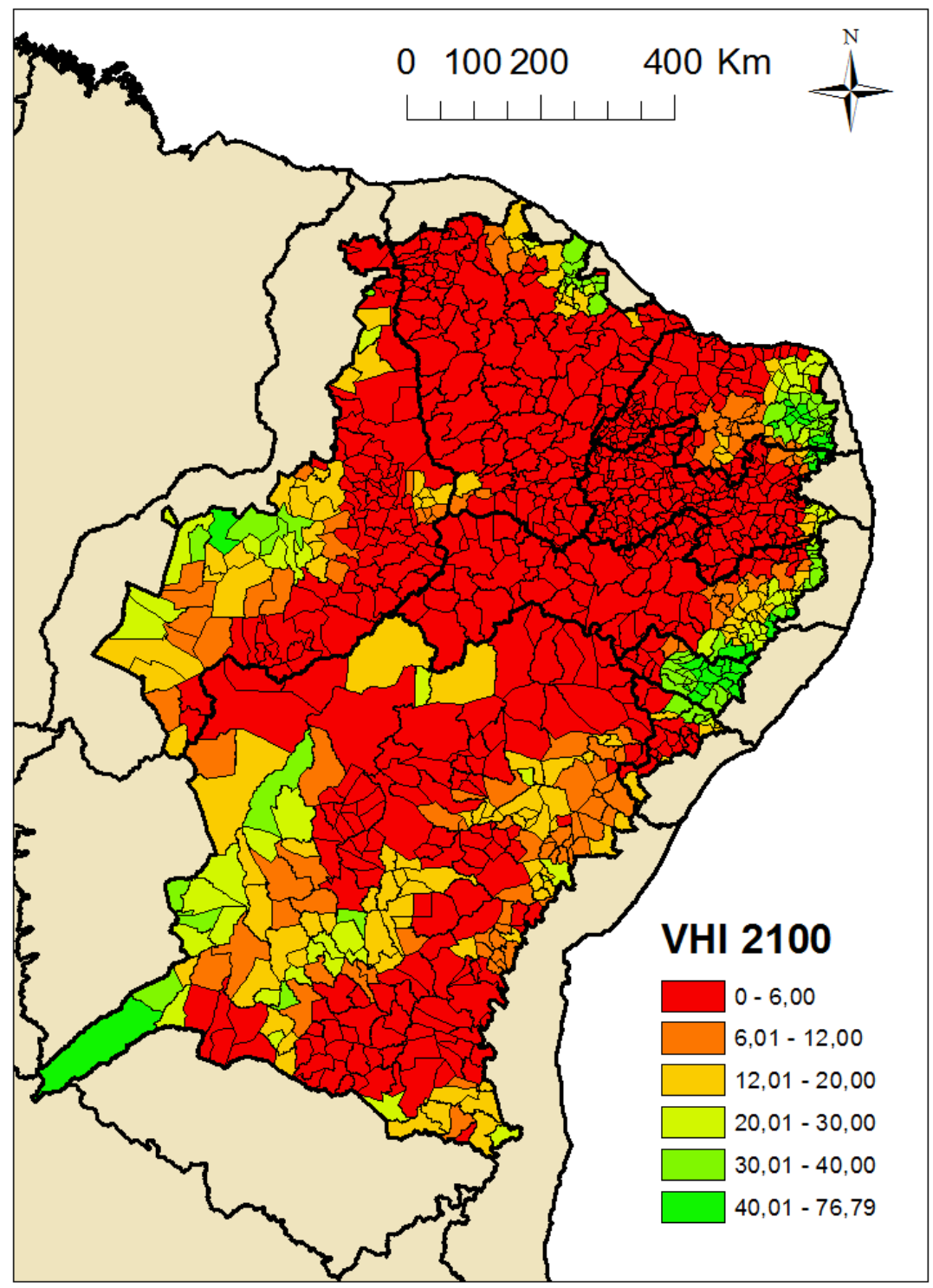

Figura 12 - Projeção do índice VHI para 2100 
Tabela 20 - Projeção do índice VHI por estado para 2100

\begin{tabular}{cccc}
\hline Estado & Média & Min & Max \\
\hline PI & 7,72 & 0,00 & 56,02 \\
CE & 4,12 & 0,00 & 33,46 \\
RN & 12,92 & 0,00 & 48,85 \\
PB & 3,06 & 0,00 & 42,90 \\
PE & 9,75 & 0,00 & 48,49 \\
AL & 36,34 & 0,00 & 76,79 \\
SE & 10,71 & 0,00 & 40,60 \\
BA & 8,32 & 0,00 & 62,82 \\
\hline
\end{tabular}

\subsection{Matriz de Insumo-Produto}

Como ponto de partida para a calibragem do modelo de equilíbrio geral, será utilizada uma matriz de insumo-produto tendo como unidade espacial os municípios, para o ano de 2015, desenvolvido pelo Núcleo de Economia Regional e Urbana (NEREUS) da Faculdade de Economia e Administração da Universidade de São Paulo. A construção de tal base de dados segue o método IIOAS, como descrito em Haddad, Júnior e Nascimento (2017), em que variáveis agregadas em nível nacional e estadual foram desagregadas para o nível municipal. Para tal são utilizadas várias bases de dados, provenientes sobretudo do IBGE.

O modelo consistirá em sub-regiões do Semiárido, em que cada região será dada pela agregação estadual dos municípios pertencentes ao Semiárido. Estas regiões serão o foco da análise deste trabalho, mas também são incluídas as agregações dos municípios não pertencentes ao Semiárido de cada estado, mais o estado do Maranhão (pertencente à região Nordeste), e o resto do Brasil. Ainda, as regiões da Bahia que não pertencem ao Semiárido foram divididas entre Leste e Oeste. A Tabela 21 demonstra as regiões do modelo e a quantidade de municípios em cada uma, e a Figura 13 ilustra as regiões levando em consideração sua população estimada em 2015.

Para se chegar à matriz de insumo-produto ao nível regional deste trabalho, os resultados de cada região foram obtidos da agregação dos dados municipais previamente obtidos da base desenvolvida pelo NEREUS. Por fim, cada região será composta por 11 setores que produzem, consomem e trocam entre si 11 produtos. Na Tabela 22 estão expostos os setores do modelo. 
Tabela 21 - Número de municípios contidos nas regiões do modelo

\begin{tabular}{lc}
\hline Região & Municípios \\
\hline Maranhão & 217 \\
Semiárido do Piauí & 127 \\
Resto do Piauí & 97 \\
Semiárido do Ceará & 150 \\
Resto do Ceará & 34 \\
Semiárido do Rio Grande do Norte & 147 \\
Resto do rio Grande do Norte & 20 \\
Semiárido da Paraíba & 170 \\
Resto da Paraíba & 53 \\
Semiárido de Pernambuco & 122 \\
Resto de Pernambuco & 63 \\
Semiárido do Alagoas & 38 \\
Resto do Alagoas & 64 \\
Semiárido do Sergipe & 29 \\
Resto do Sergipe & 46 \\
Semiárido da Bahia & 266 \\
Leste da Bahia & 134 \\
Oeste da Bahia & 17 \\
Semiárido de Minas Gerais & 85 \\
Resto de Minas Gerais & 768 \\
Resto do Brasil & 2916 \\
\hline
\end{tabular}

Tabela 22 - Setores do modelo

\begin{tabular}{ll}
\hline S01 & Agricultura \\
S02 & Pecuária e pesca \\
S03 & Extração mineral \\
S04 & Indústria de alimentos \\
S05 & Outras indústrias \\
S06 & Energia e água \\
S07 & Construção \\
S08 & Comércio \\
S09 & Transporte e armazenamento \\
S10 & Serviços \\
S11 & Administração pública \\
\hline
\end{tabular}


A Figura 14 ilustra a participação de cada região na composição do PIB Brasileiro em 2015. Mesmo dentro da região do Semiárido, há considerável heterogeneidade regional. Apenas o semiárido da Bahia apresenta produção superior a $1 \%$ do total nacional, seguido pelo Semiárido de Pernambuco e Ceará, que apresentam produção superior a $0,5 \%$ do total nacional. Fora do Semiárido, a região com maior produção é o resto de Minas Gerais, responsável por 8,47\% do PIB nacional em 2015, seguido pelo leste da Bahia, resto de Pernambuco e Ceará e o Maranhão. Ainda, o resto do Brasil foi responsável por pouco mais de três quartos da produção naquele ano.

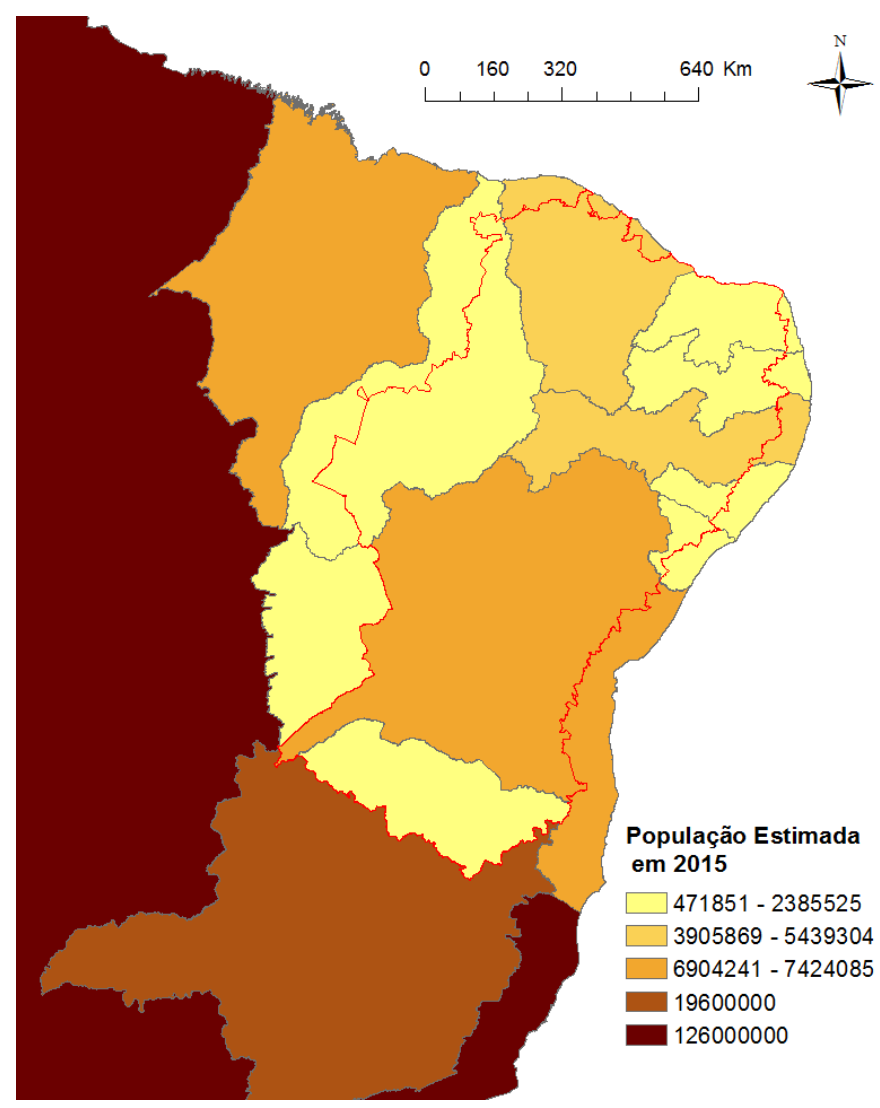

Figura 13 - População estimada em 2015 de cada região

Já a Figura 15 representa a participação de cada região no PIB nacional em 2015 levando em consideração apenas o setor agrícola. Dentro do Semiárido, Bahia, Ceará e Pernambuco detiveram as maiores participações naquele ano, com produção superior a $1 \%$ do total da agricultura nacional. Para os dois últimos estados, sua região no Semiárido inclusive deteve maior participação que a região fora dele. O resto do Brasil foi responsável por $71,81 \%$ da produção agrícola naquele ano. 


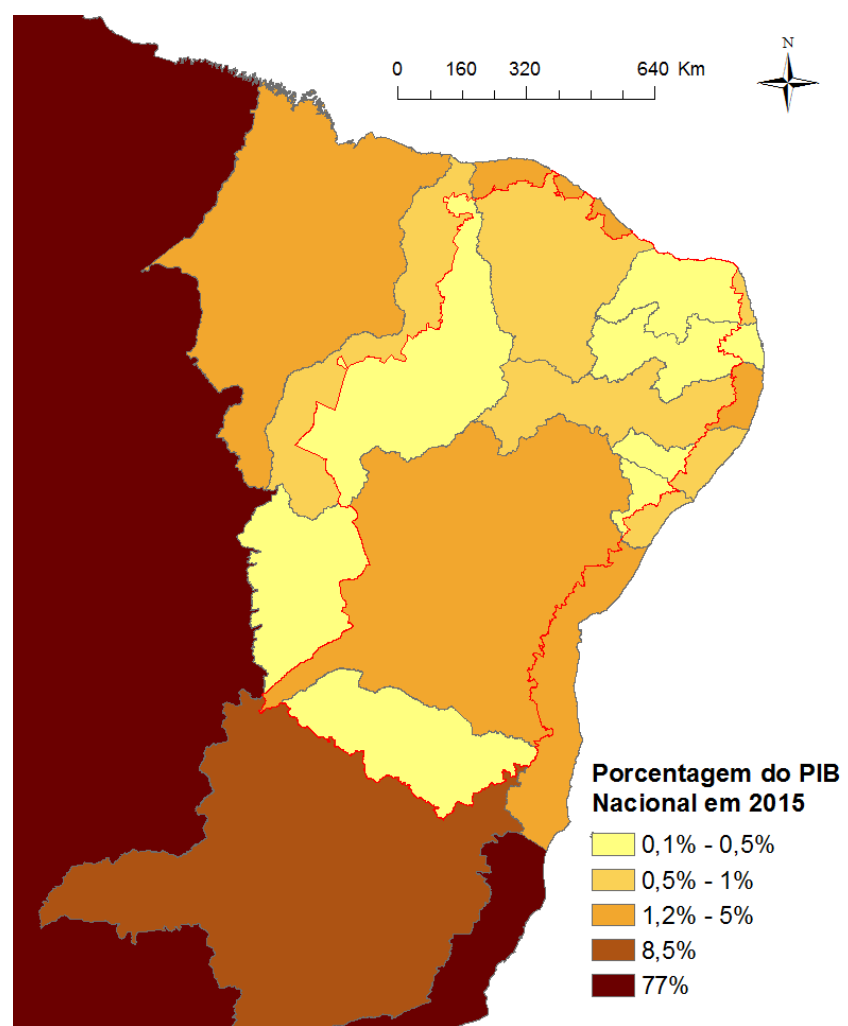

Figura 14 - Participação de cada região na composição do PIB em 2015

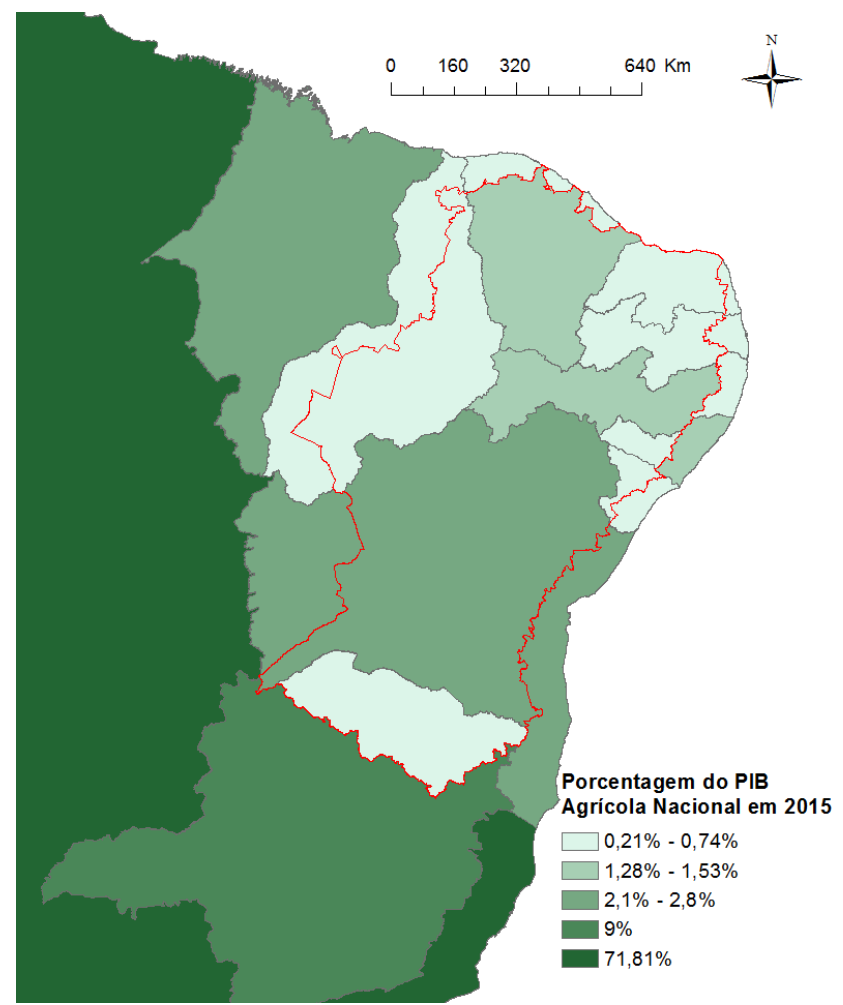

Figura 15 - Participação de cada região na composição do PIB Agrícola em 2015 
A Figura 16 expõe a participação do setor agrícola na composição do PIB de cada região em 2015. No Semiárido, as regiões com maior participação relativa do setor agrícola são Piauí, Alagoas, Sergipe e Bahia, com participação próxima a 10\% do PIB. Contudo, é importante ressaltar a importância da agricultura de subsistência e do grande setor informal no Semiárido, de forma que muito do que é produzido pela agricultura não entra no cálculo das contas regionais.

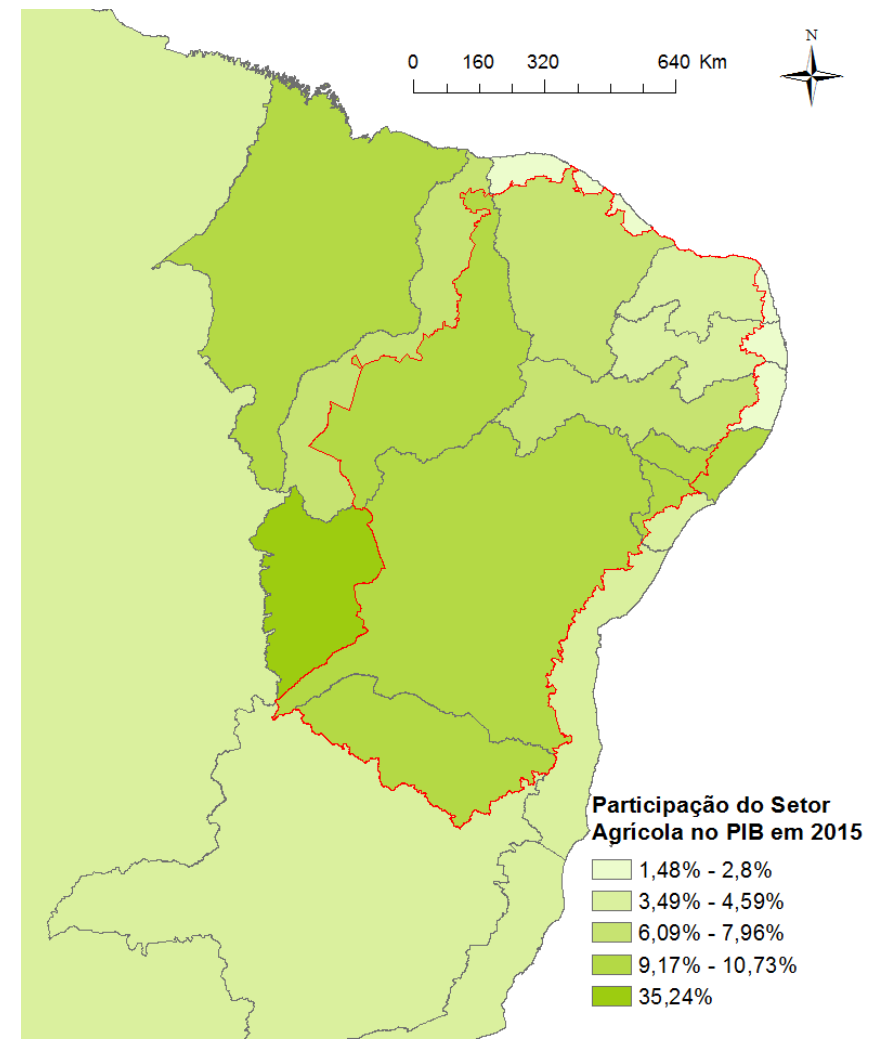

Figura 16 - Participação do Setor Agrícola no PIB regional em 2015

Por fim, a importância das transferências governamentais é uma característica marcante da economia da região. Isto é ilustrado pela Figura 17, que representa a participação do item “administração, defesa, educação e saúde públicas e seguridade social” na composição do valor adicionado regional em 2015, de acordo com a pesquisa de Produto Interno Bruto dos Municípios, elaborada pelo IBGE. Todas as regiões do Semiárido apresentaram dependência do governo superior a $28 \%$ de seu produto naquele ano, em que as regiões mais dependentes foram o Semiárido da Paraíba, Minas Gerais e do Piauí, este último com uma participação do governo de 43,13\%. Em comparação, o resto do Brasil teve uma participação governamental para este ano de $13,4 \%$. 


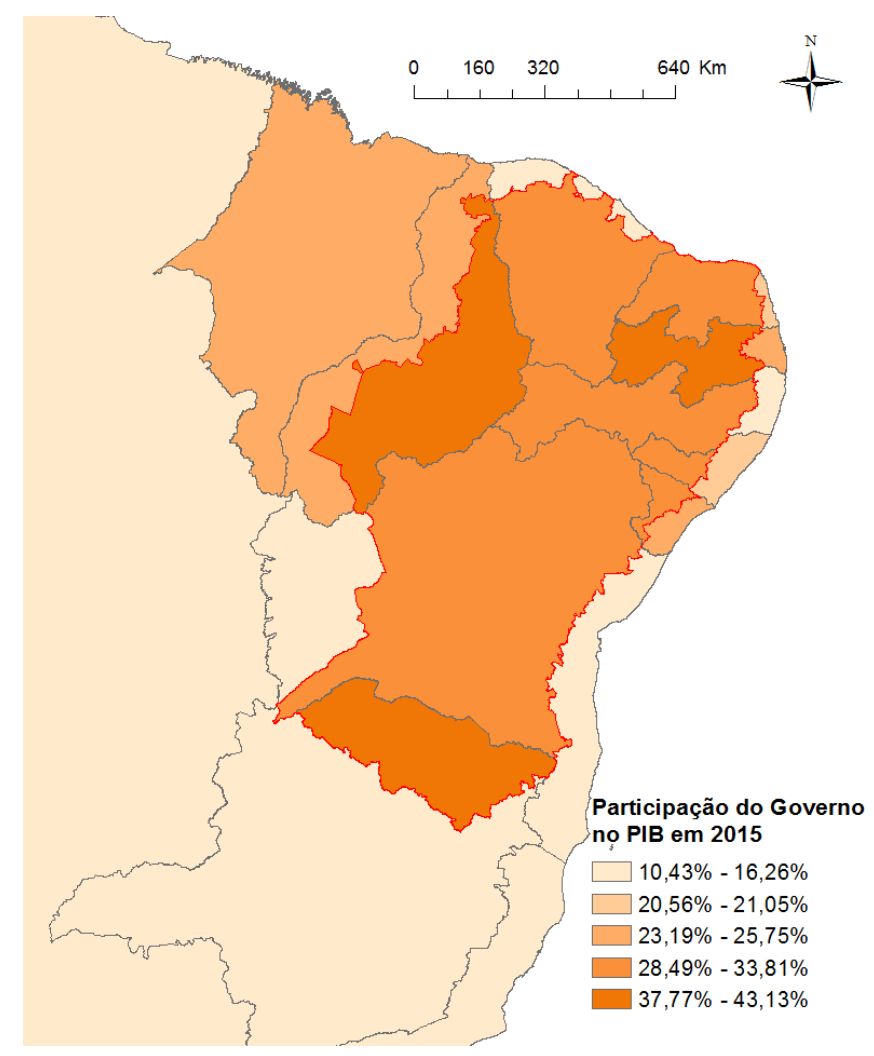

Figura 17 - Participação do Governo no PIB regional em 2015

Para explorar as relações de trocas inter-regionais, exploramos o arcabouço teórico do modelo de insumo-produto. O modelo, explicado em detalhes em Miller e Blair (2009), será aqui apresentado brevemente. Para ilustrar os conceitos básicos do modelo de insumo-produto, considere duas regiões $\mathrm{L}$ e M, cada uma com dois setores produtivos, $i$ e $j$. Desta forma, os fluxos entre os setores e regiões podem ser representados pela seguinte matriz:

$$
\mathrm{Z}=\left[\begin{array}{ll}
Z^{L L} & Z^{L M} \\
Z^{M L} & Z^{M M}
\end{array}\right]
$$

Onde:

$Z_{i j}^{L L}-$ Vendas do setor $i$ da região $L$ para o setor $j$ da região $L$;

$Z_{i j}^{M L}-$ Vendas do setor $i$ da região M para o setor $j$ da região L. 
A produção total do setor $i$ na região $\mathrm{L}, X_{i}^{L}$, é então representada dentro do modelo de insumo-produto pela seguinte equação:

$$
X_{i}^{L}=z_{i i}^{L L}+z_{i j}^{L L}+z_{i i}^{L M}+z_{i j}^{L M}+Y_{i}^{L}
$$

Em que $Y_{i}^{L}$ é a demanda final pelo bem do setor $i$ da região L. No arcabouço de insumoproduto, esta demanda final representa a demanda do governo, das famílias, do setor de investimento e setores exportadores pelo bem do setor $i$ da região L. Esta demanda também agrega as demandas provenientes de todas as regiões, de forma que, no nosso exemplo, pode ser escrita como:

$$
Y_{i}^{L}=Y_{i}^{L L}+Y_{i}^{L M}
$$

Para aplicações práticas, devemos definir a matriz de coeficientes técnicos de produção, dada por:

$$
A=Z(X)^{-1}
$$

Onde:

$$
a_{i j}^{L L}=\frac{z_{i j}^{L L}}{X_{j}^{L}} \text { e } a_{i j}^{L M}=\frac{z_{i j}^{L M}}{X_{j}^{M}}
$$

Ou seja, $a_{i j}^{L L}$, representa quanto é necessário do bem do setor $i$ da região L para a produção de uma unidade adicional do bem do setor $j$ da região L. Este coeficiente é obtido dividindo os valores de cada coluna da matriz $\mathrm{Z}$ pela produção total de cada setor.

Assim, podemos escrever:

$(I-A) X=Y$

E

$X=(I-A)^{-1} Y=L Y$ 
Em que L é denominada a inversa de Leontief. De um modo mais geral, um modelo de insumo-produto inter-regional pode ser representado como:

$$
X=\left(\begin{array}{c}
X^{1} \\
\cdots \\
X^{r}
\end{array}\right) ; Y=\left(\begin{array}{c}
Y^{1} \\
\cdots \\
Y^{r}
\end{array}\right) ; A=\left(\begin{array}{ccc}
A^{11} & \cdots & A^{1 r} \\
\vdots & \ddots & \vdots \\
A^{r 1} & \cdots & A^{r r}
\end{array}\right) ; L=\left(\begin{array}{ccc}
L^{11} & \cdots & L^{1 r} \\
\vdots & \ddots & \vdots \\
L^{r 1} & \cdots & L^{r r}
\end{array}\right)
$$

Uma forma alternativa de representar uma economia em um modelo de insumo-produto se dá pela construção da inversa de Ghosh, ao invés da inversa de Leontief. Neste caso, a matriz Z é dividida pelo produto final em cada linha, em vez de cada coluna, e a matriz resultante é denominada matriz de alocação. Esta forma pode ser representada como:

$$
X=V^{\prime}(I-B)^{-1}
$$

Onde V é um vetor de gastos em valor adicionado (ou seja, soma de pagamentos ao trabalho, capital e impostos) e B é a matriz de alocação.

Com estes conceitos em mãos, podemos aplicar o método da extração hipotética, a fim de mensurar a integração de cada região do Semiárido com as demais. Para se medir a integração para trás de uma região $i$, isto é, conhecer as principais regiões responsáveis pelo fornecimento de bens à região $i$, substituímos as colunas referentes à região $i$ na matriz A por zero e calculamos, a partir da demanda final, a nova produção de cada região $j$. Esta produção é então comparada ao caso base, com todas as regiões presentes, de modo a calcular o efeito líquido da extração da região $i$ sobre as demais. Ao normalizar este resultado pela produção inicial da região $i$, temos uma medida da dependência para trás da região $i$ em relação a cada região $j$. O mesmo pode ser feito para medir a dependência para frente da região $i$, ou seja, conhecer quais regiões representam os principais destinos para os produtos da região $i$. Contudo, neste caso, é utilizada a representação de Ghosh, em que as linhas que representam a região $i$ na matriz B são substituídas por zero.

Os resultados deste exercício em relação aos efeitos para trás estão apresentados na Tabela 23, que expõe a importância relativa para cada região do Semiárido, no contexto das regiões representadas no modelo. Nota-se que, individualmente, o maior grau de dependência para todas as regiões do Semiárido se dá em relação ao resto do Brasil, que engloba importantes centros produtores, como o estado de São Paulo. Para o semiárido do Piauí e Minas Gerais, esta 
importância é superior a 50\%, ou seja, há uma integração maior com estados fora do Semiárido e do Nordeste do que com a própria região. Para as demais regiões, apesar do comércio com o resto do país ser menos importante, a representatividade de cada estado dentro do Nordeste ou Semiárido é pulverizada. Depois do resto do Brasil, o mais importante fornecedor de produtos para cada região é ela própria. Nota-se ainda uma importância relativa do resto de Pernambuco e Minas Gerais e Leste da Bahia para a economia regional.

Tabela 23 - Efeitos para trás (em relação ao total)

\begin{tabular}{lrrrrrrrrr}
\hline \multirow{2}{*}{ Região afetada } & \multicolumn{10}{c}{ Região extraída } \\
\cline { 2 - 10 } & SA PI & SA CE & SA RN & SA PB & SA PE & SA AL & SA SE & SA BA & SA MG \\
\hline MA & 2.04 & 1.51 & 1.28 & 1.15 & 1.19 & 0.95 & 0.86 & 0.92 & 0.76 \\
SA PI & 17.60 & 0.16 & 0.13 & 0.13 & 0.17 & 0.10 & 0.10 & 0.11 & 0.07 \\
Resto PI & 1.15 & 0.68 & 0.43 & 0.44 & 0.47 & 0.36 & 0.34 & 0.33 & 0.23 \\
SA CE & 1.13 & 25.51 & 1.58 & 1.40 & 1.09 & 0.69 & 0.68 & 0.65 & 0.37 \\
Resto CE & 2.71 & 8.52 & 3.61 & 2.74 & 2.02 & 1.58 & 1.43 & 1.16 & 0.81 \\
SA RN & 0.74 & 1.39 & 26.31 & 1.53 & 0.88 & 0.66 & 0.65 & 0.47 & 0.33 \\
Resto RN & 0.47 & 0.71 & 2.69 & 1.14 & 0.70 & 0.55 & 0.48 & 0.30 & 0.20 \\
SA PB & 0.39 & 0.59 & 0.81 & 25.29 & 0.83 & 0.52 & 0.44 & 0.31 & 0.20 \\
Resto PB & 0.43 & 0.67 & 1.25 & 1.70 & 1.02 & 0.68 & 0.55 & 0.36 & 0.24 \\
SA PE & 0.88 & 0.86 & 0.85 & 1.36 & 23.84 & 1.37 & 1.03 & 0.82 & 0.35 \\
Resto PE & 2.98 & 3.51 & 5.36 & 6.80 & 7.65 & 5.72 & 4.08 & 2.41 & 1.46 \\
SA AL & 0.14 & 0.13 & 0.16 & 0.22 & 0.39 & 25.89 & 0.42 & 0.18 & 0.09 \\
Resto Al & 0.61 & 0.62 & 1.02 & 1.04 & 1.51 & 2.47 & 1.28 & 0.67 & 0.38 \\
SA SE & 0.15 & 0.17 & 0.15 & 0.23 & 0.28 & 0.56 & 28.00 & 0.24 & 0.11 \\
Resto SE & 0.68 & 0.61 & 0.89 & 0.79 & 1.02 & 1.73 & 2.71 & 0.87 & 0.43 \\
SA BA & 1.39 & 1.33 & 1.13 & 1.46 & 2.04 & 1.79 & 2.11 & 26.24 & 1.43 \\
Leste BA & 5.69 & 4.84 & 5.27 & 5.10 & 5.97 & 7.11 & 8.26 & 9.61 & 4.87 \\
Oeste BA & 0.35 & 0.20 & 0.21 & 0.20 & 0.23 & 0.20 & 0.18 & 0.35 & 0.26 \\
SA MG & 0.14 & 0.12 & 0.12 & 0.12 & 0.14 & 0.13 & 0.14 & 0.24 & 20.11 \\
Resto MG & 5.78 & 4.69 & 4.30 & 4.60 & 4.91 & 4.70 & 4.64 & 6.03 & 8.98 \\
Resto do Brasil & 54.55 & 43.17 & 42.45 & 42.57 & 43.64 & 42.23 & 41.62 & 47.72 & 58.32 \\
\hline
\end{tabular}

Um padrão semelhante pode ser observado em relação à dependência para frente das regiões do Semiárido. Considerando o destino das mercadorias produzidas no Semiárido, o resto do Brasil continua sendo a região individual com maior integração para cada região do Semiárido, excluindo-se o semiárido do Ceará. Porém, nota-se que esta importância é menor em relação à dependência para trás, com apenas o semiárido mineiro apresentando um valor superior a $50 \%$. 
Tabela 24 - Efeitos para frente (em relação ao total)

\begin{tabular}{lrrrrrrrrr}
\hline \multirow{2}{*}{ Região afetada } & \multicolumn{7}{c}{ Região extraída } \\
\cline { 2 - 10 } & SA PI & SA CE & SA RN & SA PB & SA PE & SA AL & SA SE & SA BA & SA MG \\
\hline MA & 2.28 & 1.66 & 1.64 & 1.28 & 1.35 & 1.09 & 1.15 & 1.04 & 0.88 \\
SA PI & 24.84 & 0.23 & 0.17 & 0.19 & 0.22 & 0.15 & 0.17 & 0.15 & 0.10 \\
Resto PI & 1.43 & 0.87 & 0.69 & 0.57 & 0.66 & 0.48 & 0.51 & 0.46 & 0.33 \\
SA CE & 1.55 & 34.64 & 2.21 & 1.94 & 1.46 & 0.97 & 1.31 & 0.96 & 0.56 \\
Resto CE & 2.50 & 8.75 & 4.55 & 2.27 & 1.82 & 1.25 & 1.18 & 1.11 & 0.77 \\
SA RN & 0.81 & 1.46 & 28.30 & 1.81 & 0.98 & 0.78 & 0.77 & 0.55 & 0.37 \\
Resto RN & 0.56 & 0.85 & 2.45 & 1.36 & 0.87 & 0.69 & 0.54 & 0.40 & 0.26 \\
SA PB & 0.45 & 0.71 & 0.91 & 31.19 & 0.86 & 0.59 & 0.68 & 0.39 & 0.22 \\
Resto PB & 0.70 & 0.87 & 1.59 & 2.56 & 1.24 & 1.09 & 0.77 & 0.52 & 0.34 \\
SA PE & 1.37 & 1.24 & 1.18 & 2.29 & 33.87 & 2.39 & 1.80 & 1.24 & 0.57 \\
Resto PE & 3.72 & 3.67 & 5.73 & 7.46 & 7.63 & 6.58 & 4.40 & 2.72 & 1.77 \\
SA AL & 0.13 & 0.13 & 0.14 & 0.23 & 0.32 & 25.67 & 0.59 & 0.18 & 0.09 \\
Resto Al & 0.78 & 0.67 & 0.80 & 1.01 & 1.34 & 3.06 & 1.60 & 0.76 & 0.46 \\
SA SE & 0.11 & 0.11 & 0.13 & 0.18 & 0.21 & 0.38 & 26.36 & 0.19 & 0.08 \\
Resto SE & 0.57 & 0.50 & 0.72 & 0.68 & 0.86 & 1.63 & 2.20 & 0.83 & 0.41 \\
SA BA & 1.81 & 1.56 & 1.33 & 1.80 & 2.45 & 2.35 & 3.34 & 33.48 & 2.00 \\
Leste BA & 4.35 & 3.62 & 6.00 & 4.28 & 4.71 & 7.10 & 6.81 & 8.09 & 4.70 \\
Oeste BA & 0.55 & 0.27 & 0.27 & 0.29 & 0.29 & 0.38 & 0.35 & 0.48 & 0.43 \\
SA MG & 0.16 & 0.12 & 0.13 & 0.16 & 0.14 & 0.16 & 0.21 & 0.25 & 23.42 \\
Resto MG & 6.08 & 4.35 & 4.56 & 4.73 & 4.75 & 5.66 & 5.94 & 6.24 & 10.59 \\
Resto do Brasil & 45.25 & 33.72 & 36.50 & 33.71 & 33.98 & 37.56 & 39.32 & 39.98 & 51.65 \\
\hline
\end{tabular}




\section{Resultados}

\subsection{Modelo Econométrico}

Como mencionado na seção 3.1, a equação 4 foi estimada para o rendimento médio de milho, mandioca e feijão, primeiro tendo como variáveis explicativas o IIS de 2012 a 2018 e em seguida, o índice VHI de 2001 a 2018, para os 1134 municípios do Semiárido. Deve ser ressaltado que a curta série temporal, principalmente no caso do índice IIS, constitui uma limitação para a estimação aqui realizada. Isto se deve ao fato de que o termo $\bar{x}=\frac{\Sigma_{t} x_{i t}}{T}$ na equação 4 ser uma estimativa amostral para o clima, dado por $\mu_{i}$ na equação 2 , mas, para questões climáticas, tal estimativa se torna consistente com um número T de anos não menor que 30.

Como em Souza (2018), as variáveis do índice IIS utilizadas foram as observações mensais para cada município. Já a estimação referente ao índice VHI utilizou a média anual do mesmo. Além da especificação de preferência, com efeitos fixos de estado-ano, foram estimadas regressões sem efeitos fixos e com efeitos fixos de ano e estado separadamente. Os resultados das regressões estão expostos no Apêndice C.

A partir dos resultados obtidos das regressões, podemos obter os valores previstos para o rendimento médio de cada cultura em cada município, para cada um dos cenários. Utilizamos para este cálculo os resultados obtidos da estimação de preferência, com efeitos fixos de estado-ano. Então comparamos a mudança percentual do valor do rendimento médio previsto em relação ao valor médio observado para a mesma cultura entre 2012 e 2018, para o cenário de 2012, e o valor médio observado entre 2001 e 2018 para os cenários futuros. Tal distinção se deve à indisponibilidade de dados prévios a 2012 referentes ao índice IIS, utilizado como referência para o cenário de 2012. O choque de produtividade da cultura $h$ no município $i$ referente ao cenário de 2012 será então dado por:

$$
p s_{i, 12}^{h}=\frac{r m_{i, 12}^{h}-\widehat{r m}_{i, 12: 18}^{h}}{\widehat{r m}_{i, 12: 18}^{h}}=\Delta r m_{i, 12}^{h}
$$

E para as projeções futuras: 


$$
p s_{i t}^{h}=\frac{r m_{i t}^{h}-\widehat{r m}_{i, 01: 18}^{h}}{\widehat{r m}_{i, 01: 18}^{h}}=\Delta r m_{i t}^{h}
$$

Em que $t$ corresponde a 2040, 2070 ou 2100.

Aqui, torna-se importante diferenciar os choques de curto e longo prazo. Conforme as equações 2 e 3, aqui expostas novamente, os rendimentos médio de curto e longo prazo, respectivamente, são dados por:

$$
\begin{gathered}
\mathbb{E}\left[y^{C P} \mid \alpha_{i}, \mu_{i}, x_{i}\right]=\alpha_{i}+\beta_{1} x_{i t}+\beta_{2} x_{i t}^{2}+\beta_{3}\left(x_{i t}-\mu_{i}\right)^{2} \\
\mathbb{E}\left[y^{L P} \mid \alpha_{i}, \mu_{i}, x_{i}\right]=\alpha_{i}+\beta_{1} x_{i t}+\beta_{2} x_{i t}^{2}
\end{gathered}
$$

Assim, o cálculo do rendimento médio de curto prazo levou em consideração a totalidade dos coeficientes estimados na equação 4, enquanto o rendimento médio de longo prazo desconsiderou os coeficientes de penalidade, dados por $\hat{\beta}_{3}$. Desta forma, os choques referentes ao ano de 2012 são considerados como choques de curto prazo, enquanto os choques dos cenários de 2040, 2070 e 2100 são tomados como de longo prazo. Para o ano de 2012, utilizou-se como referência o rendimento médio previsto obtido da regressão com o índice IIS. Já para os anos de 2040, 2070 e 2100, estão disponíveis apenas projeções para o índice VHI.

Finalmente, ajustamos os choques de longo prazo conforme a tendência de evolução do rendimento médio para cada cultura ao longo do tempo no Semiárido, de forma a levar em consideração fatores como progresso tecnológico e processos erosivos. As figuras 18, 19 e 20 ilustram a evolução do rendimento médio do feijão, mandioca e milho, respectivamente, tendo como recorte o Semiárido como um todo no período de 1988 a 2018. 


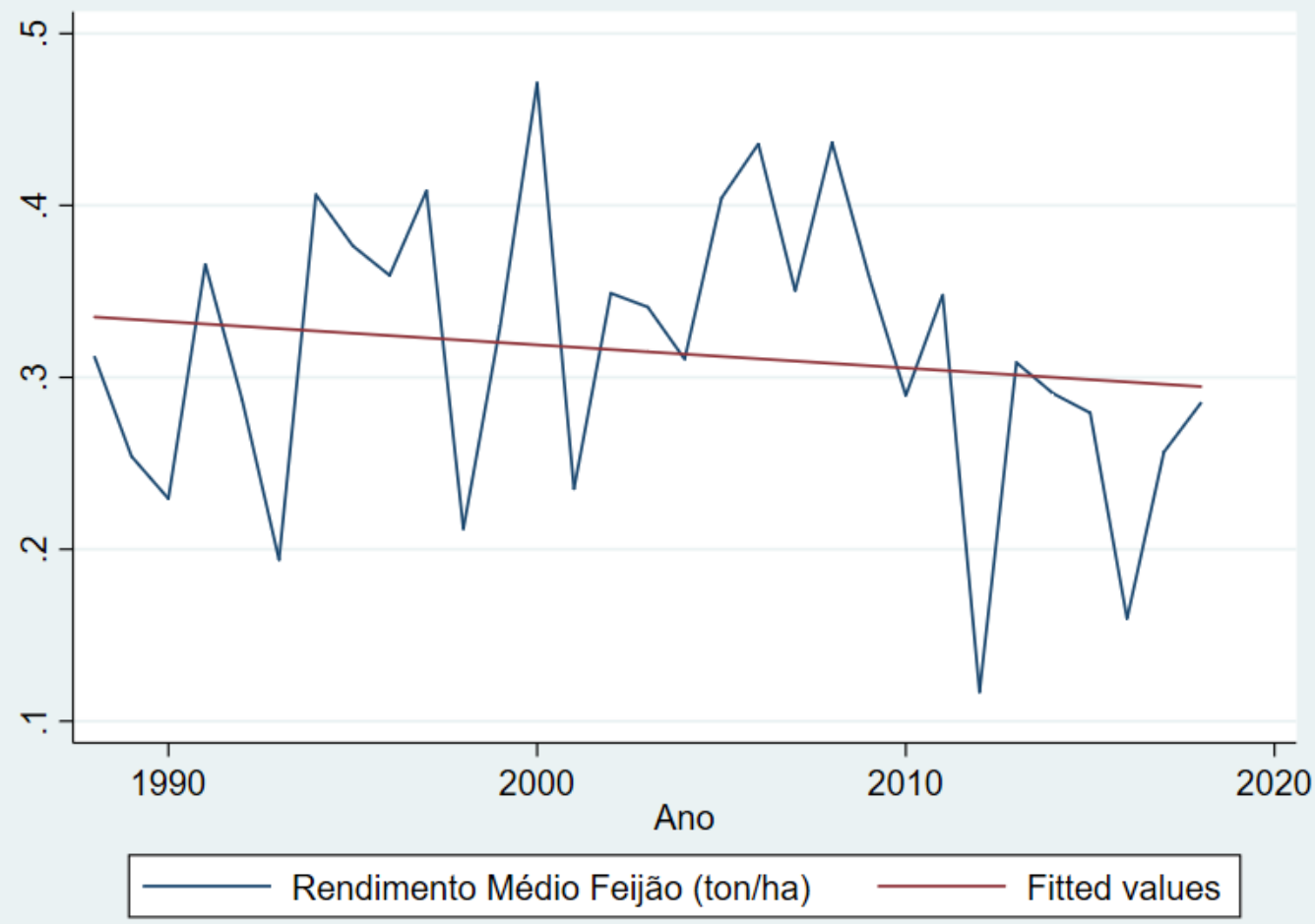

Figura 18 - Evolução do rendimento médio do feijão no Semiárido

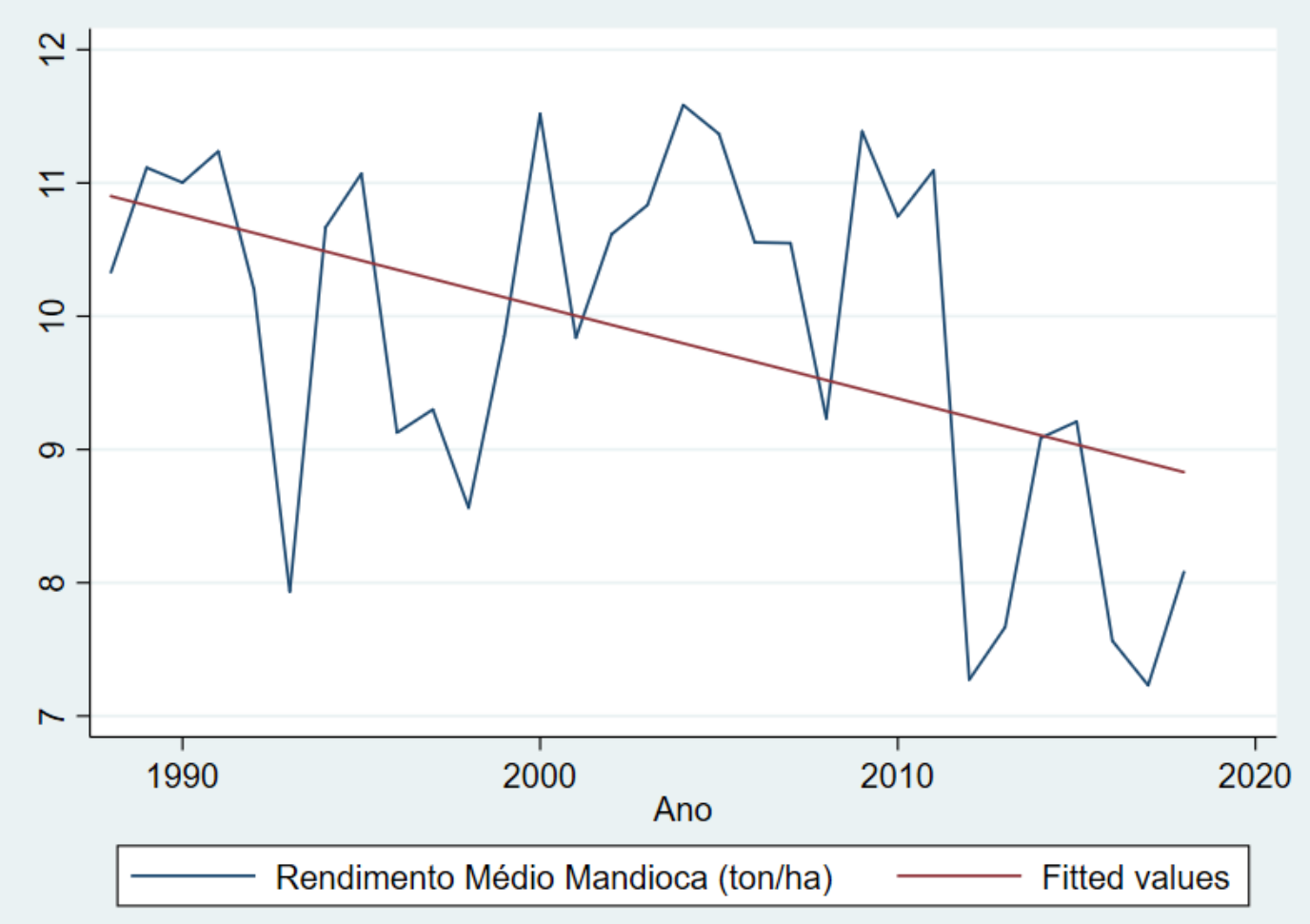

Figura 19 - Evolução do rendimento médio da mandioca no Semiárido 


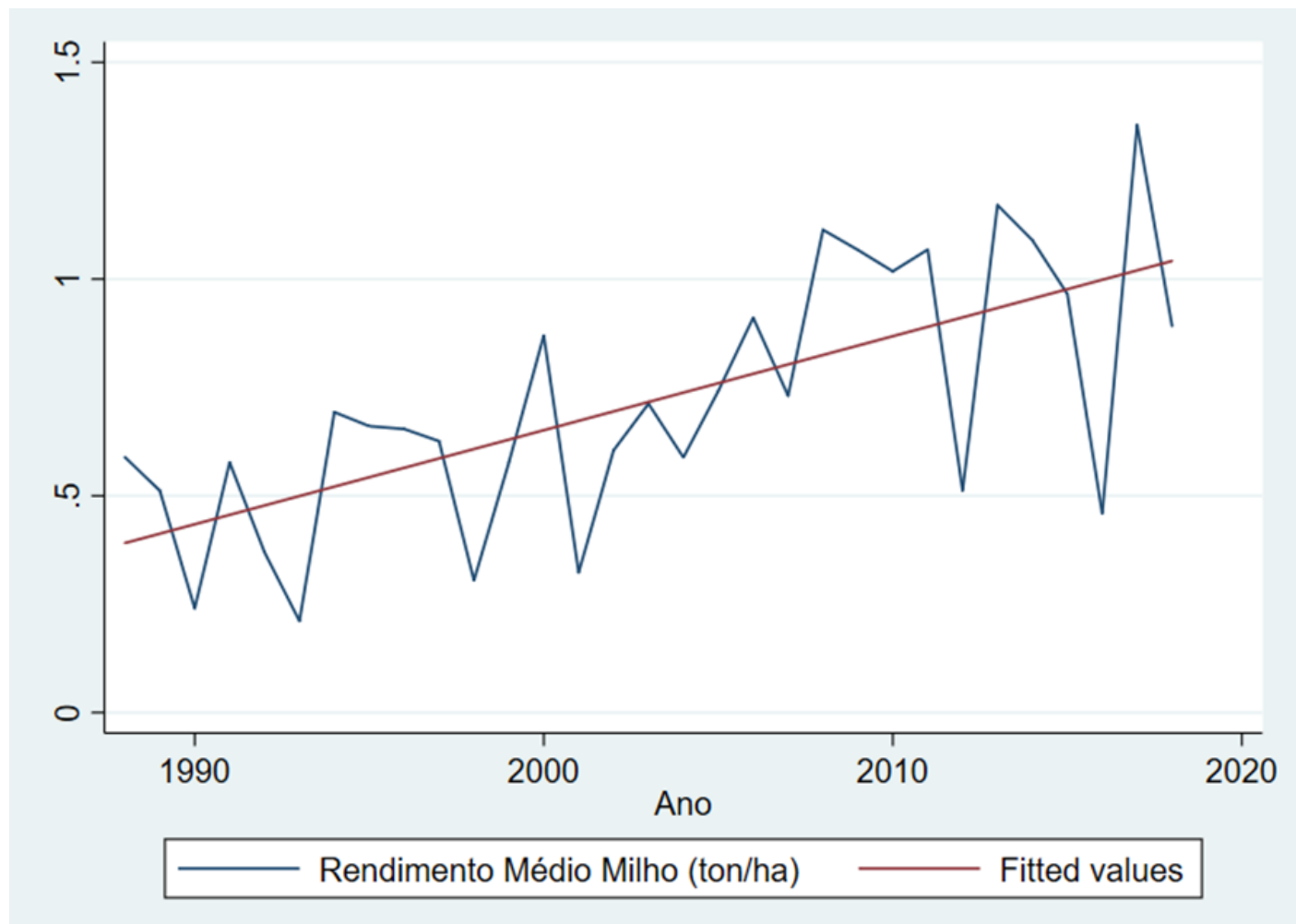

Figura 20- Evolução do rendimento médio do milho no Semiárido

Podemos notar que, no período observado, há uma tendência de queda na produtividade do feijão e da mandioca no Semiárido, enquanto se nota uma tendência positiva para o milho. O cálculo do crescimento anual de cada cultura se baseou na taxa de crescimento anual composta, dada por:

$$
t x^{h}=\left(\frac{r m_{2018}^{h}}{r m_{1988}^{h}}\right)^{31}-1
$$

Em que $r m_{2018}^{h}$ e $r m_{1988}^{h}$ são o rendimento médio da cultura $h$ no ano de 2018 e 1988 , respectivamente, para o Semiárido como um todo e 31 é o número de anos compreendidos no período analisado. Assim, esta taxa reflete quanto o rendimento médio teria crescido a cada ano se este crescimento fosse constante. A Tabela 25 expõe os valores obtidos deste cálculo. 
Tabela 25 - Taxa de crescimento anual do rendimento médio por cultura entre 1988 e 2018 no Semiárido

\begin{tabular}{lc}
\hline Cultura & Tx. Crescimento \\
\hline Feijão & $-0,0028922$ \\
Mandioca & $-0,0078872$ \\
Milho & 0,0134771 \\
\hline
\end{tabular}

Para obtermos o choque de produtividade que será aplicado na estrutura do modelo de equilíbrio geral, primeiro devemos agrupar os choques municipais de cada cultura em choques estaduais no setor agrícola como um todo. Para isso, primeiro calculamos uma média do choque referente ao rendimento de cada cultura para cada estado, ponderada pelo peso de cada município na produção desta cultura dentro do estado:

$$
p s_{e t}^{h}=\sum_{i \in E} u_{i}^{h} * p s_{i t}^{h}
$$

Em que $u_{i}^{h}$ é a participação do município $i$ na produção da cultura $h$ no estado $e$. Então, multiplicamos os choques referentes a cada cultura pelo peso de cada cultura na produção agrícola do Semiárido deste estado $e$ :

$$
p s_{e t}=\sum_{h \in H} u_{e}^{h} * p s_{e t}^{h}
$$

Em que $u_{e}^{h}$ é a média da participação da cultura $h$ na produção agrícola do estado $e$ entre 2012 e 2018 e $H$ inclui feijão, milho e mandioca. Assim, $p s_{e t}$ será o choque aplicado no modelo de equilíbrio geral no Semiárido do estado $e$ referente ao cenário do ano $t$. É importante ressaltar que a construção deste choque não inclui outras culturas que não as listadas, e desta forma, não representa o choque sobre a produtividade agrícola total em cada região. Em outras palavras, estamos estimando o impacto agregado de cada cenário sobre os setores de feijão, mandioca e milho e suas consequências indiretas sobre o resto da economia.

No cenário de 2012, o padrão de distribuição de choques é similar sob ambos os índices. Os estados mais ao norte, Piauí, Ceará, Rio Grande do Norte e Paraíba, sofreram grandes prejuízos na produção de feijão neste ano, com perdas estimadas de aproximadamente metade 
de seu rendimento médio ${ }^{2}$. Os dois primeiros também concentraram as perdas na produção de mandioca, com redução estimada de aproximadamente $30 \%$ de seu rendimento médio. Na produção de milho, os estados do Ceará, Rio Grande do Norte, Paraíba, Pernambuco e Alagoas concentraram as maiores perdas, que foram estimadas entre $33 \%$ a $50 \%$ dentre estes estados, com base no índice IIS.

Já nos cenários futuros (resultados mostrados no Apêndice D), é esperada uma deterioração da produtividade do feijão ao longo do século, com todos estados, a exceção do Alagoas, apresentando perda de produtividade a partir de 2070. Esta região permaneceria tendo ganhos positivos de produtividade do feijão em 2100, o que será também observado para o milho. Os estados do Piauí e Ceará deverão concentrar as maiores perdas no setor de feijão, que são estimadas em $76 \%$ e $87 \%$ de sua produtividade, respectivamente. As baixas médias do índice VHI para estas regiões são amplificadas pelo crescimento negativo estimado da produtividade do feijão.

O choque de produtividade estimada para a mandioca é negativo para todas regiões, com exceção do Piauí, já em 2040. A partir de 2070, a produtividade de mandioca deverá sofrer perdas em todos os estados. No final do século, a média da perda de produtividade em cada estado será em torno de $52 \%$, que em parte se deve ao crescimento negativo estimado da produtividade da mandioca.

Os choques de produtividade para a cultura do milho são heterogêneos ao longo dos anos. Em 2040, apenas Piauí deverá ter um choque positivo, estimado em ganhos de 11\%. Já a região do Semiárido mais negativamente afetada deverá ser Pernambuco, com perdas de 96\%, seguido pela Paraíba, com perdas de 90\%. Em 2070, além do Piauí, o estado do Alagoas também deverá ter ganhos de produtividade, enquanto Pernambuco e Ceará deverão sofrer perdas de $90 \%$ e $75 \%$, respectivamente. Já em 2100, os últimos dois estados deverão sofrer perdas de $82 \%$ e $83 \%$, respectivamente, e a Paraíba deverá sofrer perdas de $70 \%$. O semiárido da Bahia deverá apresentar ganhos na ordem de 35\% em sua produtividade, enquanto o Piauí terá ganhos estimados em $117 \%$. Por fim, para o final do século, os ganhos estimados de

\footnotetext{
${ }^{2}$ A Tabela D1 no Apêndice expõe os choques referentes ao cenário do ano de 2012 sobre cada cultura, tendo como base os índices IIS e VHI em separado.
} 
Alagoas na produção de milho estão em 297\%. Aqui, é fundamental destacar a importância do crescimento do rendimento médio utilizado para o milho, de 1,3\% ao ano.

A Tabela D3 do Apêndice apresenta os choques de produtividade por cultura desconsiderando o crescimento do rendimento médio. Desconsiderando o crescimento, o semiárido do Alagoas apresentaria ganhos de produtividade ao final do século, em todas as culturas. Além das projeções para o estado serem mais amenas, conforme as figuras 11 e 12 na seção de 4.2.3, a distribuição dos choques climáticos na região também é de fundamental importância. Os municípios que mais produzem feijão e milho apresentam projeções amenas para o índice VHI ao final do século, com média de valor acima de 50, diferentemente dos demais estados, conforme mostra a Tabela D6 no Apêndice. De fato, os maiores produtores destas culturas no Alagoas deverão gozar de melhores condições ao final do século que sua própria média entre 2012 e 2018, quando tiveram médias do índice VHI próximas a $40^{3}$.

Contudo, o semiárido do estado do Alagoas terá um choque final de produtividade negativo nos cenários futuros, conforme a Tabela 26. Isto se deve ao peso muito maior do feijão e da mandioca neste estado, conforme as tabelas 5, 9 e 11 (média de 39\% e 45\% na produção agrícola entre 2012 e 2018, respectivamente, enquanto o milho apresentou média de $5 \%)$ e da grande perda de produtividade da mandioca (-48\% em 2100), em comparação ao ganho do feijão (+18\% em 2100).

Em 2012, a região do Semiárido mais afetada foi Sergipe, com perda de produtividade agrícola em torno de $14 \%$, seguido de Ceará e Paraíba. Sergipe será também o mais afetado nos cenários futuros, devido à sua grande dependência no setor de milho, que deverá sofrer perdas significativas, conforme Tabela 5 e Tabela D2 no Apêndice. Devemos ressaltar que o choque de produtividade agrícola real deverá ser diferente do aqui apresentado, sendo que estamos calculando o choque proveniente apenas das 3 culturas citadas. Sendo assim, segundo a metodologia empregada, os estados mais vulneráveis às secas projetadas deverão ser Sergipe, Ceará e Paraíba, enquanto o Piauí será o menos afetado.

\footnotetext{
${ }^{3}$ Os maiores produtores de feijão, milho e mandioca do Semiárido do Alagoas tiveram médias do índice VHI de 43, 44 e 42, respectivamente, entre 2012 e 2018.
} 
Tabela 26 - Choque final de produtividade no Semiárido por região e ano

\begin{tabular}{ccccc}
\hline Região/Cenário & 2012 & 2040 & 2070 & 2100 \\
\hline PI & $-6.42 \%$ & $-2.86 \%$ & $3.54 \%$ & $13.65 \%$ \\
CE & $-9.96 \%$ & $-10.29 \%$ & $-15.49 \%$ & $-18.38 \%$ \\
RN & $-0.84 \%$ & $-3.27 \%$ & $-3.49 \%$ & $-4.42 \%$ \\
PB & $-8.19 \%$ & $-13.26 \%$ & $-14.22 \%$ & $-18.00 \%$ \\
PE & $-0.78 \%$ & $-6.59 \%$ & $-7.47 \%$ & $-8.58 \%$ \\
AL & $3.08 \%$ & $-12.17 \%$ & $-6.12 \%$ & $-6.03 \%$ \\
SE & $-13.88 \%$ & $-23.92 \%$ & $-35.23 \%$ & $-10.33 \%$ \\
BA & $-1.79 \%$ & $-1.23 \%$ & $-5.29 \%$ & $-3.80 \%$ \\
MG & $0.06 \%$ & - & - & - \\
\hline
\end{tabular}

A Tabela 27 demonstra os choques por cada cultura em separado e também o choque agregado, para cada cenário, considerando o Semiárido como um todo. ${ }^{4}$ Para se chegar ao resultado apresentado, ponderamos cada choque municipal pela sua importância dentro do Semiárido como um todo e também pelo peso de cada cultura dentro do total produzido pela agricultura do Semiárido.

O feijão foi a cultura mais afetada na seca ocorrida em 2012, perdendo pouco mais de um quarto de sua produtividade total, logo seguido pelo milho. Já a mandioca não apresentou alterações significativas em sua produtividade neste ano, e a região como um todo sofreu uma perda de $3,5 \%$ em sua produtividade agrícola total devido a estas três culturas.

Já em 2040, todas as culturas deverão sofrer significativas perdas agregadas, sendo o feijão a mais afetada. Em 2070 e 2100, as perdas de feijão e mandioca se agravam, mas o milho mantém uma estabilidade em 2070, em relação a 2040, e reverte em ganhos de produtividade da ordem de $11 \%$ em 2100. Isto pode ser explicado pelo ganho de produtividade do milho com o tempo, em comparação à perda de produtividade do feijão e mandioca. Contudo, este ganho de produtividade não é o suficiente para compensar as perdas

${ }^{4}$ O cenário de 2012 é baseado nos resultados derivados da regressão do índice IIS e os cenários futuros consideram crescimento do rendimento médio. No Apêndice D, há tabelas considerando a regressão do índice VHI para 2012 e desconsiderando o crescimento do rendimento médio para cenários futuros 
das outras culturas, e a perda de produtividade agregada se mantém negativa para todos os anos.

Tabela 27 - Choque de produtividade por ano para o Semiárido como um todo

\begin{tabular}{ccccc}
\hline Choque/Cenário & 2012 & 2040 & 2070 & 2100 \\
\hline Feijão & $-26.60 \%$ & $-35.61 \%$ & $-52.95 \%$ & $-59.95 \%$ \\
Mandioca & $-0.40 \%$ & $-12.36 \%$ & $-32.33 \%$ & $-45.60 \%$ \\
Milho & $-23.90 \%$ & $-21.99 \%$ & $-22.76 \%$ & $11.28 \%$ \\
Agregado & $-3.45 \%$ & $-4.70 \%$ & $-7.24 \%$ & $-6.12 \%$ \\
\hline
\end{tabular}

\subsection{Resultados da simulação de equilíbrio geral}

Para se calcular os choques de produtividade descritos pela Tabela 26 dentro da estrutura do modelo de equilíbrio geral, o parâmetro de produtividade al deve ser alterado. Tal parâmetro corresponde ao fator de aumento de produtividade de todos os insumos, ou seja, a implementação dos choques faz com que bens intermediários, trabalho e capital percam (ou ganhem) produtividade no setor agrícola de cada região, com magnitude descrita pela Tabela 26.

Aqui, é importante ressaltar que a simulação referente ao cenário de 2012 foi realizada sob o fechamento de curto prazo, enquanto os choques referentes aos cenários futuros foram dados sob o fechamento de longo prazo. As principais diferenças entre os dois fechamentos se referem à mobilidade do trabalho e do capital. No primeiro, o estoque de capital é fixo em cada indústria de cada região. Também é fixo o investimento, ou seja, as firmas não têm capacidade de mudar suas decisões de onde investir no curto prazo. Já o trabalho pode variar entre setores, mas somente dentro da mesma região, não havendo migração inter-regional.

No fechamento de longo prazo, em contraste, não há qualquer tipo de rigidez relacionada aos fatores de produção, de forma que capital e trabalho podem migrar livremente entre cada setor e região. A migração populacional se dá em direção aos setores e regiões mais produtivos, equilibrando o salário real entre cada uma, que poderia ser diferente entre as regiões no curto prazo. Da mesma forma, o capital é atraído para os locais mais produtivos, equalizando a taxa de retorno entre setores e regiões. Em ambos os casos, preferências dos consumidores e variáveis de produtividade das firmas são exógenas. 
Tabela 28 - Impactos nacionais em cada cenário (pontos percentuais)

\begin{tabular}{lrrrr}
\hline Variável/Ano & 2012 & 2040 & 2070 & 2100 \\
\hline Pagamentos agregados ao trabalho & $-0,0055$ & $-0,1300$ & $-0,2005$ & $-0,1716$ \\
Pagamentos agregados ao capital & $-0,0063$ & $-0,0992$ & $-0,1538$ & $-0,1321$ \\
Variação equivalente relativa & $-0,0341$ & $-0,1721$ & $-0,2618$ & $-0,2230$ \\
Estoque de capital & 0,0000 & $-0,0092$ & $-0,0152$ & $-0,0126$ \\
PIB real & $-0,0146$ & $-0,0096$ & $-0,0150$ & $-0,0117$ \\
Investimento & 0,0000 & $-0,0109$ & $-0,0193$ & $-0,0171$ \\
Consumo das famílias & $-0,0124$ & $-0,0435$ & $-0,0671$ & $-0,0568$ \\
Valor exportações & $-0,0128$ & 0,0541 & 0,0847 & 0,0781 \\
Valorimportações & 0,0027 & $-0,0641$ & $-0,1001$ & $-0,0856$ \\
\hline
\end{tabular}

A Tabela 28 expõe os resultados das simulações para variáveis macroeconômicas em nível nacional. Apesar dos diferentes impactos na produtividade agrícola em cada região para cada cenário, notam-se resultados muito próximos para as simulações de 2070 e 2100 , enquanto os impactos negativos para 2040 são em sua totalidade mais amenos em comparação aos dois últimos.

O impacto negativo sobre o PIB relativo a 2012 é maior do que os das projeções para 2040 e 2100, mesmo com projeções climáticas piores para o último ano. Isto se deve aos diferentes fechamentos utilizados em cada simulação. Ao utilizar o fechamento de longo prazo para os cenários futuros, capital e trabalho puderam se transferir para regiões e setores mais produtivos, atenuando assim o impacto negativo dos choques agrícolas sobre o PIB nacional.

Tal dinâmica pode ser observada pelo valor das importações. No curto prazo, a perda de produtividade da agricultura leva a um encarecimento do produto agrícola regional. Por não haver migração, o trabalho não se desloca para regiões onde houve ganho relativo de produtividade da agricultura, o que contribuiria para diminuição dos preços dos bens agrícolas destas regiões. Da mesma forma, o capital não se desloca entre regiões e setores, o que contribuiria para uma queda nos preços dos demais bens nacionais. O que se observa então é um aumento das importações de bens agrícolas sem uma queda proporcional na importação dos demais bens. Já no longo prazo, há um deslocamento dos fatores de produção para os demais setores que, conjuntamente com a queda na renda, leva a uma redução na importação dos demais bens superior ao aumento na importação dos bens 
agrícolas.

Considerando o bem-estar das famílias, medido pela variação equivalente relativa, os cenários do final do século trazem impactos quase sete vezes maiores que o da seca ocorrida em 2012. Seguindo a mesma tendência, o impacto no consumo das famílias é cinco vezes maior nos cenários de 2070 e 2100 do que em 2012. Apesar de pequenos $(0,012 \%$ em 2012 e aproximadamente 0,06\% em 2070 e 2100), deve-se levar em consideração que estes impactos consideram apenas as culturas de feijão, milho e mandioca produzidas dentro do Semiárido, e indicam que impactos climáticos no final do século sobre o bem-estar das famílias podem ter magnitude significativamente maior do que têm atualmente.

A Tabela 29 expõe os impactos sobre o Produto Regional Bruto (PRB) em cada cenário ${ }^{5}$. As regiões do Semiárido de Sergipe e Ceará concentram as maiores perdas. A primeira região deverá ter perdas significativas de seu produto de 2,02\%, 2,78\% e 0,94\% em 2040, 2070 e 2100, respectivamente. O semiárido do Ceará registra perdas superiores a $1 \%$ de sua produção em 2070 e 2100 (1,31\% e 1,53\%, respectivamente). Ainda dentro do Semiárido, a região mais beneficiada é o Piauí, que recebeu choques positivos em 2070 e 2100. A região oeste da Bahia registra ganhos em sua produção regional em todos os cenários, uma vez que sua agricultura se tornou relativamente mais produtiva e é um setor de grande relevância na região ${ }^{6}$.

O impacto sobre o PRB depende da composição setorial daquela região, da sua relação de trocas com as demais regiões, bem como do tipo de fechamento utilizado. O resultado final sobre as regiões que receberam os choques é uma confluência de três efeitos, conforme ilustrado pela Figura 1 na seção 3.2. Um choque negativo na produtividade agrícola de uma região leva por si só a uma diminuição da produção deste setor naquela região, já que naturalmente há um aumento de preços e então as famílias se tornam mais pobres, diminuindo sua demanda. Ocorre ainda uma distribuição de efeitos negativos através da cadeia produtiva. A diminuição da produção acarreta uma menor demanda de produtos

\footnotetext{
${ }^{5}$ No Apêndice D, as tabelas expõem resultados regionais para outras variáveis macroeconômicas.

${ }^{6}$ O setor agrícola correspondeu a 32\% da produção do oeste da Bahia em 2015.
} 
intermediários dos demais setores, como também aumenta o custo dos setores que utilizam bens agrícolas como matéria prima.

Tabela 29 - Resultados regionais de cada cenário para a produção (pontos percentuais)

\begin{tabular}{lrrrr}
\hline \multirow{2}{*}{ Região } & \multicolumn{4}{c}{ Produto Regional } \\
\cline { 2 - 5 } & 2012 & 2040 & 2070 & 2100 \\
\hline Semiárido PI & $-0,6389$ & $-0,4329$ & 0,6335 & 2,5405 \\
Semiárido CE & $-0,4954$ & $-0,9003$ & $-1,3135$ & $-1,5306$ \\
\hline Semiárido RN & $-0,0283$ & $-0,0711$ & $-0,1976$ & $-0,2171$ \\
Semiárido PB & $-0,1058$ & $-0,3194$ & $-0,3572$ & $-0,4199$ \\
Semiárido PE & $-0,0450$ & $-0,5420$ & $-0,6211$ & $-0,6924$ \\
Semiárido AL & 0,1912 & $-1,2661$ & $-0,6587$ & $-0,6465$ \\
Semiárido SE & $-0,7529$ & $-2,0178$ & $-2,7837$ & $-0,9384$ \\
Semiárido BA & $-0,1620$ & $-0,1706$ & $-0,7491$ & $-0,5394$ \\
\hline Semiárido MG & 0,0065 & 0,0275 & 0,0373 & 0,0322 \\
Maranhão & $-0,0035$ & 0,0216 & 0,0315 & 0,0289 \\
Resto PI & $-0,0081$ & 0,0018 & 0,0045 & 0,0051 \\
Resto CE & $-0,0220$ & $-0,1530$ & $-0,2182$ & $-0,2203$ \\
Resto RN & $-0,0157$ & $-0,1100$ & $-0,1519$ & $-0,1401$ \\
Resto PB & $-0,0174$ & $-0,0977$ & $-0,1326$ & $-0,1210$ \\
Resto PE & $-0,0237$ & $-0,1460$ & $-0,1952$ & $-0,1734$ \\
Resto AL & $-0,0267$ & 0,0592 & 0,0900 & 0,0825 \\
Resto SE & $-0,0121$ & $-0,0389$ & $-0,0572$ & $-0,0339$ \\
Leste BA & $-0,0087$ & 0,0216 & 0,0315 & 0,0289 \\
Oeste BA & 0,0119 & 0,1682 & 0,2509 & 0,2124 \\
Resto MG & $-0,0034$ & 0,0206 & 0,0285 & 0,0258 \\
Resto Brasil & $-0,0048$ & 0,0209 & 0,0298 & 0,0266 \\
\hline & & & &
\end{tabular}

Um choque negativo na produtividade agrícola de uma região leva por si só a uma diminuição da produção deste setor naquela região, já que naturalmente há um aumento de preços e então as famílias se tornam mais pobres, diminuindo sua demanda. Ocorre ainda uma distribuição de efeitos negativos através da cadeia produtiva. A diminuição da produção acarreta uma menor demanda de produtos intermediários dos demais setores, como também aumenta o custo dos setores que utilizam bens agrícolas como matéria prima.

Ao mesmo tempo, a queda na produtividade leva o setor agrícola a demandar mais trabalho e capital para produzir dada quantidade, pressionando o salário real. Ainda, o aumento da produtividade agrícola das demais regiões faz com que tais regiões aumentem sua produção agrícola e, consequentemente, sua demanda por bens intermediários das 
regiões de origem.

Pode-se observar que há uma predominância do primeiro efeito sobre as regiões que receberam o choque de produtividade. Regiões que receberam choques negativos tiveram uma diminuição em sua produção, como experimentaram o semiárido de Ceará e Sergipe em todos os cenários. Já regiões que experimentaram choques positivos sobre sua produtividade, como o semiárido de Alagoas em todos os cenários, tiveram um aumento em seu PRB.

Já nas regiões que não foram afetadas diretamente, o resultado final depende grandemente de sua composição setorial. O setor agrícola aumentará sua produção, mas os demais setores podem ter sua atividade diminuída, uma vez que as regiões afetadas passarão a demandar menos produtos intermediários. A Tabela 30 demonstra o impacto setorial do cenário de 2012 em cada região. A maior parte dos efeitos concentra-se sobre o próprio setor agrícola (S01). Observa-se que, nas regiões do Semiárido, os efeitos negativos sobre a atividade agrícola são ligeiramente menores do que o choque de produtividade inicial (presentes na Tabela 26), devido aos efeitos de mitigação acima descritos. Ainda, todas as regiões fora do Semiárido tiveram um aumento em sua atividade agrícola, uma vez que, nestas regiões, este setor teve um ganho de produtividade relativo. Todos os demais setores em todas as regiões sofreram uma diminuição em sua produção, com exceção dos setores de comércio e outras indústrias (não inclui indústria alimentícia) no oeste da Bahia. Este resultado demonstra a predominância do efeito negativo da perda de produtividade da atividade agrícola do Semiárido sobre os demais setores e regiões. Excluída a própria agricultura, o setor mais afetado foi a indústria de alimentos (S04), devido ao consequente aumento do seu custo de produção.

Já a Tabela 31 expõe o impacto setorial do cenário de 2070 sobre cada região. Os impactos negativos continuam concentrados sobre o setor agrícola das regiões do Semiárido e sobre a indústria de alimentos. Contudo, a livre mobilidade de capital e trabalho permitida no longo prazo favorece os setores e regiões mais produtivos. Desta forma há setores e regiões que tiveram um incremento em seu nível de atividade. De fato, extração mineral, outras indústrias, transportes e armazenamento e administração pública (S03, S05, S09 e S11) tiveram um incremento em sua atividade total. Da mesma forma, o semiárido do Piauí, 
o oeste da Bahia, Minas Gerais e o resto do Brasil apresentaram um aumento de atividade em todos os setores.

Tabela 30 - Resultados setoriais por região do cenário de 2012 (pontos percentuais)

\begin{tabular}{|c|c|c|c|c|c|c|c|c|c|c|c|}
\hline Região/Setor & S01 & $\mathrm{S} 02$ & S03 & S04 & S05 & S06 & S07 & S08 & S09 & S10 & S11 \\
\hline Semiárido PI & $-6,3138$ & $-0,0297$ & $-0,0056$ & $-0,4463$ & $-0,0163$ & $-0,0516$ & $-0,0015$ & $-0,0249$ & $-0,0241$ & $-0,0210$ & $-0,0256$ \\
\hline Semiárido CE & $-9,4129$ & $-0,0212$ & $-0,0087$ & $-0,5003$ & $-0,0317$ & $-0,0170$ & $-0,0014$ & $-0,0412$ & $-0,0427$ & $-0,0252$ & $-0,0314$ \\
\hline Semiárido RN & $-0,8434$ & $-0,0078$ & $-0,0071$ & $-0,1206$ & $-0,0323$ & $-0,0061$ & $-0,0005$ & $-0,0141$ & $-0,0185$ & $-0,0112$ & $-0,0100$ \\
\hline Semiárido PB & $-7,9478$ & $-0,0179$ & $-0,0058$ & $-0,1984$ & $-0,0273$ & $-0,0068$ & $-0,0013$ & $-0,0178$ & $-0,0226$ & $-0,0138$ & $-0,0129$ \\
\hline Semiárido PE & $-0,7682$ & $-0,0088$ & $-0,0147$ & $-0,0787$ & $-0,0171$ & $-0,0131$ & $-0,0008$ & $-0,0141$ & $-0,0184$ & $-0,0092$ & $-0,0088$ \\
\hline Semiárido AL & 3,2491 & $-0,0062$ & $-0,0072$ & 0,0584 & 0,0127 & $-0,0128$ & 0,0000 & $-0,0043$ & $-0,0041$ & $-0,0061$ & $-0,0038$ \\
\hline Semiárido SE & $-13,2739$ & $-0,0868$ & $-0,0199$ & $-0,3117$ & $-0,1342$ & $-0,0073$ & $-0,0017$ & $-0,0569$ & $-0,0490$ & $-0,0425$ & $-0,0518$ \\
\hline Semiárido BA & $-1,8464$ & $-0,0152$ & $-0,0046$ & $-0,1$ & $-0,0240$ & $-0,0131$ & $-0,0008$ & $-0,0183$ & $-0,0182$ & $-0,0107$ & $-0,0131$ \\
\hline Semiárido MG & 0,1700 & $-0,0091$ & $-0,0059$ & $-0,0117$ & $-0,0071$ & $-0,0050$ & $-0,0007$ & $-0,0031$ & $-0,0032$ & $-0,0054$ & $-0,0011$ \\
\hline Maranhão & 0,0386 & $-0,0077$ & $-0,0022$ & $-0,0063$ & $-0,0130$ & $-0,0052$ & $-0,0006$ & $-0,0070$ & $-0,0109$ & $-0,0057$ & $-0,0046$ \\
\hline Resto PI & 0,0338 & $-0,0109$ & $-0,0059$ & $-0,0514$ & $-0,0264$ & $-0,0206$ & $-0,0007$ & $-0,0123$ & $-0,0146$ & $-0,0088$ & $-0,0072$ \\
\hline Resto CE & 1108 & $-0,0126$ & $-0,0091$ & $-0,1882$ & $-0,0259$ & $-0,0118$ & $-0,0006$ & $-0,0291$ & 358 & $-0,0178$ & $-0,0122$ \\
\hline Resto RN & 0,1608 & $-0,0053$ & $-0,0085$ & $-0,0979$ & $-0,0806$ & $-0,0201$ & $-0,0011$ & $-0,0216$ & $-0,0259$ & $-0,0122$ & $-0,0098$ \\
\hline Resto PB & 0,1308 & $-0,0121$ & $-0,0109$ & $-0,1307$ & $-0,0840$ & $-0,0117$ & $-0,0014$ & $-0,0194$ & $-0,0296$ & $-0,0114$ & $-0,0110$ \\
\hline Resto PE & 0,1218 & $-0,0103$ & $-0,0167$ & $-0,1755$ & $-0,0321$ & $-0,0127$ & $-0,0009$ & $-0,0267$ & $-0,0370$ & $-0,0154$ & $-0,0134$ \\
\hline Resto AL & 0,0390 & $-0,0039$ & $-0,0040$ & $-0,3135$ & $-0,0309$ & $-0,0061$ & $-0,0004$ & $-0,0159$ & $-0,0331$ & $-0,0122$ & $-0,0151$ \\
\hline & 0,0822 & & & & & & & & & & $-0,0085$ \\
\hline Leste BA & 0,0540 & $-0,0089$ & $-0,0066$ & $-0,0405$ & $-0,0092$ & $-0,0064$ & $-0,0006$ & $-0,0123$ & $-0,0130$ & $-0,0105$ & $-0,0067$ \\
\hline Oeste BA & 0,0272 & $-0,0089$ & $-0,0079$ & $-0,0264$ & 0,0006 & $-0,0023$ & $-0,0003$ & 0,0011 & $-0,0004$ & $-0,0015$ & 0,0069 \\
\hline Resto MG & 0,0569 & $-0,0144$ & $-0,0018$ & $-0,0113$ & $-0,0049$ & $-0,0049$ & $-0,0005$ & $-0,0055$ & $-0,0066$ & $-0,0054$ & $-0,0043$ \\
\hline Resto Brasil & 0,0230 & $-0,0080$ & $-0,0027$ & $-0,0089$ & $-0,0053$ & $-0,0050$ & $-0,0005$ & $-0,0060$ & $-0,0070$ & $-0,0060$ & $-0,0051$ \\
\hline Total & $-0,1929$ & $-0,0097$ & $-0,0028$ & $-0,0303$ & $-0,0070$ & $-0,0058$ & $-0,0006$ & $-0,0080$ & $-0,0088$ & $-0,0068$ & $-0,0065$ \\
\hline
\end{tabular}

A mobilidade do trabalho entre as regiões nos cenários de longo prazo é ilustrada pelas figuras 21, 22 e 23. Dentro do Semiárido, todas as regiões perdem migrantes em 2040, condizente com o impacto negativo sobre todas suas sub-regiões, estando Sergipe, Alagoas e Ceará entre os mais afetados. A melhora da produtividade relativa do oeste da Bahia e seu forte setor agrícola leva esta região a receber proporcionalmente mais população. Já em 2070, o choque positivo sobre a região semiárida do Piauí induz uma onda migratória para o local, o que se mantém em 2100. Em todos os cenários, a região semiárida de Sergipe e Ceará estão dentre as que mais perdem migrantes em relação a sua população total, o que é condizente com o fato de que são regiões com a produtividade fortemente atingida.

Conhecer a distribuição de choques por região e setor é de fundamental importância para a formulação de políticas públicas. Contudo, também é de crucial relevância identificar as principais origens de tais impactos. A Tabela 32 desagrega o choque final sobre o PRB de cada região do cenário referente a 2040 por região de origem do choque. Regiões marcadas de 
vermelho na tabela sofreram uma diminuição em seu produto devido aos choques, enquanto regiões marcadas de azul tiveram um aumento em seu produto.

Tabela 31 - Resultados setoriais por região do cenário de 2070 (pontos percentuais)

\begin{tabular}{|c|c|c|c|c|c|c|c|c|c|c|c|}
\hline Região/Setor & S01 & $\mathrm{S} 02$ & S03 & SO4 & S05 & S06 & S07 & S08 & S09 & S10 & S11 \\
\hline Semiárido PI & 5,2340 & 0,3963 & 0,3110 & 0,4768 & 0,2343 & 0,2689 & 0,4247 & 0,3568 & 0,3162 & 0,3523 & 0,0973 \\
\hline Semiárido CE & $-15,8457$ & $-0,8198$ & $-0,4476$ & $-1,4623$ & $-0,4080$ & $-0,6902$ & $-0,8697$ & $-0,7791$ & $-0,7499$ & $-0,8003$ & $-0,2273$ \\
\hline emiárido RN & & 0,1716 & $-0,1111$ & $-0,4298$ & $-0,2114$ & $-0,1590$ & $-0,1912$ & $-0,1902$ & $-0,2035$ & $-0,1901$ & $-0,0346$ \\
\hline Semiárido PB & $-14,6924$ & $-0,3036$ & $-0,2002$ & $-0,6730$ & $-0,1785$ & $-0,2587$ & $-0,3284$ & $-0,2909$ & $-0,2910$ & $-0,2910$ & $-0,0581$ \\
\hline Semiárido PE & $-8,4368$ & $-0,3923$ & $-0,1821$ & $-0,6490$ & $-0,2587$ & $-0,3098$ & $-0,4226$ & $-0,3859$ & $-0,4005$ & $-0,3987$ & $-0,1025$ \\
\hline Semiárid & & & & & & & & & & & \\
\hline Semiárido SE & $-31,9630$ & $-1,5328$ & $-0,7708$ & $-1,7960$ & $-1,1478$ & $-1,4368$ & $-1,6145$ & $-1,5750$ & $-1,3596$ & $-1,4887$ & $-0,4040$ \\
\hline & & & & & & & & & & & \\
\hline Semiári & 0,4383 & 0,0443 & 0,0819 & 0,0323 & 0,0491 & 0,0398 & 0,0392 & 0,0169 & 0,0250 & 0,0147 & 0,0364 \\
\hline Marant & & 0,0479 & 0,0494 & 0,0134 & 43 & 95 & 90 & & & & 350 \\
\hline Resto PI & 2951 & 0,0384 & 0,0382 & $-0,0841$ & $-0,0230$ & 0,0016 & 0,0118 & $-0,0109$ & & & 0,0122 \\
\hline & 4104 & $-0,1926$ & $-0,1569$ & $-0,5264$ & $-0,2121$ & $-0,1926$ & $-0,2336$ & $-0,2411$ & $-0,2$ & $-0,2369$ & $-0,0763$ \\
\hline & & & & & & & & & & & 460 \\
\hline & 088 & $-0,1351$ & $-0,0773$ & $-0,3915$ & $-0,2820$ & $-0,1229$ & & & & & $-0,0381$ \\
\hline & & & & & & & & & & & $-0,0661$ \\
\hline & & 0,1439 & 0,1283 & $-0,5493$ & 0,0566 & & 0,1693 & & & & 0,0419 \\
\hline & & & & & & $-0,0426$ & & & & & \\
\hline Leste BA & 0,3302 & $-0,0482$ & $-0,0118$ & $-0,1578$ & $-0,0399$ & $-0,0508$ & $-0,0679$ & $-0,0724$ & $-0,0777$ & $-0,0845$ & 0,0050 \\
\hline Oeste BA & 0,3968 & 0,2351 & 0,2017 & 0,1089 & 0,1712 & 0,2442 & 0,2275 & 0,2408 & 0,2170 & 0,2320 & 0,1260 \\
\hline Resto MG & 0,2784 & 0,0404 & 0,0706 & 0,0169 & 0,0633 & 0,0270 & 0,0147 & 0,0151 & 0,0234 & 0,0075 & 0,0440 \\
\hline Resto Brasil & 0,2059 & 0,0444 & 0,0673 & 0,0394 & 0,0607 & 0,0267 & 0,0194 & 0,0175 & 0,0345 & 0,0164 & 0,0426 \\
\hline Total & $-0,2885$ & $-0,0108$ & 0,0604 & $-0,0361$ & 0,0415 & $-0,0137$ & $-0,0151$ & $-0,0184$ & 0,0083 & $-0,0092$ & 0,0225 \\
\hline
\end{tabular}

- Assim, choques com coeficientes positivos em regiões marcadas de vermelho contribuíram negativamente para a produção desta região, enquanto choques com coeficientes negativos atenuaram o efeito negativo dos demais choques. O oposto é verdade para regiões marcadas de azul. Desta forma, os choques no semiárido do Piauí, Ceará, Rio Grande do Norte e Pernambuco Bahia contribuíram para a queda no produto do semiárido do Ceará, enquanto os choques das demais regiões atenuaram este efeito negativo. Da mesma forma, os choques provenientes destas regiões contribuíram para diminuir o efeito positivo do choque das demais regiões sobre o produto do semiárido do Piauí. 


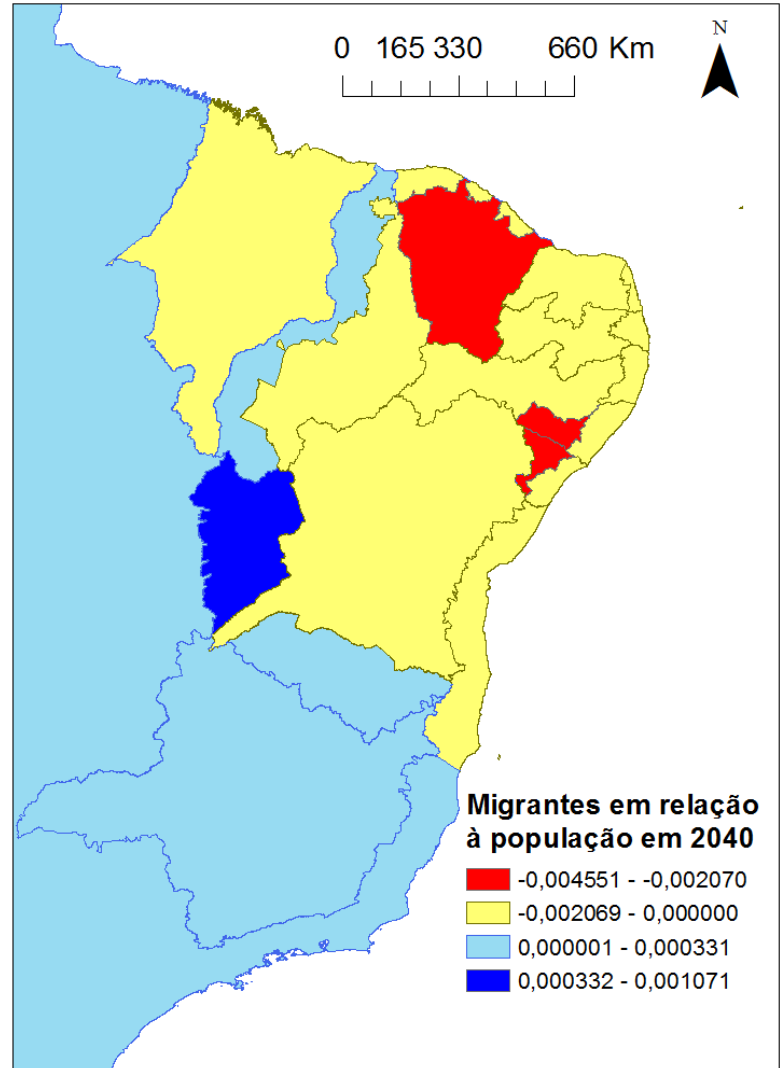

Figura 21 - Migração líquida em relação à população em 2040

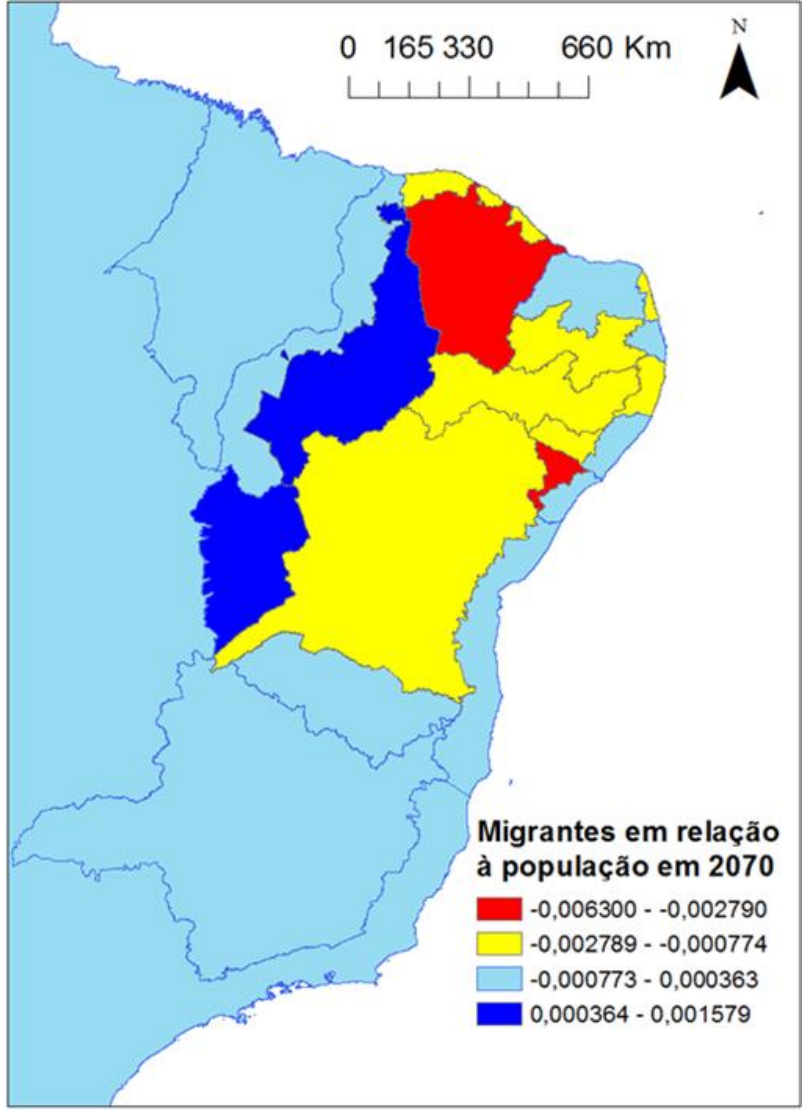

Figura 22 - Migração líquida em relação à população em 2070 


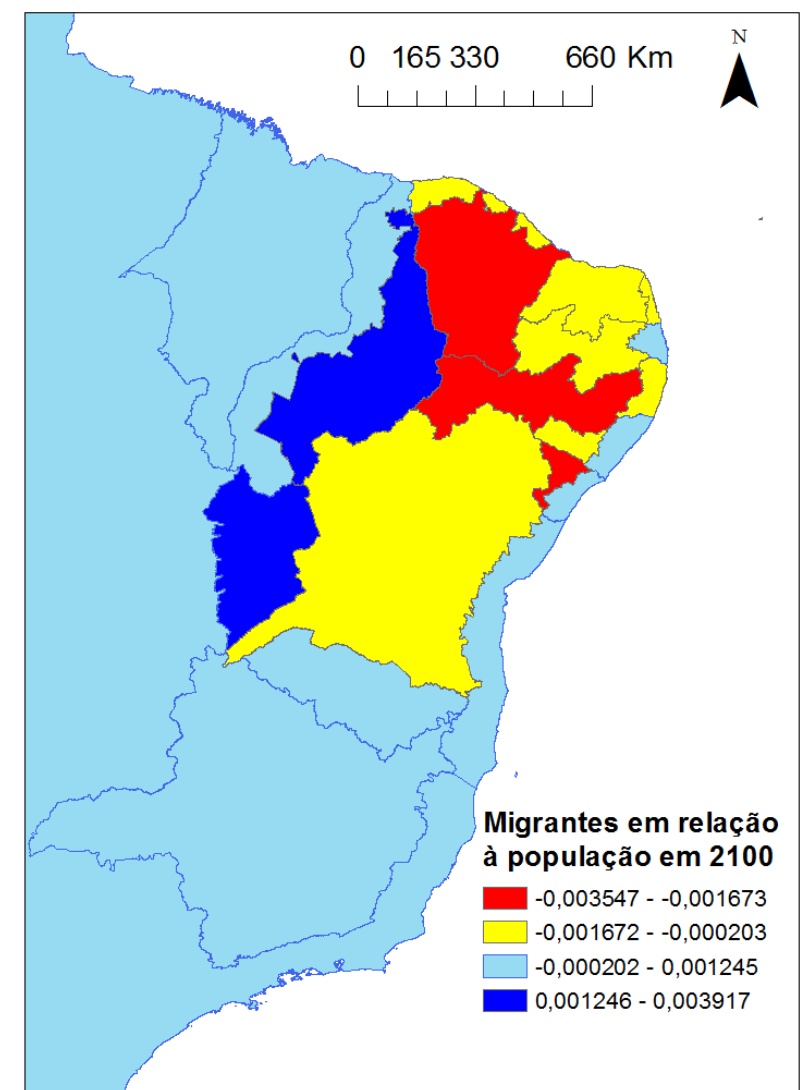

Figura 23 - Migração líquida em relação à população em 2100

Dentro do Semiárido, é possível observar que a maior parte do choque sobre cada região é proveniente da própria região. Considerando a importância de cada choque em particular, nota-se um destaque para os choques no semiárido do Ceará, Permanbuco, Bahia e Sergipe. O choque sobre o semiárido do Ceará é, individualmente, o de maior peso na composição do choque total nacional, com um peso de $35 \%$ no choque total, seguido por Pernambuco, com $25 \%$. Isto se deve à importância destas regiões na economia do Semiárido e à magnitude dos choques em 2040 (10,3\% e 6,6\%, conforme a Tabela 26). A seguir, as regiões de maior relevância para a composição do choque total são Bahia (14\%) e Sergipe (11\%). No entanto, o peso de cada choque tem explicações distintas. Mesmo sendo uma pequena região, o choque sobre o semiárido de Sergipe teve grande magnitude neste cenário (23,92\%). Já o choque sobre o semiárido da Bahia não foi tão expressivo $(1,23 \%)$, mas a importância da economia do semiárido baiano na região amplifica este impacto negativo. 
Tabela 32 - Decomposição do choque sobre o PRB de 2040 por região

\begin{tabular}{|c|c|c|c|c|c|c|c|c|c|}
\hline Região/Choque & Semiárido PI & Semiárido $\mathrm{CE}$ & Semiárido RN & Semiárido PB & Semiárido PE & Semiárido $\mathrm{AL}$ & Semiárido SE & Semiárido BA & Soma \\
\hline Semiárido PI & 1,0563 & $-0,0237$ & $-0,0002$ & $-0,0046$ & $-0,0050$ & $-0,0110$ & $-0,0062$ & $-0,0056$ & 1,00 \\
\hline Semiárido CE & 0,0003 & 1,0030 & 0,0006 & $-0,0008$ & 0,0019 & $-0,0034$ & $-0,0012$ & $-0,0004$ & 1,00 \\
\hline Semiárido RN & 0,0232 & 0,2136 & 0,5531 & 0,0128 & 0,0516 & $-0,0790$ & 0,0814 & 0,1434 & 1,00 \\
\hline Semiárido PB & 0,0043 & 0,0646 & 0,0044 & 0,8597 & 0,0343 & 0,0095 & 0,0121 & 0,0112 & 1,00 \\
\hline Semiárido PE & 0,0022 & 0,0219 & 0,0016 & 0,0041 & 0,9494 & 0,0056 & 0,0097 & 0,0056 & 1,00 \\
\hline Semiárido AL & $-0,0002$ & $-0,0059$ & 0,0001 & $-0,0012$ & 0,0021 & 1,0033 & 0,0022 & $-0,0004$ & 1,00 \\
\hline Semiárido SE & $-0,0001$ & $-0,0044$ & $-0,0001$ & $-0,0012$ & 0,0003 & $-0,0008$ & 1,0065 & $-0,0002$ & 1,00 \\
\hline Semiárido BA & $-0,0012$ & $-0,0461$ & $-0,0006$ & $-0,0105$ & 0,0144 & $-0,0212$ & $-0,0033$ & 1,0684 & 1,00 \\
\hline Semiárido MG & 0,0294 & $-0,0237$ & $-0,0002$ & $-0,0046$ & $-0,0050$ & $-0,0110$ & $-0,0062$ & $-0,0056$ & $-0,03$ \\
\hline Maranhão & 0,0034 & 0,3923 & 0,0043 & 0,0796 & 0,0939 & 0,1896 & 0,1408 & 0,0960 & 1,00 \\
\hline Resto PI & $-0,4476$ & $-1,5411$ & $-0,1295$ & 0,6149 & $-0,4279$ & 1,6881 & 0,6965 & 0,5467 & 1,00 \\
\hline Resto CE & 0,0221 & 0,7081 & 0,0187 & 0,0338 & 0,0945 & 0,0322 & 0,0485 & 0,0420 & 1,00 \\
\hline Resto RN & 0,0236 & 0,4228 & 0,0476 & 0,0882 & 0,1641 & 0,0830 & 0,1044 & 0,0664 & 1,00 \\
\hline Resto PB & 0,0238 & 0,3554 & 0,0281 & 0,1248 & 0,1999 & 0,0934 & 0,1059 & 0,0687 & 1,00 \\
\hline Resto PE & 0,0237 & 0,3213 & 0,0203 & 0,0859 & 0,2310 & 0,1273 & 0,1203 & 0,0702 & 1,00 \\
\hline Resto AL & 0,0305 & 0,5070 & 0,0158 & 0,1069 & 0,1449 & 0,0322 & 0,0629 & 0,0998 & 1,00 \\
\hline Resto SE & 0,0141 & 0,0568 & 0,0095 & 0,0087 & 0,1553 & 0,1435 & 0,5080 & 0,1040 & 1,00 \\
\hline Leste BA & 0,0287 & 0,1820 & 0,0156 & 0,0218 & 0,1959 & 0,0890 & 0,2280 & 0,2390 & 1,00 \\
\hline Oeste BA & 0,0331 & 0,4025 & 0,0154 & 0,0588 & 0,1673 & 0,0964 & 0,1142 & 0,1123 & 1,00 \\
\hline Resto MG & 0,0240 & 0,4283 & 0,0151 & 0,0676 & 0,1648 & 0,1241 & 0,1035 & 0,0727 & 1,00 \\
\hline Resto Brasil & 0,0234 & 0,4185 & 0,0138 & 0,0664 & 0,1554 & 0,1276 & 0,1068 & 0,0880 & 1,00 \\
\hline Total & 0,0522 & 0,3527 & 0,0348 & 0,0358 & 0,2457 & 0,0243 & 0,1126 & 0,1419 & 1,00 \\
\hline
\end{tabular}

\subsubsection{Análise de sensibilidade dos choques}

Há um inerente componente de incerteza associado à estimação de impactos climáticos futuros, que perpassa desde a estimação econométrica até a construção do modelo de equilíbrio geral, como argumenta Souza (2018).

A estimação econométrica em si agrega fontes de incerteza relacionadas à confiabilidade de sua base de dados, tanto da parte agrícola, que pode sofrer erros de medida em municípios menores, quanto da parte climática fornecida pelo CEMADEN, em que há uma incerteza inerente ao processo de interpolação espacial utilizado em sua construção. Ainda, há uma intrínseca incerteza relacionada à estimação econométrica, uma vez que o desconhecimento do processo gerador de dados faz com que a forma funcional escolhida na estimação não necessariamente produza as estimativas mais precisas.

A construção do modelo de equilíbrio geral também traz incertezas associadas à sua base de dados e sua estrutura funcional. A construção da matriz de insumo-produto pelo método IIOAS desagrega resultados nacionais ao nível regional de acordo com certos 
critérios, o que pode conduzir a incertezas na precisão dos dados a este nível. Ademais, o modelo traz hipóteses intrínsecas de manutenção da estrutura produtiva ao longo do século, assim como pressupostos associados ao seu fechamento, o que pode não corresponder à realidade observada.

Finalmente, as próprias projeções climáticas de cenários futuros são envoltas em incerteza, uma vez que não se conhece de fato o nível de emissões ao longo do século, o progresso tecnológico, o crescimento da população, e outros fatores que podem influenciar a dinâmica climática global.

Todas estas incertezas associadas gera um efeito "bola de neve" (Souza, 2018) em relação ao resultado final obtido neste trabalho. Desta forma, foi realizada uma análise sistemática de sensibilidade dos resultados obtidos em relação aos choques do cenário de 2100. Este exercício consistiu em estabelecer um intervalo de $100 \%$ para cada choque individual, com distribuição triangular, simétrica e independente. A variação entre os oito choques do modelo foi conduzida de forma simultânea, de forma que o método de Stroud produziu 16 soluções para as variáveis endógenas do modelo. A Tabela 33 expõe os resultados de média e desvio padrão produzidos pelas 16 simulações para variáveis macroeconômicas em nível nacional. O intervalo de confiança reportado foi obtido por meio da desigualdade de Chebychev (Greene, 2003). Para se obter um intervalo de 95\%, a média foi subtraída e somada pelo desvio padrão multiplicado por $4,47(\sim \sqrt{20})$.

Tabela 33 - Análise de sensibilidade dos choques de 2100

\begin{tabular}{llllcc}
\hline Variável & & Média & & \multicolumn{2}{c}{ Intervalo de confiança de 95\% } \\
\cline { 1 - 1 } \cline { 5 - 6 } Pagamentos agregados ao trabalho & & $-0,1690$ & & $-0,3578$ & 0,0199 \\
Pagamentos agregados ao capital & & $-0,1300$ & & $-0,2759$ & 0,0158 \\
Variação equivalente relativa & & $-0,2194$ & & $-0,4642$ & 0,0253 \\
Estoque de capital & & $-0,0124$ & & $-0,0276$ & 0,0028 \\
PIB real & & $-0,0115$ & & $-0,0257$ & 0,0027 \\
Investimento & $-0,0169$ & & $-0,0368$ & 0,0030 \\
Consumo das famílias & $-0,0559$ & & $-0,1186$ & 0,0068 \\
Valor exportações & 0,0770 & & $-0,0049$ & 0,1589 \\
Valor importações & $-0,0843$ & & $-0,1793$ & 0,0108 \\
\hline
\end{tabular}

Com exceção das exportações, todas as demais variáveis apresentaram valores 
negativos em suas médias, com o módulo do limite inferior significativamente maior ao limite superior em seu intervalo de confiança, o que indica impactos negativos robustos das condições climáticas do final do século sobre a economia como um todo. Contudo, os resultados podem ser distintos a nível regional.

A Tabela 34 traz os resultados da análise de sensibilidade para o PRB de cada região. O impacto sobre o PRB das regiões marcadas em laranja mantém o mesmo sinal no intervalo de confiança. Assim, as evidências apontam que os impactos deverão ser positivos para o Maranhão e negativos para o resto do Paraíba, Pernambuco e Sergipe.

Dentro do Semiárido, os resultados são ambíguos para todas as regiões. Isso se deve ao fato de que, ao variar simultaneamente todos os choques, são consideradas as possibilidades de o choque em dada região ser muito pequeno e em outra, muito maior, o que pode se inverter na simulação seguinte. Assim, a depender das elasticidades de substituição de Armington e da estrutura produtiva regional, um choque de maior magnitude sobre uma região de grande peso, como semiárido da Bahia ou Ceará, pode induzir a um aumento na produção agrícola regional, devido a substituição, que supere a perda pela menor demanda inter-regional pelos demais bens. Da mesma forma, um maior choque positivo sobre o semiárido do Piauí pode acarretar um aumento de demanda sobre regiões que mantêm maior relação comercial com o Piauí que supere a perda causada pelos demais choques. 
Tabela 34 - Análise de sensibilidade dos choques de 2100 sobre o PRB de cada região

\begin{tabular}{|c|c|c|c|}
\hline Variável & Média & Intervalo de co & de $95 \%$ \\
\hline Semiárido PI & 2,5980 & $-2,5563$ & 7,7522 \\
\hline Semiárido CE & $-1,5055$ & $-4,0025$ & 0,9914 \\
\hline Semiárido RN & $-0,2148$ & $-0,4589$ & 0,0292 \\
\hline Semiárido PB & $-0,4129$ & $-1,0062$ & 0,1804 \\
\hline Semiárido PE & $-0,6857$ & $-1,8254$ & 0,4541 \\
\hline Semiárido AL & $-0,6422$ & $-1,7932$ & 0,5088 \\
\hline Semiárido SE & $-0,9281$ & $-2,5602$ & 0,7039 \\
\hline Semiárido BA & $-0,5372$ & $-1,5196$ & 0,4453 \\
\hline Semiárido MG & 0,0316 & $-0,0044$ & 0,0676 \\
\hline Maranhão & 0,0285 & 0,0010 & 0,0560 \\
\hline Resto PI & 0,0052 & $-0,0080$ & 0,0185 \\
\hline Resto CE & $-0,2165$ & $-0,5232$ & 0,0902 \\
\hline Resto RN & $-0,1378$ & $-0,2835$ & 0,0079 \\
\hline Resto PB & $-0,1190$ & $-0,2366$ & $-0,0013$ \\
\hline Resto PE & $-0,1707$ & $-0,3381$ & $-0,0032$ \\
\hline Resto AL & 0,0811 & $-0,0141$ & 0,1764 \\
\hline Resto SE & $-0,0336$ & $-0,0653$ & $-0,0018$ \\
\hline Leste BA & $-0,0393$ & $-0,0842$ & 0,0055 \\
\hline Oeste BA & 0,2090 & $-0,0251$ & 0,4431 \\
\hline Resto MG & 0,0254 & $-0,0025$ & 0,0533 \\
\hline Resto Brasil & 0,0262 & $-0,0020$ & 0,0544 \\
\hline
\end{tabular}




\section{Conclusão}

Os impactos advindos das mudanças climáticas sobre a economia e sociedade serão um dos principais desafios da humanidade ao longo deste século. Este trabalho procurou investigar os danos provocados por secas ao Semiárido Brasileiro, a região mais vulnerável do país e frequentemente atingida por esta mazela climática.

Para tanto, foi investigada a relação entre secas, medidas por variáveis fornecidas pelo CEMADEN, e produtividade de milho, feijão e mandioca utilizando o ferramental econométrico de dados em painel. Com base nas estimativas obtidas, foram calculados choques de produtividade para quatro cenários: 2012, 2040, 2070 e 2100. Estes choques foram então aplicados a um modelo inter-regional de equilíbrio geral computável tendo como enfoque o Semiárido, de modo a estimar o impacto das secas sobre variáveis socioeconômicas de interesse.

Os resultados apontam para uma heterogeneidade de choques de produtividade entre regiões, com uma consequente heterogeneidade de impactos econômicos associados. A região do semiárido de Sergipe foi a mais gravemente afetada em todos os cenários, indicando uma especial vulnerabilidade aos impactos climáticos. Em contraposição, a região do semiárido do Piauí apresentou menor vulnerabilidade. Contudo, quando considerando a economia como um todo, os impactos são consistentemente negativos e devem se agravar ao longo do século. Este resultado se mantém quando realizada a análise sistemática de sensibilidade.

Deve ser ressaltado que as projeções utilizadas neste trabalho tomaram como base o cenário RCP 8.5, o mais pessimista em termos de emissões e aumento da temperatura global. Ainda, o modelo de equilíbrio geral, ao ter uma estrutura rígida de produção, não considera a possibilidade de adaptação dos produtores aos choques climáticos. Contudo, convém ressaltar que o estudo utilizou como base apenas as culturas de mandioca, milho e feijão, e assim sendo, o impacto geral sobre a agricultura, sob o cenário RCP 8.5, é grandemente subestimado. Isto é, um índice VHI de 0, presente em muitos municípios nas projeções do final do século, indicaria ausência de atividade fotossintética na região, e desta 
forma, a produtividade de todas as culturas deveria ser zero. Além da imprescindibilidade de irrigação, haveria a necessidade da construção de ambientes controlados de temperatura e umidade, impondo pesados custos a uma já empobrecida região. Desta forma, tais municípios se tornariam impróprios para o cultivo agrícola.

Outro fator que contribui para a subestimação dos resultados do modelo em relação ao impacto real das secas é a forte característica informal da economia da região, com um presente componente de autoconsumo. O modelo de equilíbrio geral leva em consideração apenas o mercado formal da região, tanto em sua base de dados quanto em sua estrutura teórica. Desta forma, não é captada por completo a perda de renda e bem-estar causada pelas secas aos agricultores de subsistência. A Tabela 35 expõe o peso da produção para autoconsumo de acordo com o Censo Agrícola de 2006, e nota-se que este tipo de produção é particularmente forte nos estados do Nordeste.

A inclusão de um módulo de autoconsumo dentro da estrutura teórica do modelo de equilíbrio geral, assim como a inclusão de estimativas para mais culturas além do milho, mandioca e feijão constituem possibilidades de aprimoramento futuro do trabalho. Outra possibilidade é a utilização de mais dados climáticos, tais como temperatura e precipitação, considerando ainda outros cenários de RCP. 
Tabela 35 - Proporção entre o valor do autoconsumo e valor da produção agrícola total em 2006

\begin{tabular}{lc}
\hline \multicolumn{1}{c}{ Estado } & $\begin{array}{c}\text { Proporção entre valor total do } \\
\text { autoconsumo e valor da produção total }\end{array}$ \\
\hline Rondônia & 10,45 \\
Acre & 32,43 \\
Amazonas & 20,46 \\
Roraima & 14,63 \\
Pará & 17,77 \\
Amapá & 7,05 \\
Tocantins & 13,39 \\
Maranhão & 30,01 \\
Piauí & 30,66 \\
Ceará & 20,34 \\
Rio Grande do Norte & 12,62 \\
Paraíba & 16,14 \\
Pernambuco & 7,17 \\
Alagoas & 4,93 \\
Sergipe & 7,98 \\
Bahia & 9,04 \\
Minas Gerais & 8,38 \\
Espírito Santo & 3,45 \\
Rio de Janeiro & 5,36 \\
São Paulo & 3,09 \\
Paraná & 5,31 \\
Santa Catarina & 11,92 \\
Rio Grande do Sul & 8,58 \\
Mato Grosso do Sul & 3,35 \\
Mato Grosso & 2,77 \\
Goiás & 4,84 \\
Distrito Federal & 2,30 \\
Brasil & 7,78 \\
\hline
\end{tabular}

Fonte: Grisa et al. (2006) 


\section{Referências}

Alvala, R., Cunha, A. P., Brito, S. S., Seluchi, M. E., Marengo, J. A., Moraes, O. L., e Carvalho, M. A. (2019). Drought monitoring in the Brazilian Semiarid region. Anais da Academia Brasileira de Ciências, 91.

Araújo, P. H. C., de Figueiredo Silva, F., Gomes, M. F. M., Féres, J. G., e Braga, M. J. (2014). Uma análise do impacto das mudanças climáticas na produtividade agrícola da região nordeste do Brasil. Revista Econômica do Nordeste, 45(3):46-57.

Auffhammer, M. e Schlenker, W. (2014). Empirical studies on agricultural impacts e adaptation. Energy Economics, 46:555-561.

Barbieri, A. F., Domingues, E., Queiroz, B. L., Ruiz, R. M., Rigotti, J. I., Carvalho, J. A., e Resende, M. F. (2010). Climate change and population migration in Brazil's Northeast: scenarios for 2025-2050. Population and Environment, 31(5):344-370.

Boyd, R. e Ibarrarán, M. E. (2009). Extreme climate events and adaptation: an exploratory analysis of drought in Mexico. Environment and Development Economics, 14(3):371-395.

Branco, D., Feres, J., et al. (2018). Weather shocks and labor allocation: Evidence from northeastern Brazil. In 2018 Conference, July 28-August 2, 2018, Vancouver, British Columbia, number 277736. International Association of Agricultural Economists.

Castricini, A., Rodrigues, M. G. V., de Jesus, A. M., e Serpa, M. F. P. (2014). Caracterização de raízes de genótipos de mandioca produzidos no semiárido de Minas Gerais. Revista Raízes e Amidos Tropicais, 10:23-37.

CEMADEN. Situação atual da seca no Semiárido e impactos - maio de 2017. http://www.cemaden.gov.br/situacao-atual-da-seca-no-semiarido-e-impactos-maio-de 2017//. Acesso: 2020-04-22.

Conab. Calendário de plantio e colheita de grãos no Brasil 2019. http: //www.conab.gov.br/institucional/publicacoes/outras-publicacoes/item/7694-calendarioagricola-plantio-e-colheita/. Acesso: 2020-04-02.

Corbi, R., Ferraz, T., et al. (2018). Rainfall, internal migration e local labor markets in Brazil. Technical report, University of São Paulo (FEA-USP).

Delazeri, L. M. M., da Cunha, D. A., e Couto-Santos, F. R. (2018). Climate change and urbanization: Evidence from the semi-arid region of Brazil. Revista Brasileira de Estudos Regionais e Urbanos, 12(2):129-154.

Deschênes, O. e Greenstone, M. (2007). The economic impacts of climate change: evidence from agricultural output and random fluctuations in weather. American Economic Review, 97(1):354-385.

Domingues, E. P., Magalhães, A. S., e Ruiz, R. M. (2011). Cenários de mudanças climáticas e 
agricultura no Brasil: impactos econômicos na região nordeste. Revista Econômica do Nordeste, 42(2):229-246.

Faria, W. R. e Haddad, E. A. (2017). Modeling land use and the effects of climate change in Brazil. Climate Change Economics, 8(01):1750002.

Food and Agriculture Organization of the United Nations. Drought. http://www.fao. org/lewater/water/drought/en/. Acesso: 2019-10-12.

Ferreira, H. A., dos Santos Souza, A., de Sousa, D. A., dos Santos Souza, A., e Maracajá, P. B. (2010). Componentes de produção e produtividade do milho submetido a doses de nitrogênio no semiárido paraibano. Revista Verde (Mossoró- RN-Brasil) v, 5(4):90-96.

International Monetary Fund (2003). Fund assistance for countries facing exogenous shocks.

Gandara, G. S. (2015). Rios nossos que estão no sertão! São Francisco e Parnaíba. Confins.Revue franco-brésilienne de geographie/Revista franco-brasileira de geografia, (23).

Gori Maia, A., Cesano, D., Miyamoto, B. C., Eusébio, G. d. S., Erade, P., et al. (2016). Climate change and adaptive strategies in agriculture: Assessing the impacts on small farmers in the Brazilian sertão. In 2016 Annual Meeting, July 31-August 2, Boston, Massachusetts, number 236255. Agricultural e Applied Economics Association.

Greene, W. H. (2003). Econometric analysis. Pearson Education India.

Griffith, M. (2012). Water resources modeling: a review. In Economic Modeling of Water, pages 59-77. Springer.

Grisa, C., Schneider, S., Conterato, M., e Ferreira, F. (2006). A producão para autoconsumo no Brasil: uma análise a partir do censo agropecuário 2006. Aspectos multidimensionais da agricultura brasileira: diferentes visões do Censo Agropecuário, 167-188.

Haddad, E. A. (2018). Regional inequality and structural changes: lessons from the Brazilian experience. Routledge.

Haddad, E. A., Júnior, C. A. G., e Nascimento, T. O. (2017). Matriz Interestadual De InsumoProduto Para o Brasil: Uma Aplicação do Método IIOAS. Revista Brasileira de Estudos Regionais e Urbanos, 11(4), 424-446.

Haddad, E. A., Farajalla, N., Camargo, M., Lopes, R. L., e Vieira, F. V. (2014). Climate change in Lebanon: Higher-order regional impacts from agriculture. Region, 1(1):9- 24.

Haddad, E. A., Porsse, A. A., Pereda, P. C., et al. (2012). Territorial economic impacts of climate anomalies in Brazil. Technical report, University of São Paulo (FEA-USP).

Karnieli, A., Bayasgalan, M., Bayarjargal, Y., Agam, N., Khudulmur, S., e Tucker, C. (2006). Comments on the use of the vegetation health index over Mongolia. 
International Journal of Remote Sensing, 27(10):2017-2024.

Kucharik, C. J. and Serbin, S. P. (2008). Impacts of recent climate change on Wisconsin corn and soybean yield trends. Environmental Research Letters, 3(3):034003.

Kuwayama, Y., Thompson, A., Bernknopf, R., Zaitchik, B., e Vail, P. (2019). Estimating the impact of drought on agriculture using the US drought monitor. American Journal of Agricultural Economics, 101(1):193-210.

Linhares, M. Y. et al. (1990). História geral do Brasil. Campus Rio de Janeiro.

Marengo, J. A. (2010). Vulnerabilidade, impactos e adaptação à mudança do clima no Semiárido do Brasil. Parcerias estratégicas, 13(27):149-176.

Marengo, J. A., Cunha, A. P., Soares, W. R., Torres, R. R., Alves, L. M., de Barros Brito, S. S., Cuartas, L. A., Leal, K., Neto, G. R., Alvalá, R. C., et al. (2019). Increase risk of drought in the semiarid lands of Northeast Brazil due to regional warming above $4 \mathrm{c}$. In Climate change risks in Brazil, pages 181-200. Springer.

Marengo, J. A., Torres, R. R., e Alves, L. M. (2017). Drought in Northeast Brazil—past, present, e future. Theoretical e Applied Climatology, 129(3-4):1189-1200.

McCarl, B. A., Villavicencio, X., e Wu, X. (2008). Climate change e future analysis: is stationarity dying? American Journal of Agricultural Economics, 90(5):1241-1247.

Mérel, P. e Gammans, M. (2018). Climate econometrics: Can the panel approach account for long-run adaptation?

Miller, R. E., e Blair, P. D. (2009). Input-output analysis: foundations and extensions. Cambridge University Press.

Moss, R. H., Edmonds, J. A., Hibbard, K. A., Manning, M. R., Rose, S. K., Van Vuuren, D. P., Carter, T. R., Emori, S., Kainuma, M., Kram, T., et al. (2010). The next generation of scenarios for climate change research and assessment. Nature, 463(7282):747-756.

Oury, B. (1965). Allowing for weather in crop production model building. Journal of Farm Economics, 47(2):270-283.

Pachauri, R. e Reisinger, A. (2008). Climate change 2007: synthesis report. Contribution of Working Groups I, II and II to the fourth assessment report. Cambridge University Press, Cambridge.

Pachauri, R. K., Allen, M. R., Barros, V. R., Broome, J., Cramer, W., Christ, R., Church, J. A., Clarke, L., Dahe, Q., Dasgupta, P., et al. (2014). Climate change 2014: synthesis report. Contribution of Working Groups I, II e III to the fifth assessment report of the Intergovernmental Panel on Climate Change. IPCC. 
Pereira, R. F., de Lima, A. S., Maia Filho, F. d. C. F., Cavalcante, S. N., dos Santos, J. G. R., e Erade, R. (2013). Produção de feijão vigna sob adubação orgânica em ambiente semiárido. Agropecuária Científica no Semiárido, 9(2):27-32.

Rocha, R. e Soares, R. R. (2015). Water scarcity e birth outcomes in the Brazilian semiarid. Journal of Development Economics, 112:72-91.

Sanghi, A. e Mendelsohn, R. (2008). The impacts of global warming on farmers in Brazil and India. Global Environmental Change, 18(4):655-665.

Silva, A. F., Santana, L. M. d., França, C. R., Magalhães, C. A. d. S., Araújo, C. R. d., e Azevedo, S. G. d. (2009). Produção de diferentes variedades de mandioca em sistema agroecológico. Revista Brasileira de Engenharia Agrícola e Ambiental, 13(1):33-38.

Silva, M. R. R., Vanzela, L. S., Vazquez, G. H., e Sanches, A. C. (2012). Influência da irrigação e cobertura morta do solo sobre as características agronômicas e produtividade de milho. Irriga, 1(01):170-180.

Souza, B. S. d. Mudanças climáticas no Brasil: efeitos sistêmicos sobre a economia Brasileira provenientes de alterações na produtividade agrícola. Tese de Doutorado, Universidade de São Paulo.

Souza, L. S. B. d., Moura, M. S. B. d., Sediyama, G. C., e Silva, T. G. F. d. (2011). Eficiência do uso da água das culturas do milho e do feijão-caupi sob sistemas de plantio exclusivo e consorciado no Semiárido Brasileiro. Bragantia, 70(3):715-721.

Stern, N. e Stern, N. H. (2007). The economics of climate change: the Stern review. Cambridge University Press.

Thurlow, J., Dorosh, P., e Yu, W. (2012). A stochastic simulation approach to estimat- ing the economic impacts of climate change in Bangladesh. Review of Development Economics, $16(3): 412-428$.

Wittrock, V., Kulshreshtha, S. N., e Wheaton, E. (2011). Canadian prairie rural communities: their vulnerabilities e adaptive capacities to drought. Mitigation and Adaptation Strategies for Global Change, 16(3):267-290.

Wittwer, G. e Griffith, M. (2011). Modelling drought e recovery in the Southern MurrayDarling basin. Australian Journal of Agricultural e Resource Economics, 55(3):342-359.

Zhong, S., Sha, J., Shen, L., Okiyama, M., Tokunaga, S., Yan, J., e Liu, L. (2016). Measuring drought based on a CGE model with multi-regional irrigation water. Water Policy, 18(4):877891. 
Apêndice A - Média Mensal do IIS

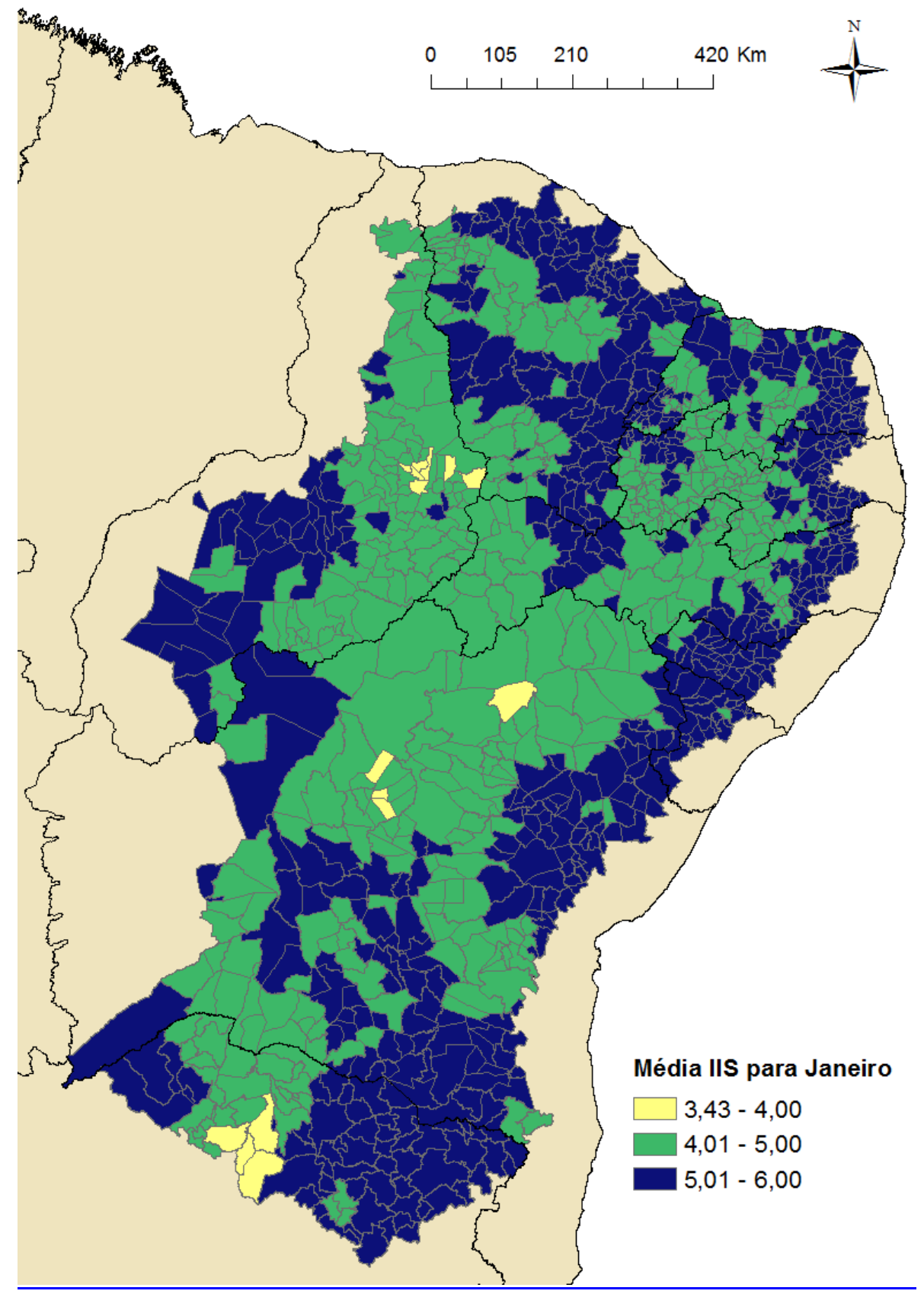

Figura A1 - Média do índice IIS para Janeiro (entre 2012 e 2018) 


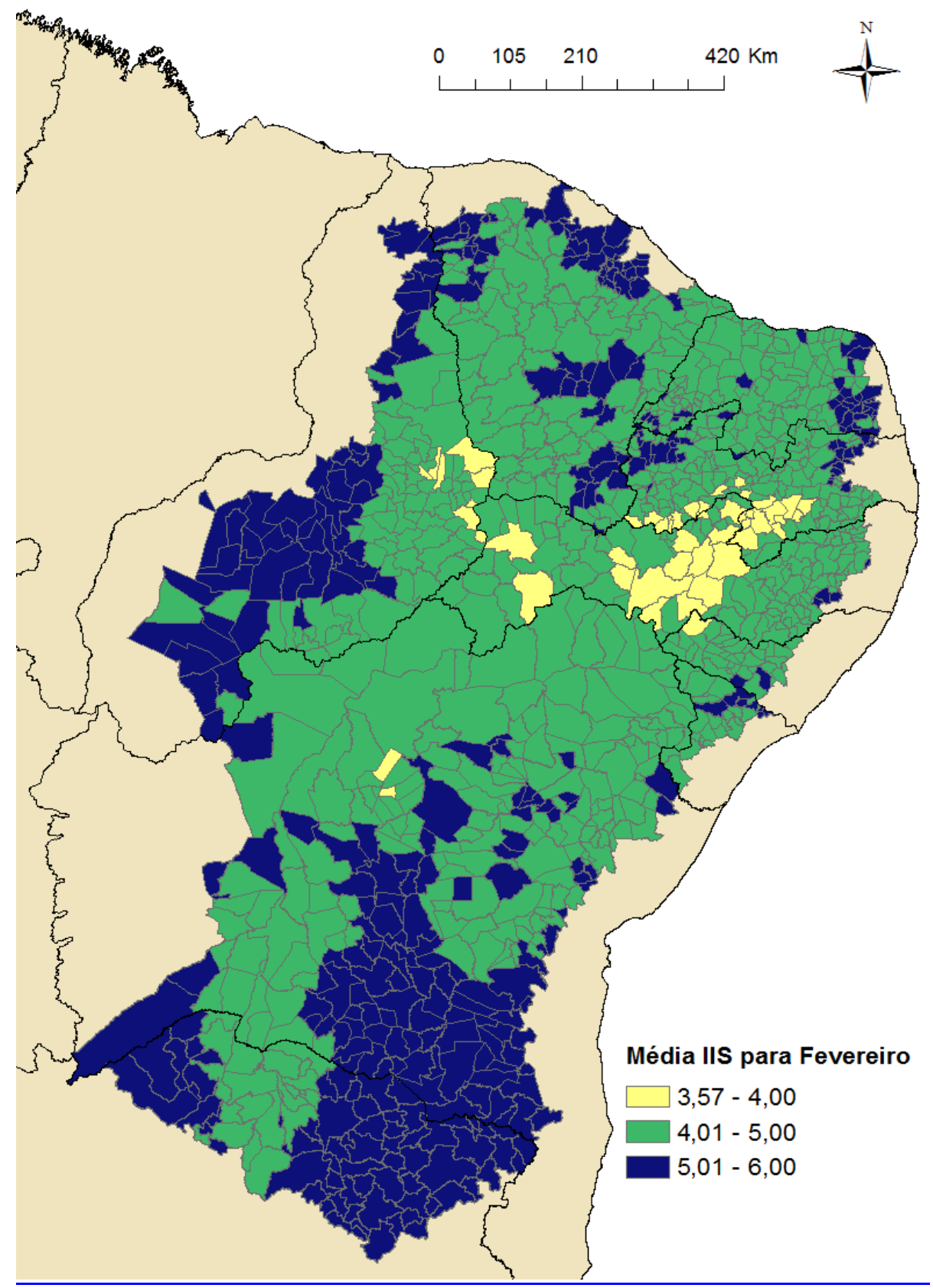

Figura A2 - Média do índice IIS para Fevereiro (entre 2012 e 2018) 


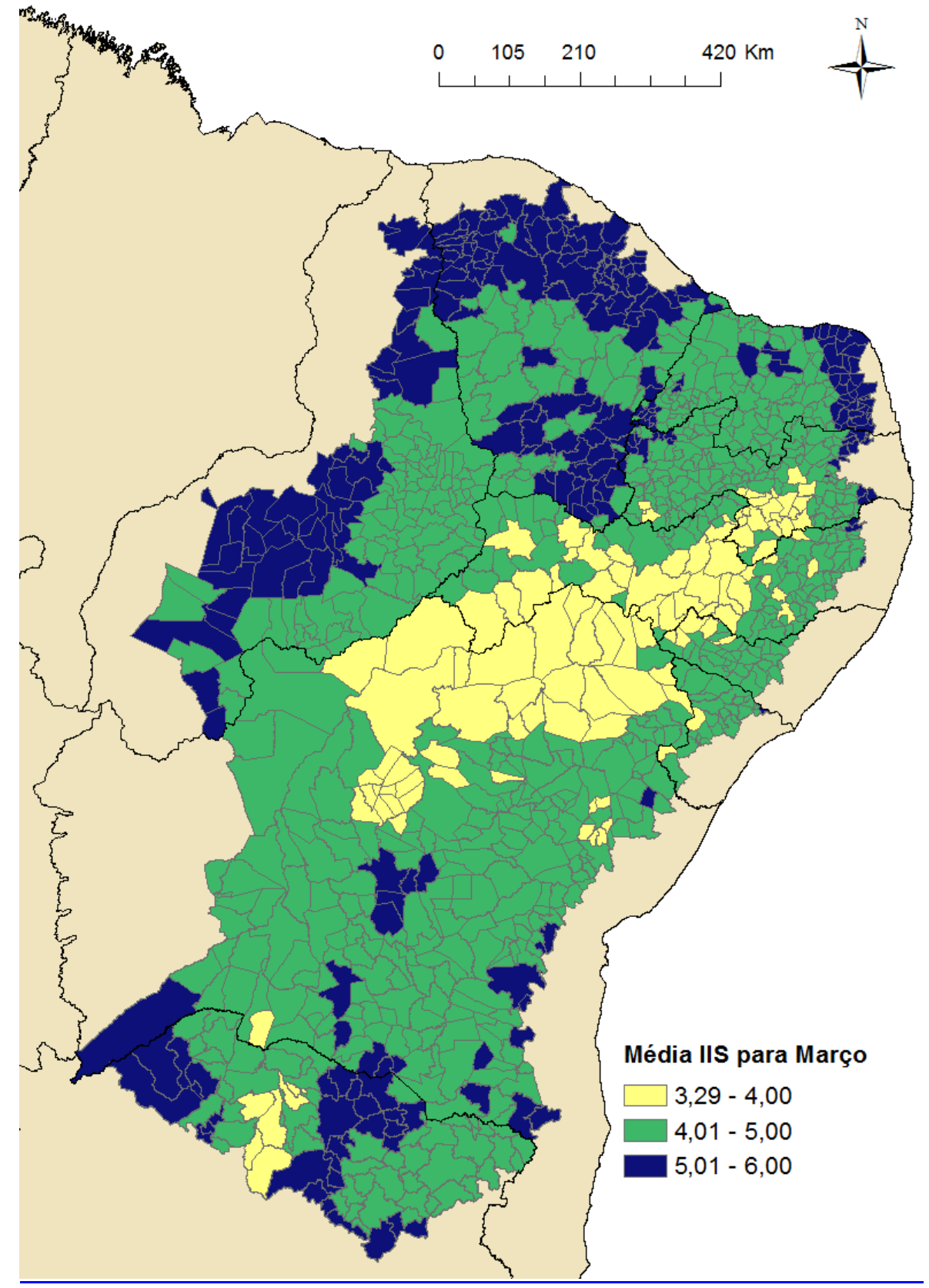

Figura A3 - Média do índice IIS para Março (entre 2012 e 2018) 


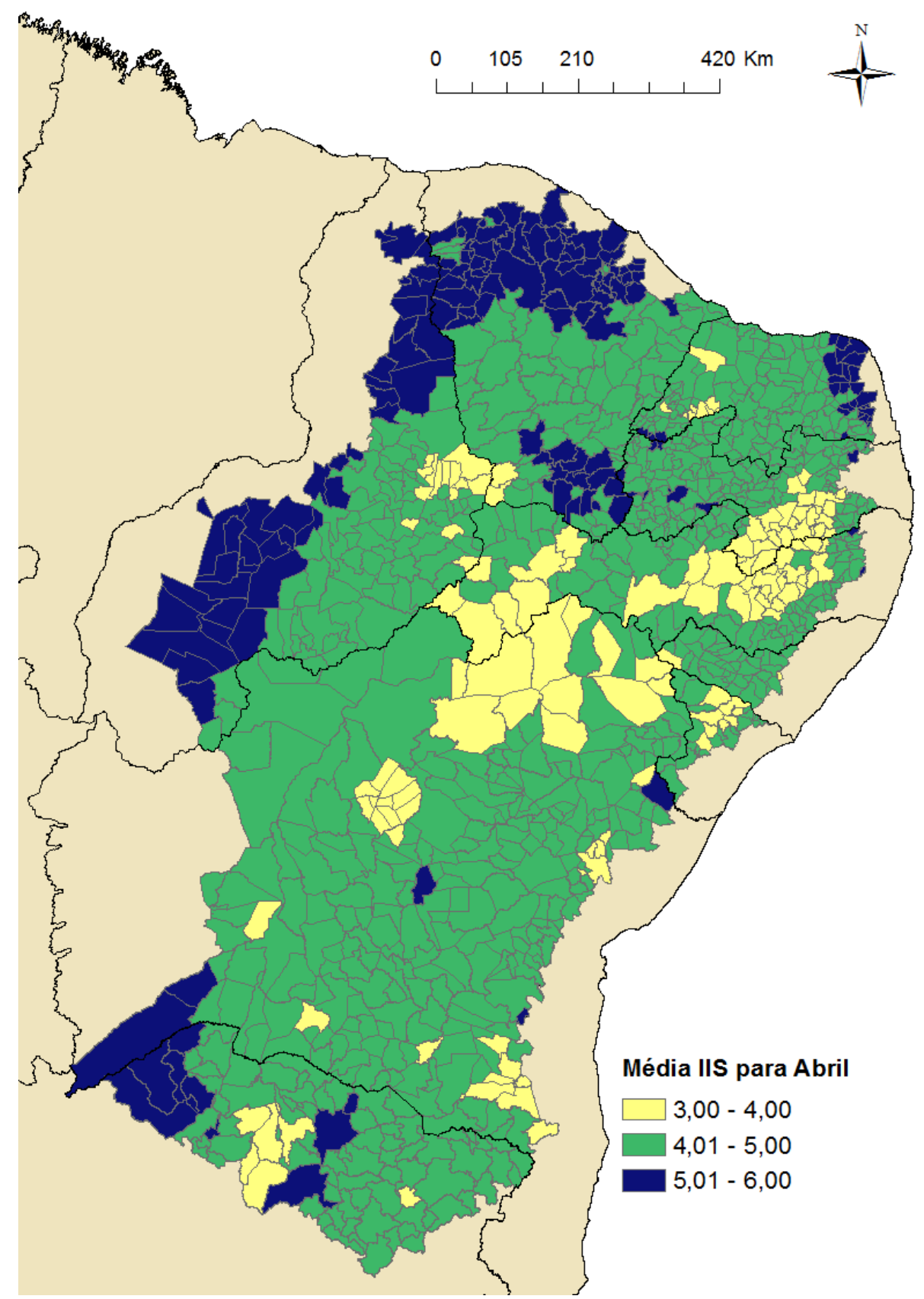

Figura A4 - Média do índice IIS para Abril (entre 2012 e 2018) 


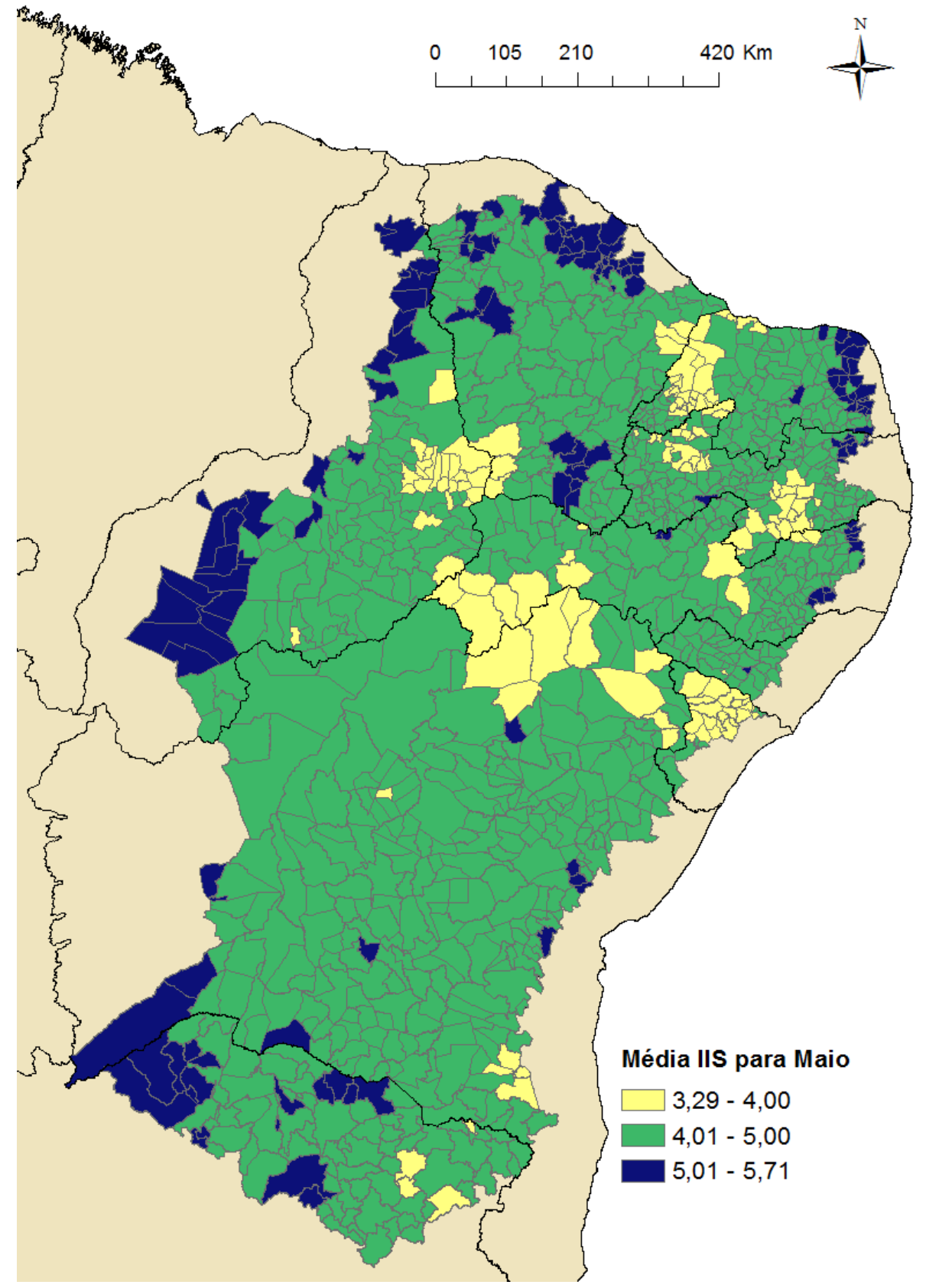

Figura A5 - Média do índice IIS para Maio (entre 2012 e 2018) 


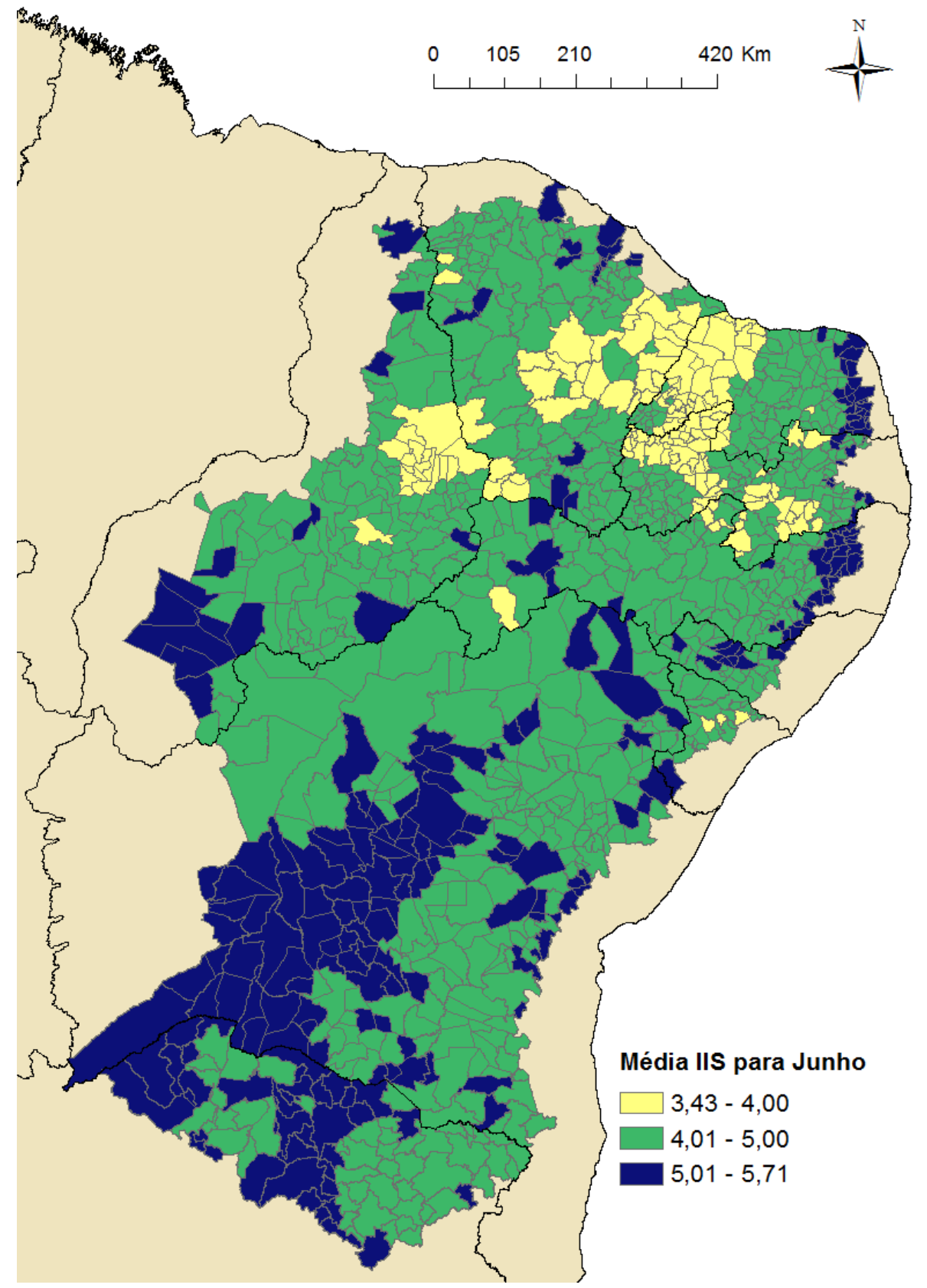

Figura A6 - Média do índice IIS para Junho (entre 2012 e 2018) 


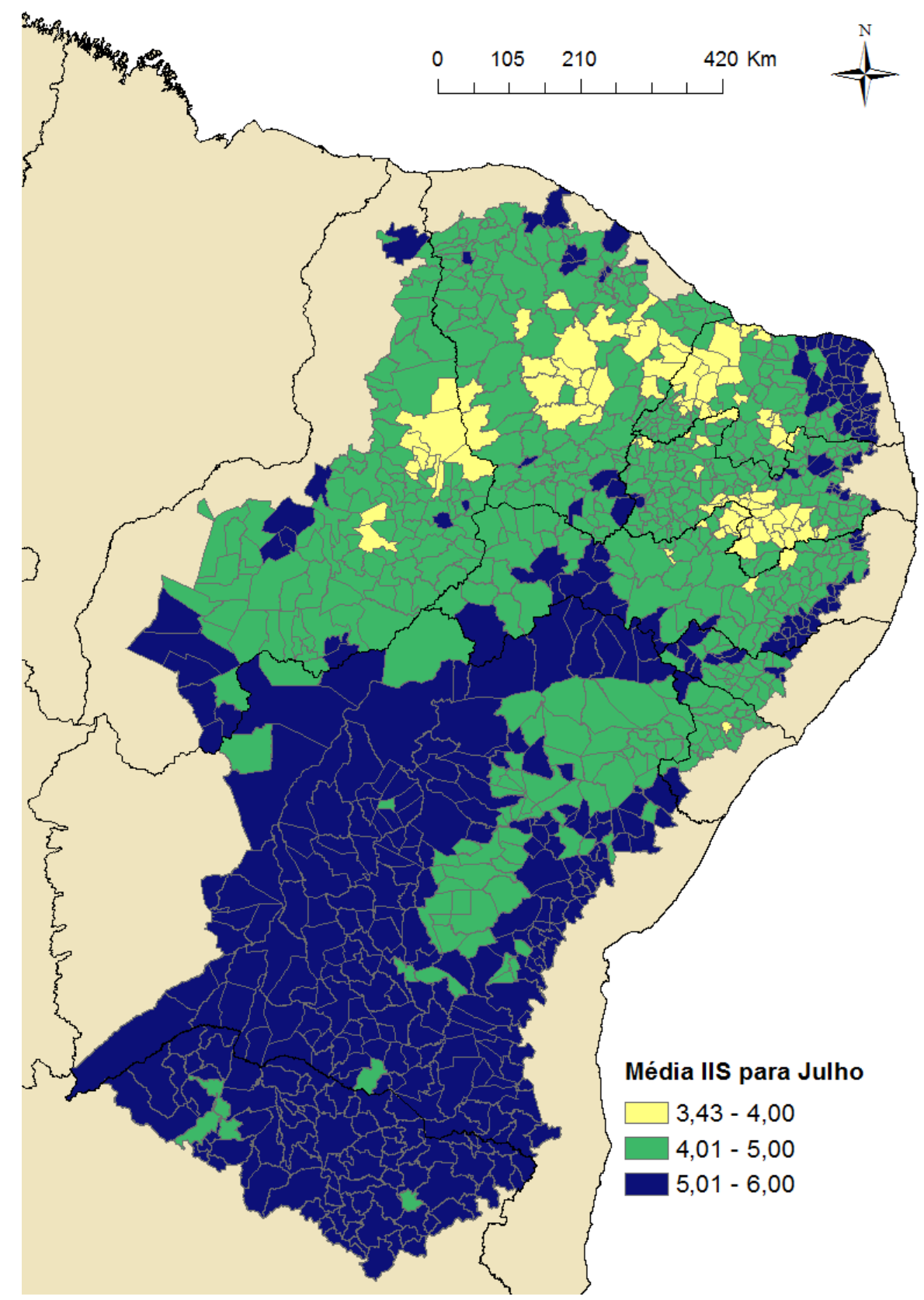

Figura A7 - Média do índice IIS para Julho (entre 2012 e 2018) 


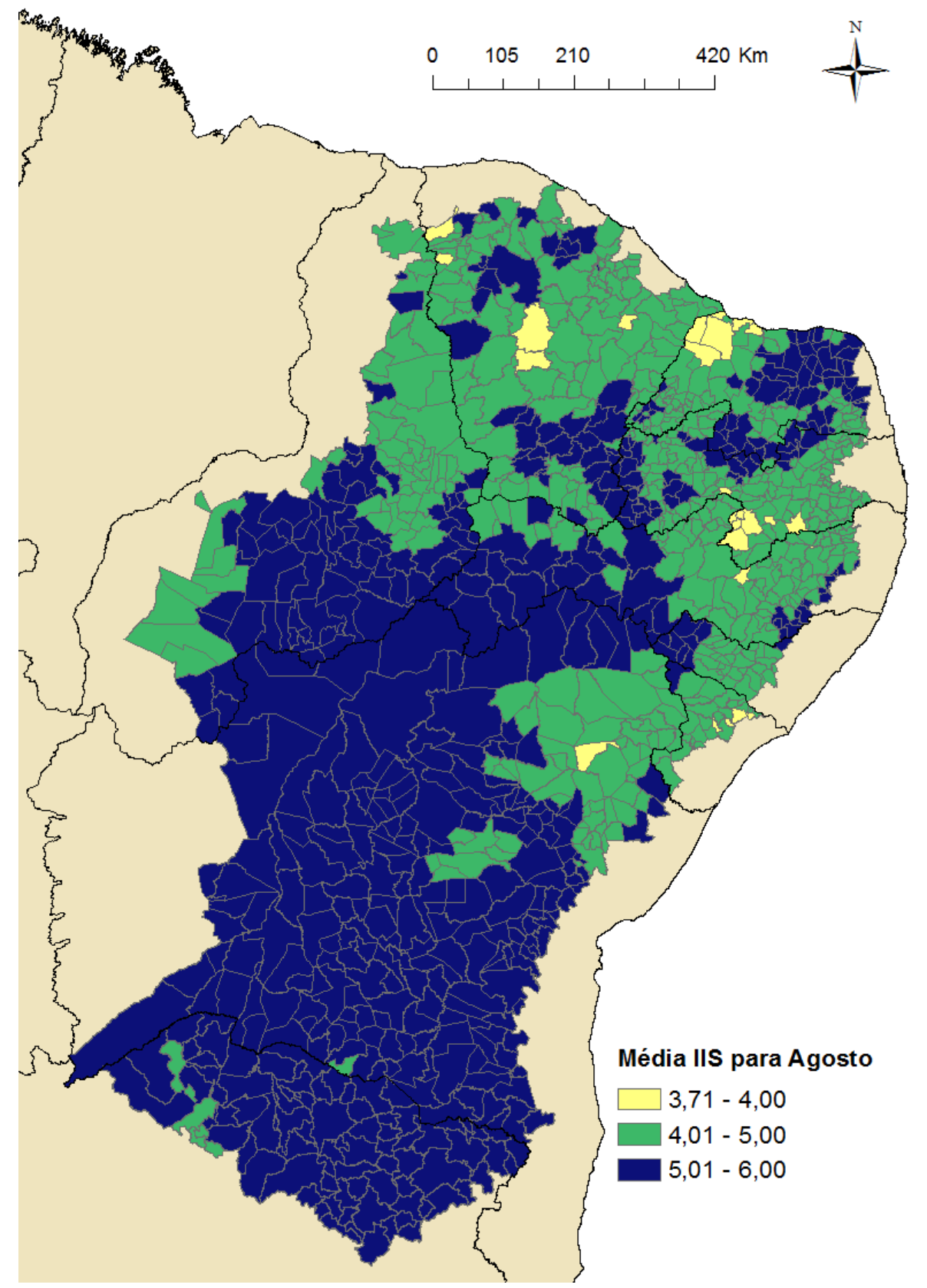

Figura A8 - Média do índice IIS para Agosto (entre 2012 e 2018) 


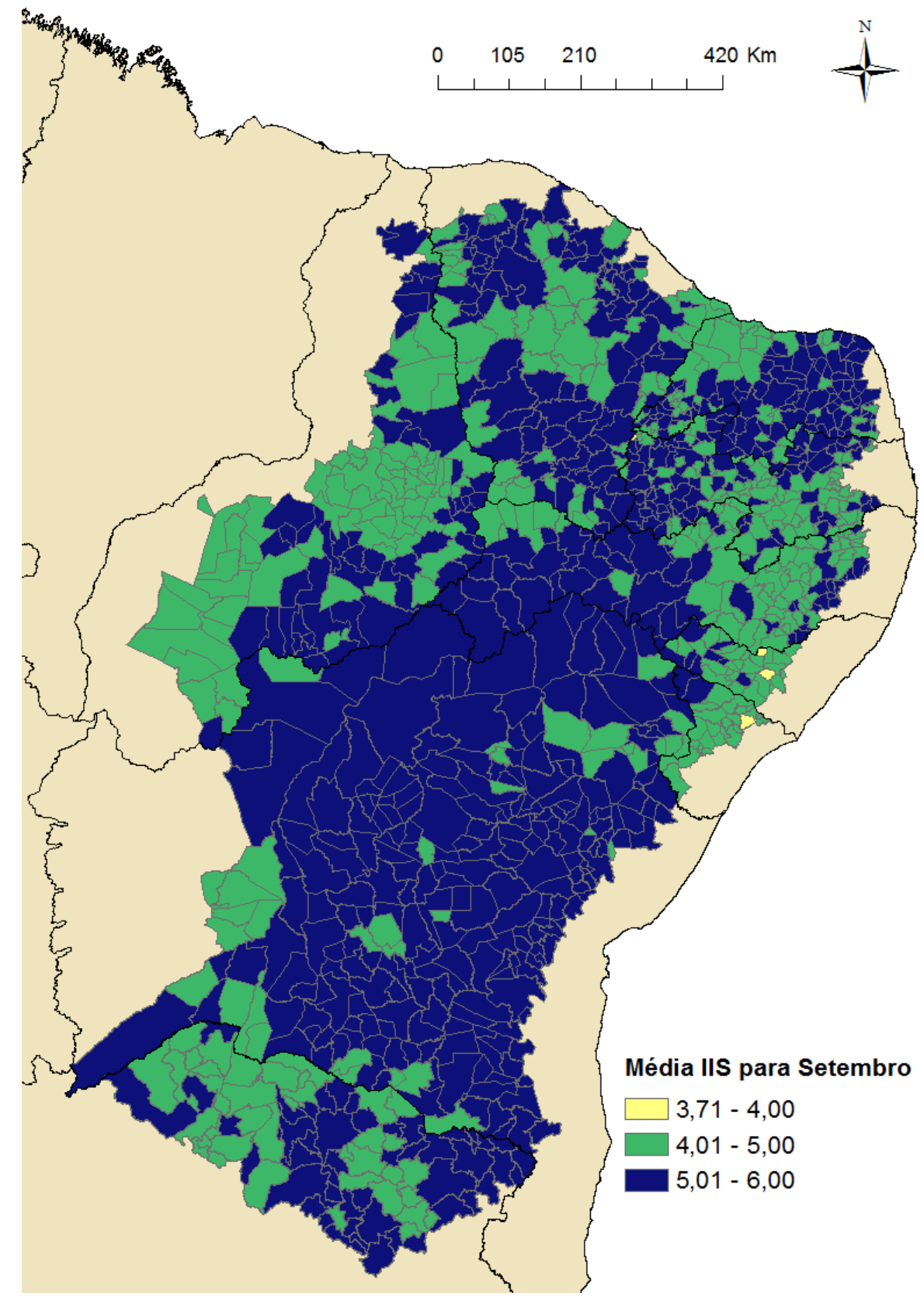

Figura A9 - Média do índice IIS para Setembro (entre 2012 e 2018) 


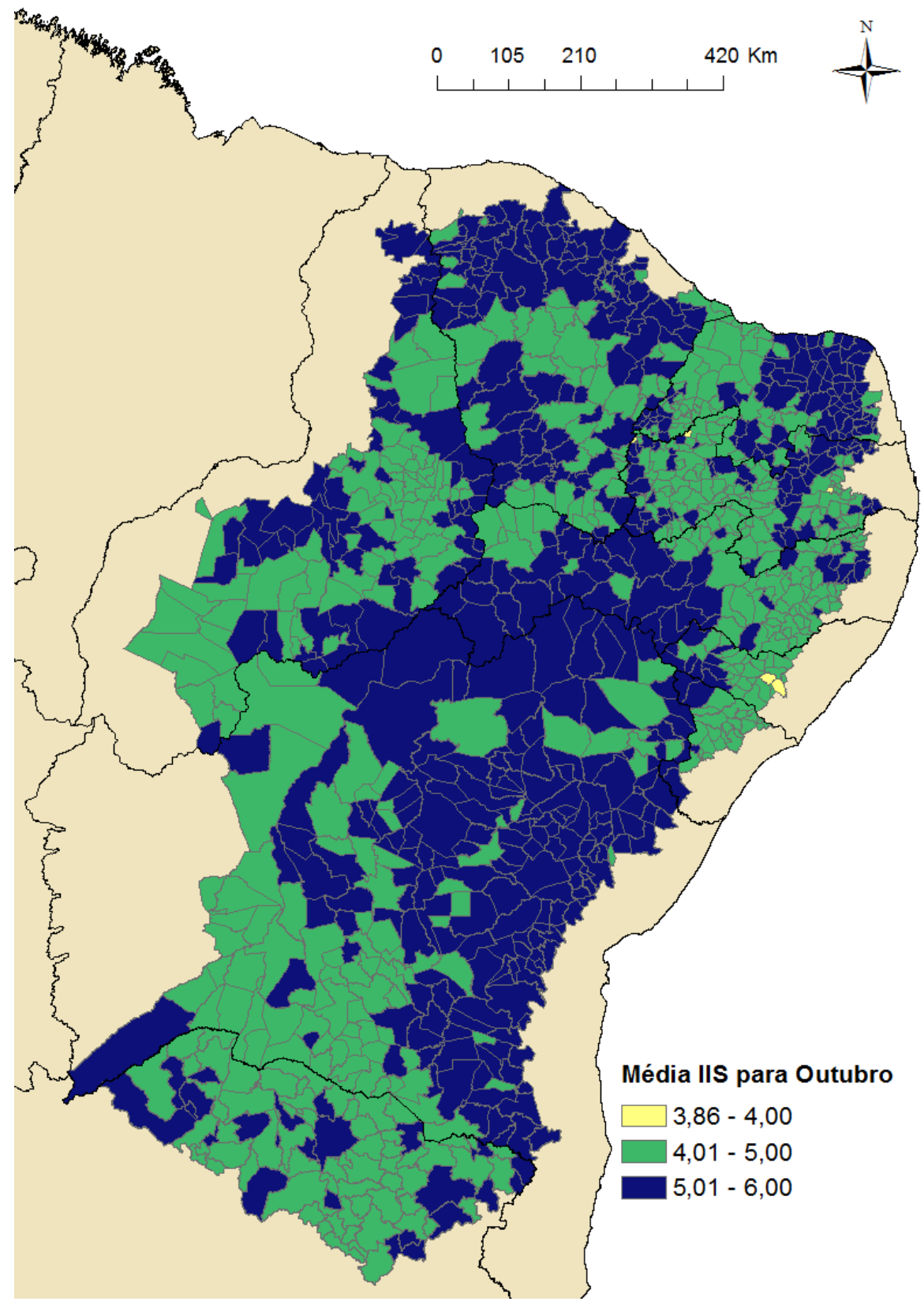

Figura A10 - Média do índice IIS para Outubro (entre 2012 e 2018) 


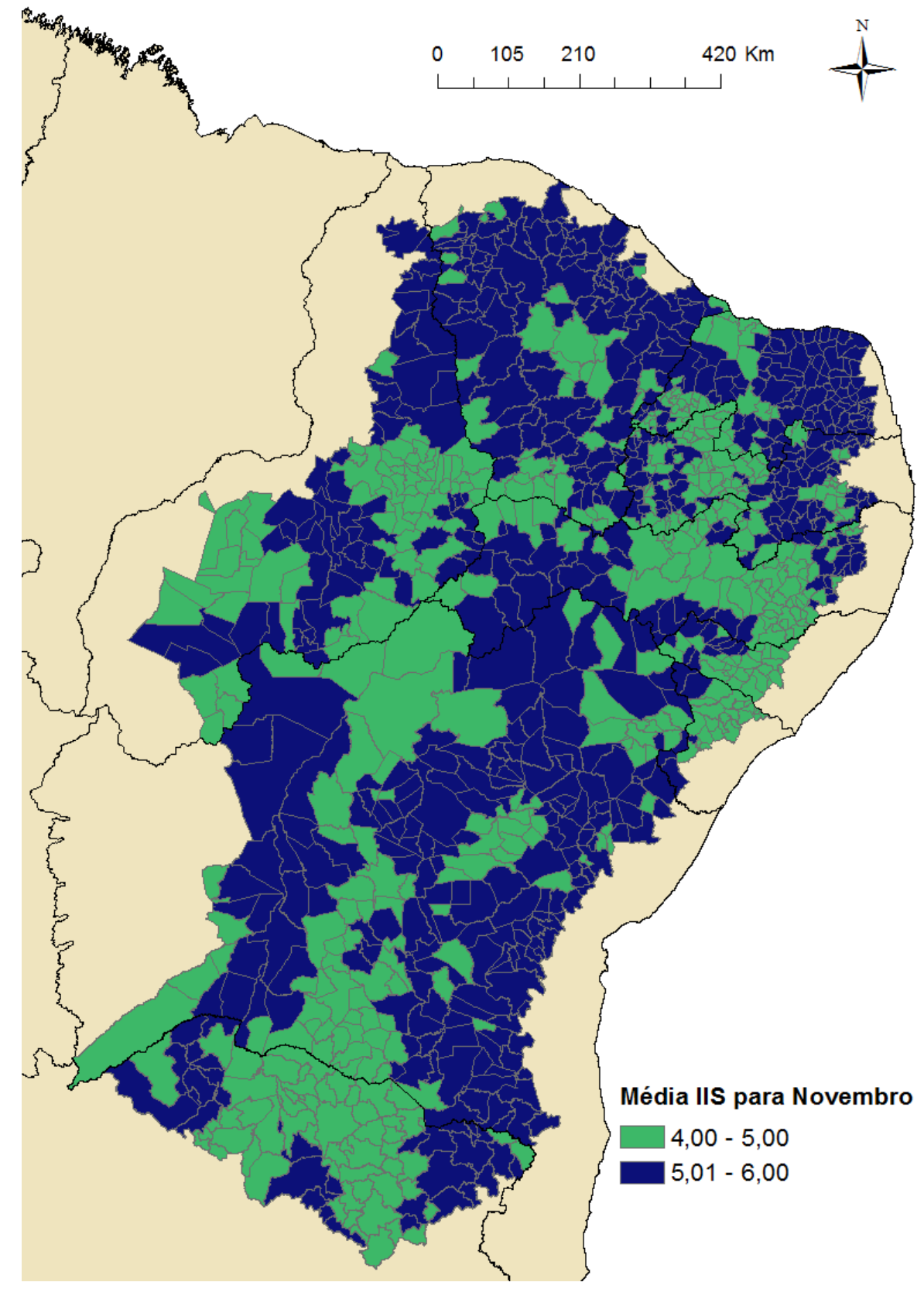

Figura A11 - Média do índice IIS para Novembro (entre 2012 e 2018) 


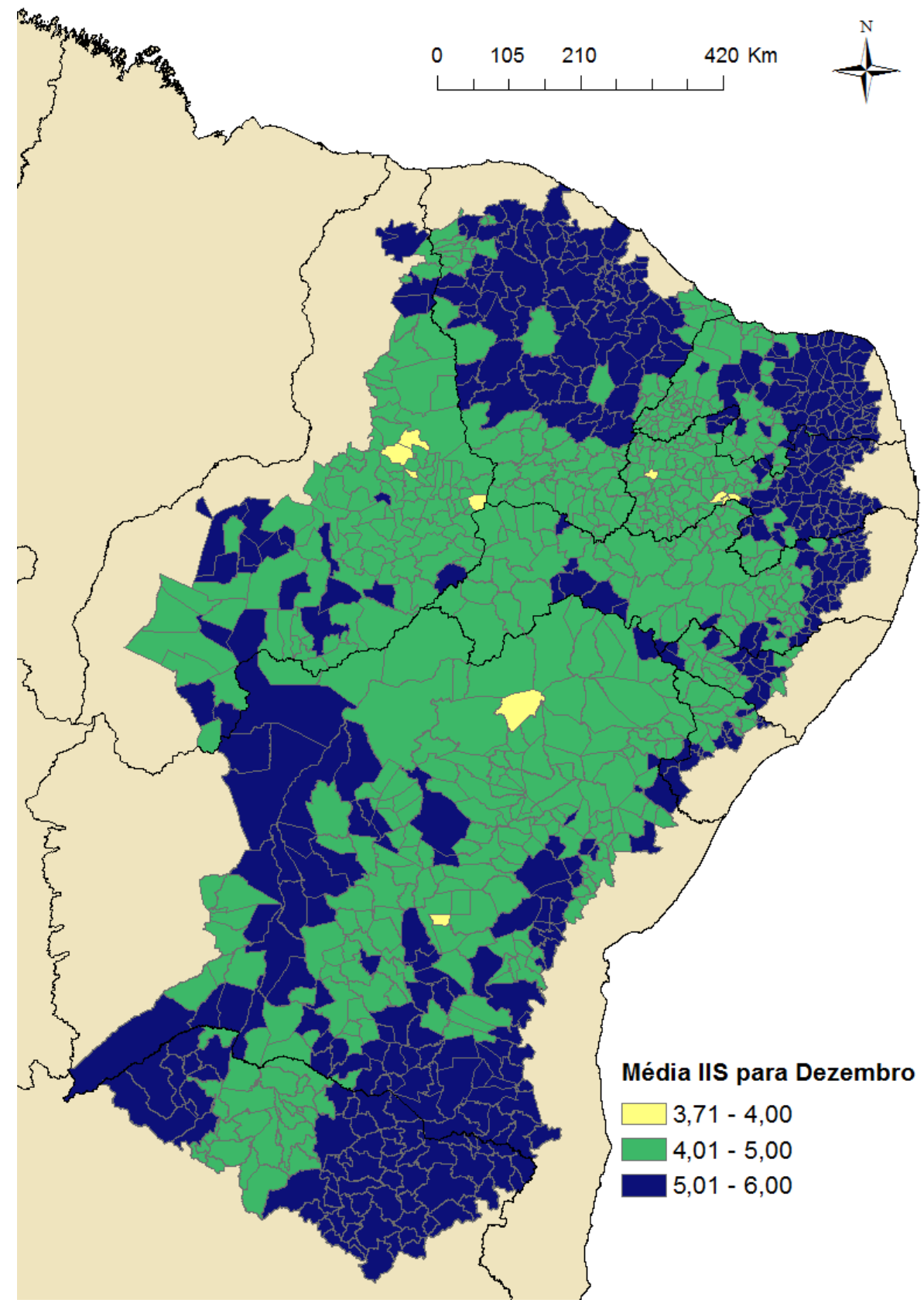

Figura A12 - Média do índice IIS para Dezembro (entre 2012 e 2018) 


\section{Apêndice B - Resultados Extração Regional}

Figura B1-Efeitos para trás relativos

\begin{tabular}{|c|c|c|c|c|c|c|c|c|c|}
\hline \multirow{2}{*}{ Região afetada } & \multicolumn{9}{|c|}{ Região extraída } \\
\hline & SA PI & SACE & SA RN & SA PB & SA PE & SA AL & SA SE & SA BA & SA MG \\
\hline MA & 0,90 & 0,72 & 0,69 & 0,47 & 0,58 & 0,37 & 0,41 & 0,49 & 0,38 \\
\hline SA PI & 7,79 & 0,08 & 0,07 & 0,05 & 0,08 & 0,04 & 0,05 & 0,06 & 0,03 \\
\hline Resto PI & 0,51 & 0,33 & 0,23 & 0,18 & 0,23 & 0,14 & 0,16 & 0,17 & 0,12 \\
\hline SA CE & 0,50 & 12,16 & 0,85 & 0,58 & 0,53 & 0,27 & 0,32 & 0,34 & 0,18 \\
\hline Resto CE & 1,20 & 4,06 & 1,94 & 1,13 & 0,98 & 0,61 & 0,67 & 0,61 & 0,40 \\
\hline SA RN & 0,33 & 0,66 & 14,17 & 0,63 & 0,43 & 0,26 & 0,30 & 0,25 & 0,16 \\
\hline Resto RN & 0,21 & 0,34 & 1,45 & 0,47 & 0,34 & 0,21 & 0,22 & 0,16 & 0,10 \\
\hline SA PB & 0,17 & 0,28 & 0,44 & 10,41 & 0,40 & 0,20 & 0,21 & 0,16 & 0,10 \\
\hline Resto PB & 0,19 & 0,32 & 0,68 & 0,70 & 0,49 & 0,26 & 0,26 & 0,19 & 0,12 \\
\hline SA PE & 0,39 & 0,41 & 0,46 & 0,56 & 11,59 & 0,53 & 0,48 & 0,43 & 0,17 \\
\hline Resto PE & 1,32 & 1,67 & 2,89 & 2,80 & 3,72 & 2,22 & 1,91 & 1,27 & 0,73 \\
\hline SA AL & 0,06 & 0,06 & 0,08 & 0,09 & 0,19 & 10,03 & 0,20 & 0,10 & 0,05 \\
\hline Resto Al & 0,27 & 0,30 & 0,55 & 0,43 & 0,74 & 0,96 & 0,60 & 0,35 & 0,19 \\
\hline SA SE & 0,07 & 0,08 & 0,08 & 0,10 & 0,14 & 0,22 & 13,12 & 0,13 & 0,06 \\
\hline Resto SE & 0,30 & 0,29 & 0,48 & 0,33 & 0,49 & 0,67 & 1,27 & 0,46 & 0,22 \\
\hline SA BA & 0,62 & 0,64 & 0,61 & 0,60 & 0,99 & 0,69 & 0,99 & 13,85 & 0,71 \\
\hline Leste BA & 2,52 & 2,31 & 2,84 & 2,10 & 2,90 & 2,76 & 3,87 & 5,08 & 2,42 \\
\hline Oeste BA & 0,16 & 0,10 & 0,12 & 0,08 & 0,11 & 0,08 & 0,08 & 0,18 & 0,13 \\
\hline SA MG & 0,06 & 0,06 & 0,06 & 0,05 & 0,07 & 0,05 & 0,06 & 0,13 & 10,00 \\
\hline Resto MG & 2,56 & 2,23 & 2,32 & 1,90 & 2,39 & 1,82 & 2,18 & 3,18 & 4,47 \\
\hline Resto do Brasil & 24,14 & 20,58 & 22,87 & 17,53 & 21,22 & 16,36 & 19,50 & 25,20 & 29,00 \\
\hline Soma & 44,26 & 47,67 & 53,87 & 41,18 & 48,64 & 38,74 & 46,86 & 52,80 & 49,73 \\
\hline
\end{tabular}

Figura B2-Efeitos para frente relativos

\begin{tabular}{|c|c|c|c|c|c|c|c|c|c|}
\hline \multirow{2}{*}{ Região afetada } & \multicolumn{9}{|c|}{ Região extraída } \\
\hline & SA PI & SA CE & SA RN & SA PB & SA PE & SA AL & SA SE & SA BA & SA MG \\
\hline MA & 0,71 & 0,58 & $\quad 0,82$ & 0,43 & 0,46 & 0,43 & 0,57 & 0,43 & 0,38 \\
\hline SA PI & 7,79 & 0,08 & 0,09 & 0,06 & 0,08 & 0,06 & 0,09 & 0,06 & 0,04 \\
\hline Resto PI & 0,45 & 0,30 & 0,34 & 0,19 & 0,23 & 0,19 & 0,25 & 0,19 & 0,14 \\
\hline SA CE & 0,49 & 12,16 & 1,11 & 0,65 & 0,50 & 0,38 & 0,65 & 0,40 & 0,24 \\
\hline Resto CE & 0,78 & 3,07 & 2,28 & 0,76 & 0,62 & 0,49 & 0,59 & 0,46 & 0,33 \\
\hline SA RN & 0,25 & 0,51 & 14,17 & 0,60 & 0,33 & 0,30 & 0,38 & 0,23 & 0,16 \\
\hline Resto RN & 0,18 & 0,30 & 1,23 & 0,45 & 0,30 & 0,27 & 0,27 & 0,17 & 0,11 \\
\hline SA PB & 0,14 & 0,25 & 0,46 & 10,41 & 0,30 & 0,23 & 0,34 & 0,16 & 0,09 \\
\hline Resto PB & 0,22 & 0,30 & 0,80 & 0,85 & 0,42 & 0,43 & 0,38 & 0,22 & 0,15 \\
\hline SA PE & 0,43 & 0,44 & 0,59 & 0,77 & 11,59 & 0,93 & 0,90 & 0,51 & 0,24 \\
\hline Resto PE & 1,17 & 1,29 & 2,87 & 2,49 & 2,61 & 2,57 & 2,19 & 1,13 & 0,75 \\
\hline SA AL & 0,04 & 0,04 & 0,07 & 0,08 & 0,11 & 10,03 & 0,29 & 0,07 & 0,04 \\
\hline Resto Al & 0,24 & 0,23 & 0,40 & 0,34 & 0,46 & 1,19 & 0,80 & 0,31 & 0,20 \\
\hline SA SE & 0,04 & 0,04 & 0,06 & 0,06 & 0,07 & 0,15 & 13,12 & 0,08 & 0,03 \\
\hline Resto SE & 0,18 & 0,17 & 0,36 & 0,23 & 0,29 & 0,63 & 1,10 & 0,34 & 0,18 \\
\hline SA BA & 0,57 & 0,55 & 0,67 & 0,60 & 0,84 & 0,92 & 1,66 & 13,85 & 0,85 \\
\hline Leste BA & 1,37 & 1,27 & 3,01 & 1,43 & 1,61 & 2,78 & 3,39 & 3,35 & 2,01 \\
\hline Oeste BA & 0,17 & 0,10 & 0,13 & 0,10 & 0,10 & 0,15 & 0,17 & 0,20 & 0,18 \\
\hline SA MG & 0,05 & 0,04 & 0,06 & 0,05 & 0,05 & 0,06 & 0,11 & 0,10 & 10,00 \\
\hline Resto MG & 1,91 & 1,53 & 2,28 & 1,58 & 1,63 & 2,21 & 2,96 & 2,58 & 4,52 \\
\hline Resto do Brasil & 14,19 & 11,84 & 18,28 & 11,25 & 11,63 & 14,68 & 19,57 & 16,54 & 22,06 \\
\hline Soma & 31,36 & 35,11 & 50,08 & 33,39 & 34,23 & 39,08 & 49,77 & 41,37 & 42,71 \\
\hline
\end{tabular}




\section{Apêndice C - Resultados Regressões}

Tabela C1 - Regressão IIS Mensal: Rendimento Médio Feijão

\begin{tabular}{|c|c|c|c|}
\hline \multirow{3}{*}{ Variáveis } & (1) & $(2)$ & $(3)$ \\
\hline & $\mathrm{RM}$ & RM & RM \\
\hline & Feijão & Feijão & Feijão \\
\hline \multirow[t]{2}{*}{ IIS Janeiro } & -44.31 & $142.8^{*}$ & 113.3 \\
\hline & (133.6) & $(70.76)$ & (66.09) \\
\hline \multirow[t]{2}{*}{ IIS Fevereiro } & -9.504 & -50.87 & $-72.32 *$ \\
\hline & $(62.67)$ & (39.31) & (31.76) \\
\hline \multirow[t]{2}{*}{ IIS Março } & -13.63 & -45.59 & $-45.61 *$ \\
\hline & (35.71) & $(27.34)$ & (23.79) \\
\hline \multirow[t]{2}{*}{ IIS Abril } & 4.049 & 0.651 & 41.16 \\
\hline & $(32.32)$ & $(31.40)$ & (32.69) \\
\hline \multirow[t]{2}{*}{ IIS Maio } & 13.54 & 17.56 & -0.921 \\
\hline & $(50.96)$ & $(26.38)$ & (26.96) \\
\hline \multirow[t]{2}{*}{ IIS Junho } & -14.77 & 14.75 & -12.62 \\
\hline & $(28.17)$ & (19.85) & (15.55) \\
\hline \multirow[t]{2}{*}{ IIS Julho } & -26.90 & -0.965 & -26.91 \\
\hline & $(36.06)$ & $(25.92)$ & $(27.01)$ \\
\hline \multirow[t]{2}{*}{ IIS Agosto } & 20.95 & $78.46 * *$ & 40.75 \\
\hline & $(29.13)$ & $(27.27)$ & $(23.32)$ \\
\hline \multirow[t]{2}{*}{ IIS Setembro } & 28.75 & $-51.29 *$ & -35.75 \\
\hline & (34.13) & $(26.16)$ & $(23.98)$ \\
\hline \multirow[t]{2}{*}{ IIS Outubro } & -32.28 & 32.04 & 15.99 \\
\hline & $(52.50)$ & (38.14) & (39.77) \\
\hline \multirow[t]{3}{*}{ IIS Novembro } & -45.86 & 29.57 & 61.24 \\
\hline & $(84.05)$ & $(52.02)$ & (39.08) \\
\hline & & - & \\
\hline \multirow[t]{2}{*}{ IIS Dezembro } & 4.811 & $49.27 * * *$ & -1.273 \\
\hline & (38.69) & (9.779) & $(19.80)$ \\
\hline \multirow[t]{2}{*}{ IIS Janeiro 2} & 5.051 & $-15.17^{*}$ & -12.20 \\
\hline & $(14.02)$ & $(6.883)$ & (6.791) \\
\hline \multirow[t]{2}{*}{ IIS Fevereiro 2} & 4.685 & 8.676 & $9.626 * *$ \\
\hline & $(6.062)$ & $(5.129)$ & (3.794) \\
\hline \multirow[t]{2}{*}{ IIS Março 2} & 0.282 & 4.760 & 5.453 \\
\hline & $(4.254)$ & $(3.316)$ & (3.061) \\
\hline \multirow[t]{2}{*}{ IIS Abril 2} & -0.918 & -0.167 & -3.990 \\
\hline & $(3.028)$ & (3.793) & $(4.406)$ \\
\hline \multirow[t]{2}{*}{ IIS Maio 2} & -1.946 & -1.228 & 1.087 \\
\hline & $(5.567)$ & $(2.870)$ & $(2.625)$ \\
\hline \multirow[t]{2}{*}{ IIS Junho 2} & 5.705 & 1.643 & 2.224 \\
\hline & (3.529) & $(2.746)$ & (2.195) \\
\hline \multirow[t]{2}{*}{ IIS Julho 2} & 5.405 & -0.819 & 3.743 \\
\hline & $(5.121)$ & $(3.070)$ & $(2.854)$ \\
\hline \multirow[t]{2}{*}{ IIS Agosto 2} & 1.014 & -5.873 & -1.228 \\
\hline & $(4.790)$ & (3.457) & (2.133) \\
\hline
\end{tabular}




\begin{tabular}{|c|c|c|c|}
\hline IIS Setembro 2 & $\begin{array}{l}-4.711 \\
(4.650)\end{array}$ & $\begin{array}{c}4.894 \\
(3.218)\end{array}$ & $\begin{array}{c}3.363 \\
(2.809)\end{array}$ \\
\hline \multirow[t]{2}{*}{ IIS Outubro 2} & 3.630 & -2.683 & -1.591 \\
\hline & $(5.814)$ & $(4.100)$ & $(4.224)$ \\
\hline \multirow[t]{2}{*}{ IIS Novembro 2} & 5.516 & -1.644 & -5.269 \\
\hline & $(9.078)$ & (6.009) & $(4.741)$ \\
\hline \multirow[t]{2}{*}{ IIS Dezembro 2} & 0.0471 & $6.391 * * *$ & 1.846 \\
\hline & $(4.743)$ & $(1.407)$ & $(2.237)$ \\
\hline \multirow[t]{2}{*}{ Desvio IIS Janeiro } & 14.23 & -0.0231 & -1.136 \\
\hline & $(13.03)$ & (8.955) & (6.183) \\
\hline \multirow[t]{2}{*}{ Desvio IIS Fevereiro } & -12.97 & -0.384 & 2.924 \\
\hline & $(9.375)$ & $(2.849)$ & $(4.764)$ \\
\hline \multirow[t]{2}{*}{ Desvio IIS Março } & -13.20 & 3.856 & 0.873 \\
\hline & $(12.49)$ & $(6.046)$ & (5.929) \\
\hline \multirow[t]{2}{*}{ Desvio IIS Abril } & -15.39 & -2.419 & -6.981 \\
\hline & $(12.41)$ & (4.966) & (4.547) \\
\hline \multirow[t]{2}{*}{ Desvio IIS Maio } & $42.51^{*}$ & -7.462 & -2.451 \\
\hline & $(18.73)$ & (7.926) & (7.349) \\
\hline \multirow[t]{2}{*}{ Desvio IIS Junho } & $-26.90 *$ & 5.890 & 8.326 \\
\hline & $(14.43)$ & $(9.572)$ & $(10.05)$ \\
\hline \multirow[t]{2}{*}{ Desvio IIS Julho } & 3.461 & 3.019 & -1.422 \\
\hline & (18.59) & (8.049) & (7.900) \\
\hline \multirow[t]{2}{*}{ Desvio IIS Agosto } & 11.70 & -1.020 & -1.403 \\
\hline & $(7.481)$ & $(6.687)$ & $(6.472)$ \\
\hline \multirow[t]{2}{*}{ Desvio IIS Setembro } & -3.153 & 5.694 & 4.511 \\
\hline & $(15.64)$ & $(5.071)$ & (4.151) \\
\hline \multirow[t]{2}{*}{ Desvio IIS Outubro } & $20.54 * *$ & -4.372 & -3.912 \\
\hline & $(6.812)$ & $(2.902)$ & $(4.620)$ \\
\hline \multirow[t]{2}{*}{ Desvio IIS Novembro } & $-21.88 * *$ & 7.319 & 6.358 \\
\hline & $(7.551)$ & $(6.048)$ & (6.265) \\
\hline \multirow[t]{2}{*}{ Desvio IIS Dezembro } & -1.330 & -2.734 & -0.769 \\
\hline & $(7.213)$ & $(8.490)$ & $(7.720)$ \\
\hline \multirow[t]{2}{*}{ Constant } & 276.7 & -398.4 & -365.2 \\
\hline & (219.6) & $(358.1)$ & $(464.2)$ \\
\hline Observations & 7,922 & 7,922 & 7,922 \\
\hline EF de Município & Não & Sim & Sim \\
\hline EF de Ano & Não & Sim & Não \\
\hline EF de Estado-Ano & Não & Não & Sim \\
\hline R-squared & 0.079 & 0.607 & 0.639 \\
\hline
\end{tabular}

Robust standard errors in parentheses

*** $\mathrm{p}<0.01, * * \mathrm{p}<0.05, * \mathrm{p}<0.1$

Tabela C2 - Regressão IIS Mensal: Rendimento Médio Mandioca

\begin{tabular}{cccc}
\hline & $(1)$ & $(2)$ & $(3)$ \\
Variáveis & RM & RM & RM \\
& Mandioca & Mandioca & Mandioca \\
\hline
\end{tabular}




\begin{tabular}{|c|c|c|c|}
\hline IIS Janeiro & $\begin{array}{c}-3,788 \\
(2,292)\end{array}$ & $\begin{array}{c}-1,565 \\
(1,547)\end{array}$ & $\begin{array}{l}-338.9 \\
(1,345)\end{array}$ \\
\hline \multirow[t]{2}{*}{ IIS Fevereiro } & 328.6 & 714.3 & -333.8 \\
\hline & (852.1) & $(788.2)$ & (735.4) \\
\hline \multirow[t]{2}{*}{ IIS Março } & 6.283 & -180.6 & 125.5 \\
\hline & $(433.2)$ & (476.6) & (435.5) \\
\hline \multirow[t]{2}{*}{ IIS Abril } & 300.5 & -66.96 & 613.6 \\
\hline & (338.8) & $(439.2)$ & (341.1) \\
\hline \multirow[t]{2}{*}{ IIS Maio } & -554.1 & 106.1 & 470.2 \\
\hline & $(573.0)$ & (332.3) & (341.7) \\
\hline \multirow[t]{2}{*}{ IIS Junho } & -100.2 & -73.85 & -519.9 \\
\hline & $(400.0)$ & (433.3) & $(467.8)$ \\
\hline \multirow[t]{2}{*}{ IIS Julho } & 182.1 & -453.0 & $-715.6 * *$ \\
\hline & $(257.3)$ & (298.9) & (250.9) \\
\hline \multirow[t]{2}{*}{ IIS Agosto } & -255.8 & $1,424^{*}$ & 376.8 \\
\hline & $(546.3)$ & (753.2) & (389.1) \\
\hline \multirow[t]{2}{*}{ IIS Setembro } & 994.7 & -531.2 & 7.688 \\
\hline & $(626.2)$ & (396.9) & (307.2) \\
\hline \multirow[t]{2}{*}{ IIS Outubro } & -346.5 & 695.2 & 232.0 \\
\hline & (627.9) & (621.9) & (247.4) \\
\hline \multirow[t]{2}{*}{ IIS Novembro } & $-1,245$ & -428.0 & 207.9 \\
\hline & $(802.0)$ & $(426.7)$ & (302.0) \\
\hline \multirow[t]{2}{*}{ IIS Dezembro } & $-1,199 * * *$ & $-1,007 * * *$ & -544.8 \\
\hline & (330.4) & $(261.7)$ & (428.6) \\
\hline \multirow[t]{2}{*}{ IIS Janeiro 2} & 416.4 & 120.0 & -9.066 \\
\hline & $(226.2)$ & (156.1) & (138.9) \\
\hline \multirow[t]{2}{*}{ IIS Fevereiro 2} & 25.55 & -32.27 & 47.06 \\
\hline & $(88.54)$ & (92.16) & (76.25) \\
\hline \multirow[t]{2}{*}{ IIS Março 2} & -8.276 & 23.00 & 3.327 \\
\hline & (49.35) & $(56.74)$ & $(50.90)$ \\
\hline \multirow[t]{2}{*}{ IIS Abril 2} & -58.60 & -19.17 & -71.85 \\
\hline & $(43.17)$ & $(48.87)$ & $(42.27)$ \\
\hline \multirow[t]{2}{*}{ IIS Maio 2} & 62.92 & 5.626 & -39.56 \\
\hline & (69.38) & $(40.75)$ & (39.42) \\
\hline \multirow[t]{2}{*}{ IIS Junho 2} & 44.87 & 37.38 & 65.67 \\
\hline & (39.51) & (44.92) & $(53.50)$ \\
\hline \multirow[t]{2}{*}{ IIS Julho 2} & 21.90 & 38.57 & $87.95 * *$ \\
\hline & (34.21) & $(32.25)$ & $(29.13)$ \\
\hline \multirow[t]{2}{*}{ IIS Agosto 2} & 57.09 & -121.8 & -13.42 \\
\hline & $(72.94)$ & $(82.24)$ & $(29.28)$ \\
\hline \multirow[t]{2}{*}{ IIS Setembro 2} & -138.5 & 39.70 & -13.43 \\
\hline & (82.10) & $(36.38)$ & $(35.43)$ \\
\hline \multirow[t]{2}{*}{ IIS Outubro 2} & 64.14 & -58.83 & -23.80 \\
\hline & (66.59) & $(53.78)$ & (31.83) \\
\hline IIS Novembro 2 & $141.1^{*}$ & $69.35^{*}$ & -2.992 \\
\hline & (71.19) & (33.12) & (34.38) \\
\hline IIS Dezembro 2 & $114.4 * *$ & $101.1^{* * *}$ & 63.00 \\
\hline & $(48.20)$ & $(26.26)$ & (44.63) \\
\hline Desvio IIS Janeiro & 150.4 & -116.8 & -93.91 \\
\hline & $(127.1)$ & $(134.4)$ & (94.20) \\
\hline Desvio IIS Fevereiro & -148.5 & -127.8 & 82.55 \\
\hline
\end{tabular}




\begin{tabular}{|c|c|c|c|}
\hline & (229.1) & $(166.5)$ & $(114.2)$ \\
\hline \multirow[t]{2}{*}{ Desvio IIS Março } & -154.9 & 123.6 & -28.31 \\
\hline & $(183.2)$ & $(169.3)$ & (120.1) \\
\hline \multirow[t]{2}{*}{ Desvio IIS Abril } & 95.05 & 146.3 & 48.88 \\
\hline & $(131.7)$ & $(115.3)$ & $(126.0)$ \\
\hline \multirow[t]{2}{*}{ Desvio IIS Maio } & 155.2 & -125.1 & -48.65 \\
\hline & $(233.0)$ & $(86.42)$ & (79.98) \\
\hline \multirow[t]{2}{*}{ Desvio IIS Junho } & $-526.7 *$ & 106.9 & 158.0 \\
\hline & (279.7) & $(75.38)$ & (94.54) \\
\hline \multirow[t]{2}{*}{ Desvio IIS Julho } & -25.99 & 83.76 & 96.47 \\
\hline & (197.4) & (93.16) & $(85.15)$ \\
\hline \multirow[t]{2}{*}{ Desvio IIS Agosto } & 297.3 & $-211.7 * *$ & $-187.0 * *$ \\
\hline & $(168.8)$ & (70.06) & $(58.54)$ \\
\hline \multirow[t]{2}{*}{ Desvio IIS Setembro } & -127.8 & 62.16 & 12.18 \\
\hline & $(216.9)$ & $(39.97)$ & $(50.14)$ \\
\hline \multirow[t]{2}{*}{ Desvio IIS Outubro } & 19.27 & -143.9 & -132.0 \\
\hline & $(139.7)$ & $(95.48)$ & $(115.2)$ \\
\hline \multirow[t]{2}{*}{ Desvio IIS Novembro } & -62.17 & 13.14 & 75.02 \\
\hline & $(104.6)$ & $(126.9)$ & $(118.4)$ \\
\hline \multirow[t]{2}{*}{ Desvio IIS Dezembro } & -59.82 & -32.72 & -85.19 \\
\hline & $(141.8)$ & $(118.5)$ & (77.72) \\
\hline \multirow[t]{2}{*}{ Constant } & $15,909 * *$ & 7,886 & 5,111 \\
\hline & $(5,033)$ & $(4,566)$ & $(3,553)$ \\
\hline Observations & 7,922 & 7,922 & 7,922 \\
\hline EF de Município & Não & Sim & Sim \\
\hline EF de Ano & Não & Sim & Não \\
\hline EF de Estado-Ano & Não & Não & Sim \\
\hline R-squared & 0.090 & 0.570 & 0.632 \\
\hline
\end{tabular}

Tabela C3 - Regressão IIS Mensal: Rendimento Médio Milho

\begin{tabular}{lccc}
\hline \multirow{2}{*}{ Variáveis } & $(1)$ & $(2)$ & $(3)$ \\
& RM Milho & RM Milho & RM Milho \\
\hline \multirow{3}{*}{ IIS Janeiro } & & & \\
& -25.07 & -26.01 & 86.86 \\
IIS Fevereiro & $(785.2)$ & $(303.6)$ & $(288.6)$ \\
& 131.1 & -151.6 & $-131.7^{* *}$ \\
IIS Março & $(174.3)$ & $(83.18)$ & $(51.94)$ \\
IIS Abril & 312.5 & 164.4 & 124.6 \\
& $(223.7)$ & $(148.3)$ & $(127.8)$ \\
IIS Maio & 32.80 & -30.86 & -26.76 \\
& $(136.2)$ & $(33.56)$ & $(34.44)$ \\
IIS Junho & 111.6 & 63.88 & 37.34 \\
& $(138.5)$ & $(83.23)$ & $(56.81)$ \\
& -183.8 & -27.92 & -15.86
\end{tabular}


IIS Julho

IIS Agosto

IIS Setembro

IIS Outubro

IIS Novembro

IIS Dezembro

IIS Janeiro 2

IIS Fevereiro 2

IIS Março 2

IIS Abril 2

IIS Maio 2

IIS Junho 2

IIS Julho 2

IIS Agosto 2

IIS Setembro 2

IIS Outubro 2

IIS Novembro 2

IIS Dezembro 2

Desvio IIS Janeiro

Desvio IIS Fevereiro

Desvio IIS Março

Desvio IIS Abril

Desvio IIS Maio

Desvio IIS Junho

Desvio IIS Julho

\begin{tabular}{|c|c|c|}
\hline (119.9) & (94.88) & (103.0) \\
\hline-59.38 & 103.6 & 85.16 \\
\hline (99.04) & (139.1) & (152.7) \\
\hline 224.3 & $324.6^{*}$ & 51.28 \\
\hline (325.9) & (157.5) & (164.4) \\
\hline 261.0 & -72.94 & -47.51 \\
\hline (254.5) & (97.02) & (85.69) \\
\hline-450.3 & 76.67 & -28.56 \\
\hline (315.1) & (100.00) & (71.51) \\
\hline-181.3 & 149.9 & 202.0 \\
\hline$(227.4)$ & (145.0) & (125.2) \\
\hline 183.1 & -76.97 & 122.0 \\
\hline (167.9) & (88.65) & (84.85) \\
\hline 8.519 & 1.965 & -7.047 \\
\hline (76.98) & $(28.25)$ & (27.32) \\
\hline-10.97 & 19.99 & $15.64 *$ \\
\hline (18.92) & (10.88) & (7.085) \\
\hline-38.86 & -22.39 & -18.41 \\
\hline (28.29) & (19.13) & (16.87) \\
\hline-5.464 & 1.915 & 2.675 \\
\hline (15.34) & (5.926) & (5.839) \\
\hline-8.961 & -1.738 & -0.783 \\
\hline (14.75) & (7.386) & (5.317) \\
\hline $32.52 * *$ & 14.61 & 5.987 \\
\hline (13.81) & (11.60) & (11.27) \\
\hline 19.84 & -12.68 & -5.910 \\
\hline (15.62) & $(15.83)$ & (15.61) \\
\hline-21.01 & $-27.46^{*}$ & 2.117 \\
\hline$(43.00)$ & (14.67) & (13.79) \\
\hline-42.10 & 4.213 & 2.058 \\
\hline (27.18) & (9.005) & (8.772) \\
\hline 48.04 & -5.754 & 2.942 \\
\hline (35.77) & (11.05) & (7.329) \\
\hline 24.61 & -13.27 & -16.49 \\
\hline$(23.12)$ & (13.58) & (12.85) \\
\hline-22.84 & 11.18 & -8.600 \\
\hline (21.15) & (10.30) & (8.280) \\
\hline 106.8 & -6.506 & -7.854 \\
\hline (66.67) & $(25.54)$ & (22.62) \\
\hline-37.39 & 19.60 & -13.09 \\
\hline (23.99) & $(29.86)$ & (25.99) \\
\hline$-73.78 * *$ & -15.60 & -10.78 \\
\hline$(23.54)$ & (12.34) & (16.51) \\
\hline$-100.8 * *$ & -52.36 & -47.85 \\
\hline (39.86) & (36.74) & (40.47) \\
\hline 163.4 & -21.97 & 25.60 \\
\hline$(90.92)$ & (34.47) & (40.29) \\
\hline-91.35 & 24.36 & 15.43 \\
\hline (56.59) & (19.22) & (22.23) \\
\hline 3.433 & 33.02 & 19.67 \\
\hline (61.14) & (28.91) & (26.74) \\
\hline
\end{tabular}




\begin{tabular}{lccc} 
Desvio IIS Agosto & $89.79 *$ & 29.57 & 20.94 \\
& $(47.68)$ & $(26.02)$ & $(30.33)$ \\
Desvio IIS Setembro & -5.296 & -75.18 & -28.46 \\
& $(112.3)$ & $(58.89)$ & $(46.80)$ \\
Desvio IIS Outubro & 38.52 & 15.71 & -9.427 \\
& $(61.05)$ & $(40.64)$ & $(24.54)$ \\
Desvio IIS Novembro & -67.92 & 25.98 & 35.09 \\
& $(83.59)$ & $(37.68)$ & $(37.39)$ \\
Desvio IIS Dezembro & -13.19 & 4.165 & 4.659 \\
& $(50.50)$ & $(18.06)$ & $(15.72)$ \\
Constant & -524.7 & $-1,280$ & $-1,201$ \\
& $(2,248)$ & $(1,346)$ & $(1,486)$ \\
& & & \\
Observations & 7,922 & 7,922 & 7,922 \\
EF de Município & Não & Sim & Sim \\
EF de Ano & Não & Sim & Não \\
EF de Estado-Ano & Não & Não & Sim \\
R-squared & 0.067 & 0.725 & 0.754 \\
\hline
\end{tabular}

Robust standard errors in parentheses

$* * * \mathrm{p}<0.01, * * \mathrm{p}<0.05, * \mathrm{p}<0.1$

Tabela C4 - Regressão VHI: Rendimento Médio Feijão

\begin{tabular}{lccc}
\hline \multicolumn{1}{c}{ Variáveis } & $(1)$ & $(2)$ & $(3)$ \\
& RM Feijão & RM Feijão & RM Feijão \\
\hline VHI & & & \\
& $13.86^{* * *}$ & 5.111 & 4.437 \\
VHI 2 & $(3.098)$ & $(3.091)$ & $(3.051)$ \\
& $-0.107^{* *}$ & -0.0140 & -0.0143 \\
Desvio VHI & $(0.0384)$ & $(0.0350)$ & $(0.0353)$ \\
& $-0.108^{* *}$ & -0.0497 & -0.0643 \\
Constant & $(0.0354)$ & $(0.0403)$ & $(0.0518)$ \\
& 1.429 & -19.07 & -23.59 \\
& $(37.31)$ & $(59.66)$ & $(62.61)$ \\
Observations & & & \\
EF de Município & 20,393 & 20,393 & 20,393 \\
EF de Ano & Não & Sim & Sim \\
EF de Estado-Ano & Não & Sim & Não \\
R-squared & Não & Não & Sim \\
\hline Robust standard erro & 0.038 & 0.587 & 0.626 \\
\hline
\end{tabular}

Robust standard errors in parentheses

$* * * \mathrm{p}<0.01, * * \mathrm{p}<0.05, * \mathrm{p}<0.1$

Tabela C5 - Regressão VHI: Rendimento Médio Mandioca

Variáveis

(1) (2) (3)

RM RM RM




\begin{tabular}{lccc}
\hline & Mandioca & Mandioca & Mandioca \\
\hline & & & \\
VHI & $420.9^{* *}$ & $272.7^{* *}$ & $106.5^{*}$ \\
VHI 2 & $(132.4)$ & $(104.0)$ & $(56.13)$ \\
& $-4.100^{* *}$ & $-2.572^{*}$ & -1.036 \\
Desvio VHI & $(1.466)$ & $(1.121)$ & $(0.641)$ \\
& -0.148 & 1.651 & 0.464 \\
Constant & $(1.297)$ & $(1.071)$ & $(0.829)$ \\
& $-1,426$ & 3,727 & $9,082^{* * *}$ \\
& $(2,544)$ & $(2,132)$ & $(1,201)$ \\
Observations & & & \\
EF de Município & 20,393 & 20,393 & 20,393 \\
EF de Ano & Não & Sim & Sim \\
EF de Estado-Ano & Não & Sim & Não \\
R-squared & Não & Não & Sim \\
\hline Robust standard erros & 0.053 & 0.606 & 0.665 \\
\hline
\end{tabular}

Robust standard errors in parentheses

$* * * p<0.01, * * p<0.05, * p<0.1$

Tabela C6 - Regressão VHI: Rendimento Médio Milho

\begin{tabular}{lccc}
\hline \multicolumn{1}{c}{ Variáveis } & $\begin{array}{c}(1) \\
\text { RM Milho }\end{array}$ & $\begin{array}{c}(2) \\
\text { RM Milho }\end{array}$ & $\begin{array}{c}(3) \\
\text { RM Milho }\end{array}$ \\
\hline & & & \\
VHI & $49.50^{* *}$ & $30.81^{* *}$ & $35.45^{*}$ \\
& $(14.79)$ & $(12.70)$ & $(16.69)$ \\
VHI 2 & $-0.486^{* *}$ & -0.223 & -0.302 \\
& $(0.178)$ & $(0.135)$ & $(0.185)$ \\
Desvio VHI & 0.0478 & 0.0693 & 0.176 \\
& $(0.118)$ & $(0.148)$ & $(0.176)$ \\
Constant & -440.7 & $-664.2^{*}$ & $-826.7^{* *}$ \\
& $(261.4)$ & $(300.6)$ & $(352.0)$ \\
& & & \\
Observations & 20,393 & 20,393 & 20,393 \\
EF de Município & Não & Sim & Sim \\
EF de Ano & Não & Sim & Não \\
EF de Estado-Ano & Não & Não & Sim \\
R-squared & 0.014 & 0.580 & 0.642 \\
\hline
\end{tabular}

Robust standard errors in parentheses

$* * * \mathrm{p}<0.01, * * \mathrm{p}<0.05, * \mathrm{p}<0.1$ 


\section{Apêndice D - Choque por cultura e agregado em diversas metodologias}

Tabela D1 - Comparação do choque por cultura do cenário de 2012 tendo como base os índices IIS e VHI

\begin{tabular}{crrrrrr}
\hline \multirow{2}{*}{ Região } & \multicolumn{3}{c}{ IIS } & \multicolumn{3}{c}{ VHI } \\
\cline { 2 - 7 } & Feijão & \multicolumn{3}{c}{ Mandioca Milho } & \multicolumn{1}{l}{ Feijão } & \multicolumn{2}{c}{ Mandioca Milho } \\
\hline PI & $-48,93 \%$ & $-25,19 \%$ & $2,15 \%$ & $-50,61 \%$ & $-37,47 \%$ & $-4,08 \%$ \\
CE & $-45,96 \%$ & $-28,74 \%$ & $-46,56 \%$ & $-44,71 \%$ & $-33,78 \%$ & $-44,96 \%$ \\
RN & $-50,93 \%$ & $8,48 \%$ & $-50,24 \%$ & $-55,44 \%$ & $13,22 \%$ & $-44,92 \%$ \\
PB & $-46,53 \%$ & $-3,78 \%$ & $-28,33 \%$ & $-48,08 \%$ & $-0,53 \%$ & $-41,79 \%$ \\
PE & $-9,20 \%$ & $1,52 \%$ & $-33,38 \%$ & $-6,38 \%$ & $0,57 \%$ & $-41,78 \%$ \\
AL & $-13,88 \%$ & $13,58 \%$ & $-36,96 \%$ & $-5,26 \%$ & $22,15 \%$ & $-63,14 \%$ \\
SE & $-15,86 \%$ & $19,21 \%$ & $-22,01 \%$ & $-25,24 \%$ & $6,00 \%$ & $-24,45 \%$ \\
BA & $-12,72 \%$ & $2,14 \%$ & $-24,01 \%$ & $-11,81 \%$ & $2,50 \%$ & $-30,68 \%$ \\
MG & $10,57 \%$ & $6,60 \%$ & $-26,28 \%$ & $10,11 \%$ & $8,12 \%$ & $-27,46 \%$ \\
\hline
\end{tabular}

Tabela D2 - Choques dos cenários futuros por cultura (considerando crescimento do rendimento médio)

\begin{tabular}{crrrrrrrrr}
\hline \multirow{2}{*}{ Estado } & \multicolumn{3}{c}{2040} & \multicolumn{3}{c}{2070} & \multicolumn{3}{c}{2100} \\
\cline { 2 - 10 } & Feijão & \multicolumn{1}{c}{ Mandioca Milho } & \multicolumn{1}{l}{ Feijão } & \multicolumn{2}{c}{ Mandioca Milho } & \multicolumn{2}{c}{ Feijão } & \multicolumn{2}{c}{ Mandioca Milho } \\
\hline PI & $-44.88 \%$ & $8.02 \%$ & $10.55 \%$ & $-58.65 \%$ & $-21.92 \%$ & $54.72 \%$ & $-76.34 \%$ & $-43.87 \%$ & $117.38 \%$ \\
CE & $-53.66 \%$ & $-8.38 \%$ & $-52.35 \%$ & $-75.87 \%$ & $-30.63 \%$ & $-74.85 \%$ & $-87.41 \%$ & $-51.50 \%$ & $-83.32 \%$ \\
RN & $-42.41 \%$ & $-31.83 \%$ & $-79.84 \%$ & $-44.17 \%$ & $-39.41 \%$ & $-41.90 \%$ & $-50.50 \%$ & $-53.32 \%$ & $-39.64 \%$ \\
PB & $-38.51 \%$ & $-28.80 \%$ & $-90.32 \%$ & $-47.21 \%$ & $-43.47 \%$ & $-62.93 \%$ & $-60.69 \%$ & $-59.33 \%$ & $-70.40 \%$ \\
PE & $-57.44 \%$ & $-31.55 \%$ & $-95.59 \%$ & $-56.24 \%$ & $-44.89 \%$ & $-89.58 \%$ & $-60.65 \%$ & $-57.65 \%$ & $-81.78 \%$ \\
AL & $14.42 \%$ & $-26.56 \%$ & $-33.43 \%$ & $21.78 \%$ & $-33.58 \%$ & $149.93 \%$ & $18.01 \%$ & $-47.62 \%$ & $296.58 \%$ \\
SE & $-29.93 \%$ & $-17.35 \%$ & $-31.00 \%$ & $-49.83 \%$ & $-43.06 \%$ & $-43.01 \%$ & $-50.89 \%$ & $-52.97 \%$ & $-5.34 \%$ \\
BA & $-16.63 \%$ & $-1.96 \%$ & $-3.82 \%$ & $-44.41 \%$ & $-32.76 \%$ & $-12.90 \%$ & $-46.60 \%$ & $-46.26 \%$ & $35.87 \%$ \\
\hline
\end{tabular}

Tabela D3 - Choques dos cenários futuros por cultura (não considerando crescimento do rendimento médio)

\begin{tabular}{crrrrrrrrr}
\hline \multirow{2}{*}{ Estado } & \multicolumn{3}{c}{2040} & \multicolumn{3}{c}{2070} & \multicolumn{3}{c}{2100} \\
\cline { 2 - 10 } & Feijão & \multicolumn{1}{c}{ Mandioca Milho } & \multicolumn{1}{l}{ Feijão } & \multicolumn{1}{c}{ Mandioca Milho } & \multicolumn{1}{l}{ Feijão } & \multicolumn{2}{c}{ Mandioca Milho } \\
\hline PI & $-41.11 \%$ & $29.56 \%$ & $-18.71 \%$ & $-51.85 \%$ & $18.71 \%$ & $-23.83 \%$ & $-70.01 \%$ & $8.14 \%$ & $-28.35 \%$ \\
CE & $-50.50 \%$ & $9.41 \%$ & $-64.96 \%$ & $-72.08 \%$ & $3.03 \%$ & $-87.34 \%$ & $-84.33 \%$ & $-10.91 \%$ & $-94.12 \%$ \\
RN & $-39.23 \%$ & $-18.86 \%$ & $-83.27 \%$ & $-37.49 \%$ & $-9.60 \%$ & $-65.99 \%$ & $-41.28 \%$ & $-13.12 \%$ & $-72.96 \%$ \\
PB & $-34.28 \%$ & $-14.58 \%$ & $-92.89 \%$ & $-38.45 \%$ & $-13.99 \%$ & $-81.76 \%$ & $-50.01 \%$ & $-21.54 \%$ & $-90.26 \%$ \\
PE & $-54.51 \%$ & $-17.87 \%$ & $-96.76 \%$ & $-48.99 \%$ & $-16.16 \%$ & $-94.87 \%$ & $-49.96 \%$ & $-18.29 \%$ & $-94.00 \%$ \\
AL & $22.31 \%$ & $-11.89 \%$ & $-51.09 \%$ & $41.99 \%$ & $1.05 \%$ & $22.90 \%$ & $50.09 \%$ & $1.07 \%$ & $30.50 \%$ \\
SE & $-25.11 \%$ & $-0.84 \%$ & $-49.29 \%$ & $-41.51 \%$ & $-13.36 \%$ & $-71.97 \%$ & $-37.54 \%$ & $-9.27 \%$ & $-68.84 \%$ \\
BA & $-10.89 \%$ & $17.62 \%$ & $-29.31 \%$ & $-35.19 \%$ & $2.30 \%$ & $-57.16 \%$ & $-32.09 \%$ & $3.68 \%$ & $-55.27 \%$ \\
\hline
\end{tabular}


Tabela D4 - Comparação do choque final do cenário de 2012 tendo como base os índices IIS e VHI

\begin{tabular}{clcc}
\hline Região & IIS & VHI & Diferença \\
\hline PI & $-0,0642$ & $-0,0842$ & 0,0199 \\
CE & $-0,0996$ & $-0,0993$ & $-0,0002$ \\
RN & $-0,0084$ & $-0,0061$ & $-0,0023$ \\
PB & $-0,0819$ & $-0,0887$ & 0,0068 \\
PE & $-0,0078$ & $-0,0082$ & 0,0004 \\
AL & 0,0308 & 0,0658 & $-0,0350$ \\
SE & $-0,1388$ & $-0,1710$ & 0,0322 \\
BA & $-0,0179$ & $-0,0206$ & 0,0027 \\
MG & 0,0006 & 0,0011 & $-0,0005$ \\
\hline
\end{tabular}

Tabela D5 - Choque final dos cenários futuros, com e sem crescimento do rendimento médio

\begin{tabular}{ccccccc}
\hline \multirow{2}{*}{ Estado } & \multicolumn{3}{c}{ Com Crescimento RM } & \multicolumn{3}{c}{ Sem Crescimento RM } \\
\cline { 2 - 7 } & 2040 & 2070 & 2100 & 2040 & 2070 & 2100 \\
\hline PI & $-2.86 \%$ & $3.54 \%$ & $13.65 \%$ & $-7.68 \%$ & $-10.47 \%$ & $-14.01 \%$ \\
CE & $-10.29 \%$ & $-15.49 \%$ & $-18.38 \%$ & $-10.10 \%$ & $-14.48 \%$ & $-16.99 \%$ \\
RN & $-3.27 \%$ & $-3.49 \%$ & $-4.42 \%$ & $-2.46 \%$ & $-1.76 \%$ & $-2.09 \%$ \\
PB & $-13.26 \%$ & $-14.22 \%$ & $-18.00 \%$ & $-11.46 \%$ & $-11.29 \%$ & $-14.06 \%$ \\
PE & $-6.59 \%$ & $-7.47 \%$ & $-8.58 \%$ & $-5.41 \%$ & $-4.97 \%$ & $-5.17 \%$ \\
AL & $-12.17 \%$ & $-6.12 \%$ & $-6.03 \%$ & $-5.58 \%$ & $5.63 \%$ & $6.78 \%$ \\
SE & $-23.92 \%$ & $-35.23 \%$ & $-10.33 \%$ & $-34.77 \%$ & $-52.06 \%$ & $-49.40 \%$ \\
BA & $-1.23 \%$ & $-5.29 \%$ & $-3.80 \%$ & $-0.91 \%$ & $-4.70 \%$ & $-4.35 \%$ \\
\hline
\end{tabular}

Tabela D6 - Média do índice VHI para os municípios que produzem acima da média de cada cultura dentro do Semiárido de cada estado em 2100

\begin{tabular}{cccc}
\hline Estado & Feijão & Milho & Mandioca \\
\hline PI & 9,92 & 21,70 & 4,56 \\
CE & 2,55 & 1,98 & 4,80 \\
RN & 9,00 & 14,52 & 28,76 \\
PB & 10,14 & 8,66 & 11,21 \\
PE & 12,87 & 10,40 & 13,38 \\
AL & 52,14 & 55,04 & 55,65 \\
SE & 6,41 & 4,26 & 7,49 \\
BA & 11,81 & 11,77 & 8,89 \\
\hline
\end{tabular}


Tabela D7 - Comparação dos choques do cenário de 2012 para o Semiárido como um todo tendo como base os índices IIS e VHI

\begin{tabular}{lcc}
\hline Choque & \multicolumn{1}{c}{ IIS } & VHI \\
\hline Feijão & $-26,60 \%$ & $-25,97 \%$ \\
Mandioca & $-0,40 \%$ & $-0,83 \%$ \\
Milho & $-23,90 \%$ & $-27,22 \%$ \\
Final & $-3,45 \%$ & $-3,68 \%$ \\
\hline
\end{tabular}

Tabela D8 - Choque dos cenários futuros para o Semiárido como um todo, com e sem crescimento do rendimento médio

\begin{tabular}{ccccccc}
\hline \multirow{2}{*}{ Estado } & \multicolumn{3}{c}{ Com Crescimento RM } & \multicolumn{3}{c}{ Sem Crescimento RM } \\
\cline { 2 - 7 } & 2040 & 2070 & \multicolumn{1}{c}{2100} & \multicolumn{1}{c}{2040} & \multicolumn{1}{c}{2070} & \multicolumn{1}{c}{2100} \\
\hline Feijão & $-35.61 \%$ & $-52.95 \%$ & $-59.95 \%$ & $-31.64 \%$ & $-46.32 \%$ & $-50.98 \%$ \\
Mandioca & $-12.36 \%$ & $-32.33 \%$ & $-45.60 \%$ & $3.17 \%$ & $-2.35 \%$ & $-4.49 \%$ \\
Milho & $-21.99 \%$ & $-22.76 \%$ & $11.28 \%$ & $-41.54 \%$ & $-59.80 \%$ & $-60.45 \%$ \\
Total & $-4.70 \%$ & $-7.24 \%$ & $-6.12 \%$ & $-4.80 \%$ & $-7.44 \%$ & $-7.93 \%$ \\
\hline
\end{tabular}

\section{Apêndice E - Resultados regionais das simulações de equilíbrio geral}

Tabela E1 - Resultados regionais para o cenário de 2012

\begin{tabular}{lrrrrrrr}
\hline Região/Variável Pag. trabalho Pag. capital & Var. equivalente & Produto & Consumo & Exportações Importações \\
\hline Semiárido PI & $-0,0630$ & $-0,6359$ & $-0,3010$ & $-0,6389$ & $-0,1026$ & $-5,2412$ & $-0,0547$ \\
Semiárido CE & $-0,0899$ & $-0,4749$ & $-0,4067$ & $-0,4954$ & $-0,1387$ & $-0,9687$ & $-0,0510$ \\
Semiárido RN & $-0,0180$ & $-0,0542$ & $-0,0946$ & $-0,0283$ & $-0,0322$ & $-0,3933$ & $-0,0110$ \\
Semiárido PB & $-0,0268$ & $-0,1413$ & $-0,1485$ & $-0,1058$ & $-0,0506$ & $-0,0343$ & $-0,0162$ \\
Semiárido PE & $-0,0131$ & $-0,0437$ & $-0,0742$ & $-0,0450$ & $-0,0252$ & $-0,7073$ & $-0,0047$ \\
Semiárido AL & 0,0082 & 0,2049 & $-0,0419$ & 0,1912 & 0,0143 & 0,0597 & 0,0038 \\
Semiárido SE & $-0,1748$ & $-0,6504$ & $-0,7037$ & $-0,7529$ & $-0,2405$ & $-0,2132$ & $-0,1030$ \\
Semiárido BA & $-0,0307$ & $-0,1210$ & $-0,1309$ & $-0,1620$ & $-0,0446$ & $-0,7806$ & $-0,0197$ \\
Semiárido MG & 0,0094 & 0,0331 & 0,0094 & 0,0065 & 0,0032 & $-0,0710$ & 0,0123 \\
Maranhão & 0,0002 & 0,0169 & $-0,0211$ & $-0,0035$ & $-0,0072$ & $-0,1321$ & 0,0005 \\
Resto PI & $-0,0062$ & 0,0206 & $-0,0467$ & $-0,0081$ & $-0,0159$ & $-0,2290$ & $-0,0012$ \\
Resto CE & $-0,0292$ & $-0,0493$ & $-0,1369$ & $-0,0220$ & $-0,0466$ & $-0,0645$ & $-0,0121$ \\
Resto RN & $-0,0192$ & $-0,0365$ & $-0,0940$ & $-0,0157$ & $-0,0320$ & $-0,0911$ & $-0,0102$ \\
Resto PB & $-0,0210$ & $-0,0255$ & $-0,0965$ & $-0,0174$ & $-0,0328$ & $-0,1758$ & $-0,0143$ \\
Resto PE & $-0,0317$ & $-0,0472$ & $-0,1239$ & $-0,0237$ & $-0,0422$ & $-0,0667$ & $-0,0209$ \\
Resto AL & $-0,0428$ & 0,0804 & $-0,1464$ & $-0,0267$ & $-0,0498$ & $-0,2409$ & $-0,0267$ \\
Resto SE & $-0,0125$ & $-0,0016$ & $-0,0707$ & $-0,0121$ & $-0,0241$ & $-0,1241$ & $-0,0089$ \\
Leste BA & $-0,0086$ & $-0,0066$ & $-0,0518$ & $-0,0087$ & $-0,0176$ & $-0,0345$ & $-0,0038$ \\
Oeste BA & 0,0330 & 0,0990 & 0,0751 & 0,0119 & 0,0255 & $-0,1305$ & 0,0249 \\
Resto MG & 0,0001 & 0,0010 & $-0,0146$ & $-0,0034$ & $-0,0050$ & $-0,0264$ & 0,0017 \\
Resto Brasil & $-0,0023$ & 0,0021 & $-0,0201$ & $-0,0048$ & $-0,0069$ & $-0,0317$ & $-0,0011$ \\
\hline
\end{tabular}


Tabela E2 - Resultados regionais para o cenário de 2040

\begin{tabular}{lrrrrrrrr}
\hline Região/Variável & Pagamentos L & Pagamentos K Estoque K & Produto & Investimento & Consumo & Exportações Importações \\
\hline Semiárido PI & $-0,0605$ & $-0,2729$ & $-0,3066$ & $-0,3187$ & $-0,3069$ & $-0,0950$ & $-2,4477$ & $-0,1580$ \\
Semiárido CE & $-0,0842$ & $-0,2458$ & $-0,2725$ & $-0,3818$ & $-0,2728$ & $-0,1291$ & $-0,4763$ & $-0,1434$ \\
Semiárido RN & $-0,1006$ & $-0,1148$ & $-0,0697$ & $-0,0640$ & $-0,0697$ & $-0,0641$ & $-0,5139$ & $-0,0926$ \\
Semiárido PB & $-0,0196$ & $-0,0468$ & $-0,0458$ & $-0,0507$ & $-0,0459$ & $-0,0232$ & $-0,0123$ & $-0,0291$ \\
Semiárido PE & $-0,0604$ & $-0,1193$ & $-0,1236$ & $-0,1666$ & $-0,1237$ & $-0,0679$ & $-1,4779$ & $-0,0804$ \\
Semiárido AL & 0,1657 & 0,9052 & 1,0360 & 1,3500 & 1,0316 & 0,3933 & 0,9627 & 0,5242 \\
Semiárido SE & $-0,6169$ & $-1,4460$ & $-1,6392$ & $-2,2522$ & $-1,6534$ & $-0,8314$ & $-0,8058$ & $-1,0051$ \\
Semiárido BA & 0,0937 & 0,2597 & 0,2889 & 0,3741 & 0,2886 & 0,1414 & 1,2826 & 0,1800 \\
Semiárido MG & $-0,0099$ & $-0,0075$ & $-0,0009$ & 0,0007 & $-0,0009$ & $-0,0009$ & 0,0136 & $-0,0070$ \\
Maranhão & $-0,0101$ & $-0,0070$ & $-0,0018$ & $-0,0017$ & $-0,0018$ & $-0,0043$ & $-0,0001$ & $-0,0068$ \\
Resto PI & $-0,0127$ & $-0,0108$ & $-0,0064$ & $-0,0061$ & $-0,0064$ & $-0,0086$ & $-0,0084$ & $-0,0101$ \\
Resto CE & $-0,0315$ & $-0,0357$ & $-0,0384$ & $-0,0380$ & $-0,0384$ & $-0,0404$ & $-0,0212$ & $-0,0371$ \\
Resto RN & $-0,0174$ & $-0,0195$ & $-0,0166$ & $-0,0146$ & $-0,0166$ & $-0,0159$ & $-0,0072$ & $-0,0185$ \\
Resto PB & $-0,0157$ & $-0,0154$ & $-0,0111$ & $-0,0098$ & $-0,0111$ & $-0,0117$ & $-0,0067$ & $-0,0149$ \\
Resto PE & $-0,0162$ & $-0,0152$ & $-0,0104$ & $-0,0091$ & $-0,0104$ & $-0,0109$ & 0,0043 & $-0,0133$ \\
Resto AL & $-0,0019$ & $-0,0099$ & $-0,0016$ & 0,0058 & $-0,0016$ & 0,0104 & 0,0646 & 0,0002 \\
Resto SE & $-0,0167$ & $-0,0144$ & $-0,0104$ & $-0,0094$ & $-0,0104$ & $-0,0115$ & $-0,0103$ & $-0,0145$ \\
Leste BA & $-0,0064$ & $-0,0023$ & 0,0054 & 0,0070 & 0,0054 & 0,0057 & 0,0122 & 0,0011 \\
Oeste BA & $-0,0082$ & $-0,0057$ & 0,0006 & 0,0015 & 0,0006 & 0,0004 & 0,0114 & $-0,0051$ \\
Resto MG & $-0,0080$ & $-0,0060$ & 0,0002 & 0,0013 & 0,0002 & $-0,0004$ & 0,0073 & $-0,0040$ \\
Resto Brasil & $-0,0084$ & $-0,0067$ & $-0,0007$ & 0,0004 & $-0,0007$ & $-0,0014$ & 0,0076 & $-0,0046$ \\
\hline
\end{tabular}

Tabela E3 - Resultados regionais para o cenário de 2070

\begin{tabular}{lrrrrrrrr}
\hline Região/Variável & Pagamentos L & Pagamentos K Estoque K & Produto & Investimento & Consumo & Exportações & Importações \\
\hline Semiárido PI & $-0,2566$ & $-0,5128$ & $-0,4494$ & $-0,6402$ & $-0,4497$ & $-0,2097$ & $-4,2657$ & $-0,3436$ \\
Semiárido CE & $-0,4234$ & $-0,9154$ & $-0,9043$ & $-1,1853$ & $-0,9066$ & $-0,4885$ & $-1,5679$ & $-0,5726$ \\
Semiárido RN & $-0,2286$ & $-0,2712$ & $-0,1759$ & $-0,1743$ & $-0,1759$ & $-0,1614$ & $-1,1508$ & $-0,2220$ \\
Semiárido PB & $-0,2340$ & $-0,3639$ & $-0,2722$ & $-0,2778$ & $-0,2726$ & $-0,1858$ & 0,0241 & $-0,2524$ \\
Semiárido PE & $-0,3189$ & $-0,4707$ & $-0,3874$ & $-0,5118$ & $-0,3877$ & $-0,2722$ & $-4,2688$ & $-0,3392$ \\
Semiárido AL & $-0,1583$ & 0,0215 & 0,1572 & 0,2074 & 0,1569 & $-0,0228$ & 0,2164 & $-0,0339$ \\
Semiárido SE & $-0,9242$ & $-2,0706$ & $-2,3051$ & $-3,2732$ & $-2,3325$ & $-1,1999$ & $-1,1073$ & $-1,4569$ \\
Semiárido BA & $-0,3115$ & $-0,4607$ & $-0,3695$ & $-0,5599$ & $-0,3697$ & $-0,2544$ & $-1,7403$ & $-0,3448$ \\
Semiárido MG & $-0,1586$ & $-0,0936$ & 0,0347 & 0,0323 & 0,0346 & $-0,0323$ & 0,0506 & $-0,0783$ \\
Maranhão & $-0,1643$ & $-0,0986$ & 0,0276 & 0,0254 & 0,0276 & $-0,0428$ & $-0,0084$ & $-0,0865$ \\
Resto PI & $-0,1891$ & $-0,1123$ & 0,0098 & $-0,0002$ & 0,0097 & $-0,0749$ & $-0,1243$ & $-0,1026$ \\
Resto CE & $-0,2978$ & $-0,2991$ & $-0,2141$ & $-0,1987$ & $-0,2141$ & $-0,2501$ & $-0,0252$ & $-0,2688$ \\
Resto RN & $-0,2536$ & $-0,2576$ & $-0,1578$ & $-0,1342$ & $-0,1578$ & $-0,1817$ & $-0,0450$ & $-0,2250$ \\
Resto PB & $-0,2464$ & $-0,2310$ & $-0,1309$ & $-0,1156$ & $-0,1310$ & $-0,1686$ & $-0,1661$ & $-0,2165$ \\
Resto PE & $-0,2910$ & $-0,2818$ & $-0,1855$ & $-0,1680$ & $-0,1856$ & $-0,2222$ & $-0,0155$ & $-0,2453$ \\
Resto AL & $-0,2033$ & 0,0370 & 0,1727 & 0,0804 & 0,1725 & $-0,0740$ & $-0,2027$ & $-0,0458$ \\
Resto SE & $-0,2101$ & $-0,1632$ & $-0,0519$ & $-0,0536$ & $-0,0520$ & $-0,1202$ & $-0,1273$ & $-0,1565$ \\
Leste BA & $-0,2095$ & $-0,1735$ & $-0,0588$ & $-0,0477$ & $-0,0589$ & $-0,1084$ & 0,0711 & $-0,1260$ \\
Oeste BA & $-0,0057$ & 0,1036 & 0,2625 & 0,2213 & 0,2625 & 0,1292 & 0,1013 & 0,0887 \\
Resto MG & $-0,1634$ & $-0,1199$ & 0,0090 & 0,0246 & 0,0089 & $-0,0318$ & 0,0985 & $-0,0693$ \\
Resto Brasil & $-0,1666$ & $-0,1154$ & 0,0129 & 0,0256 & 0,0128 & $-0,0338$ & 0,1071 & $-0,0728$ \\
\hline
\end{tabular}


Tabela E4 - Resultados regionais para o cenário de 2100

\begin{tabular}{lrrrrrrrr}
\hline Região/Variável & Pagamentos L & Pagamentos K & Estoque K & Produto & Investimento & Consumo & Exportações Importações \\
\hline Semiárido PI & $-0,1404$ & 0,1085 & 0,2637 & 0,2797 & 0,2633 & $-0,0012$ & 1,3872 & 0,0066 \\
Semiárido CE & $-0,4828$ & $-1,1062$ & $-1,1209$ & $-1,4641$ & $-1,1247$ & $-0,5885$ & $-1,9523$ & $-0,6823$ \\
Semiárido RN & $-0,2384$ & $-0,2931$ & $-0,2012$ & $-0,2094$ & $-0,2013$ & $-0,1778$ & $-1,5089$ & $-0,2405$ \\
Semiárido PB & $-0,2511$ & $-0,4364$ & $-0,3520$ & $-0,3711$ & $-0,3530$ & $-0,2199$ & $-0,0107$ & $-0,2933$ \\
Semiárido PE & $-0,3469$ & $-0,5341$ & $-0,4564$ & $-0,6110$ & $-0,4569$ & $-0,3093$ & $-5,1306$ & $-0,3806$ \\
Semiárido AL & $-0,1786$ & $-0,0846$ & 0,0378 & 0,0299 & 0,0376 & $-0,0670$ & 0,1077 & $-0,0956$ \\
Semiárido SE & $-0,6199$ & $-1,2963$ & $-1,3855$ & $-1,9812$ & $-1,3944$ & $-0,7414$ & $-0,6068$ & $-0,9145$ \\
Semiárido BA & $-0,2883$ & $-0,4020$ & $-0,3042$ & $-0,4654$ & $-0,3044$ & $-0,2206$ & $-1,4619$ & $-0,3031$ \\
Semiárido MG & $-0,1594$ & $-0,0944$ & 0,0350 & 0,0330 & 0,0350 & $-0,0315$ & 0,0549 & $-0,0790$ \\
Maranhão & $-0,1640$ & $-0,0982$ & 0,0288 & 0,0264 & 0,0287 & $-0,0418$ & $-0,0083$ & $-0,0861$ \\
Resto PI & $-0,1901$ & $-0,1124$ & 0,0104 & $-0,0001$ & 0,0103 & $-0,0752$ & $-0,1241$ & $-0,1030$ \\
Resto CE & $-0,3120$ & $-0,3175$ & $-0,2380$ & $-0,2236$ & $-0,2380$ & $-0,2746$ & $-0,0439$ & $-0,2893$ \\
Resto RN & $-0,2577$ & $-0,2638$ & $-0,1655$ & $-0,1420$ & $-0,1655$ & $-0,1892$ & $-0,0554$ & $-0,2315$ \\
Resto PB & $-0,2497$ & $-0,2354$ & $-0,1365$ & $-0,1216$ & $-0,1366$ & $-0,1747$ & $-0,1800$ & $-0,2220$ \\
Resto PE & $-0,2948$ & $-0,2865$ & $-0,1908$ & $-0,1735$ & $-0,1909$ & $-0,2276$ & $-0,0189$ & $-0,2508$ \\
Resto AL & $-0,1995$ & 0,0400 & 0,1767 & 0,0849 & 0,1765 & $-0,0692$ & $-0,1920$ & $-0,0422$ \\
Resto SE & $-0,2041$ & $-0,1559$ & $-0,0408$ & $-0,0408$ & $-0,0409$ & $-0,1071$ & $-0,0863$ & $-0,1465$ \\
Leste BA & $-0,2066$ & $-0,1698$ & $-0,0532$ & $-0,0416$ & $-0,0532$ & $-0,1020$ & 0,0759 & $-0,1218$ \\
Oeste BA & $-0,0069$ & 0,1017 & 0,2615 & 0,2211 & 0,2615 & 0,1298 & 0,1059 & 0,0876 \\
Resto MG & $-0,1634$ & $-0,1199$ & 0,0100 & 0,0258 & 0,0099 & $-0,0304$ & 0,1005 & $-0,0691$ \\
Resto Brasil & $-0,1667$ & $-0,1156$ & 0,0135 & 0,0265 & 0,0135 & $-0,0327$ & 0,1091 & $-0,0727$ \\
\hline
\end{tabular}

